\title{
Lighting up: the social history of smoking in New Zealand c.1920-1962
}

\author{
by Susie C. Johnston
}

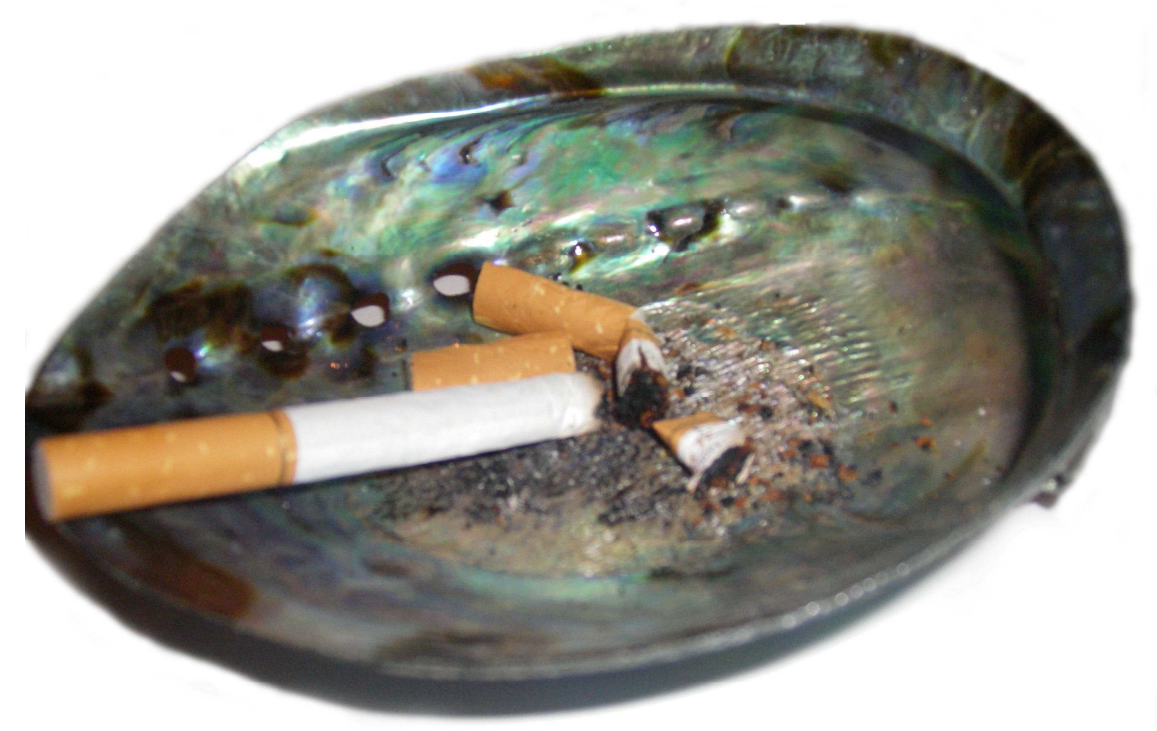

A thesis submitted to Victoria University of Wellington in fulfilment of the requirements for the degree of Master of Arts in History

Victoria University of Wellington

2009 


\begin{abstract}
The period 1920-1962 saw a significant increase in tobacco consumption in New Zealand. This period was one in which there was an expansion of the tobacco industry, tobacco consumers and smoking as a part of modern society. Smoking became an increasingly popular, prevalent and sociable habit, emerging as an integral part of twentieth-century life. Through this period smoking was uncontroversial and was often considered healthy. In 1962 London's Royal College of Physicians (RCP) released the findings of their report Smoking and health, culminating over a decade of health research. In 1964 the United States Surgeon General's report Smoking and health produced similar findings. The reports proved conclusive links between smoking and lung cancer as well as other negative health effects of the use of tobacco. Though the reports were clear, their reception by New Zealanders did not lead to an immediate reduction in smoking rates remained high until the mid-1970s and declined thereafter. By 1990 the rate of tobacco consumption per adult head of population had returned to 1920 levels.
\end{abstract}

This thesis examines the rise in tobacco consumption from the 1920s to the release of the RCP's report in 1962. Prior to the inclusion of a smoking question in the New Zealand Census of Populations and Dwellings in 1976, no survey data was collected showing any systematic evidence as to who was smoking in New Zealand. The overall historical pattern discovered in this study fits within an international historiography while at the same time revealing some distinctive features of a pattern of consumption and local expression of smoking culture in New Zealand. This study draws on advertising, ephemera, photographs and other visual sources in order to describe the upward trend in tobacco consumption. The study reveals that industry and government efforts to develop and protect a domestic tobacco industry were major contributors to the rise in availability and affordability of smoking over this period, despite an ongoing negotiation over tobacco's status as a luxury or essential item. The commercial impetus of the tobacco industry, expressed through widespread and targeted advertising, was the major driver through this period, propelling the temporal, spatial and gendered expansion of smoking throughout New Zealand society. This study examines, in particular, the ways that advertisers promoted the many and varied promises or functions of smoking in the smoking spaces and activities of leisure, work and war. Alongside the rising prevalence and popularity of smoking, knowledge of the health or other risks around smoking were contradictory and limited and as such there was a marked absence of anti-smoking rhetoric through the period 1920-1962. Rather, prompted by the constant and pervasive images and messages in advertising, New Zealanders expressed their 'right' to smoke across time and space. 
Table of Contents

$\begin{array}{lr}\text { Abstract } & \text { ii } \\ \text { Table of Contents } & \text { iii } \\ \text { Acknowledgements } & \text { iv } \\ \text { List of Abbreviations } & \text { v } \\ \text { List of Figures and Graphs } & \text { vi }\end{array}$

Introduction 1

Chapter One

Growing, selling and smoking: the development of the tobacco industry and the long term consumption trends

Chapter Two

'Yes thanks - I will!': tobacco advertising and the expansion of smoking among consumers

Chapter Three

'As harmless as fresh air'? arguments and discourses around smoking c.1900-1962

Conclusion

Bibliography 


\section{Acknowledgements}

Firstly, I gratefully acknowledge the guidance of my supervisor, Charlotte Macdonald, who generously gave her time and unending enthusiasm to this project. Her thoughtful and challenging suggestions have motivated me to push further with ideas and to consider the many different ways of approaching the topic.

Thank you to the staff and postgraduates in the history department at Victoria University of Wellington, particularly Hayley Brown, Sam Ritchie and Vivian Rodriguez. A special thank you to Susann Liebich and Deb Salter for their friendship and support despite being engaged in their own theses, they have made this past year fun, at times crazy, but very memorable.

I am very grateful for a VUW Masters Scholarship and F. P. Wilson Scholarship in New Zealand history which funded this thesis, and for a Faculty Research Grant which funded a visit to libraries in Dunedin. I would also like to thank the staff at the VUW Library, the Medical Library at Otago University, the Alexander Turnbull Library, Archives New Zealand, the Hocken Library, and the Salvation Army Archives for their assistance.

My wonderful family and friends have provided support in so many ways over all my years at university, and for this I thank them for their love and patience; I promise I am done now. Finally to Peg and Tam King; Katie, Margaret, Gavin, Sylvia and the late Stuart Johnston - thank you for everything. 


\section{Abbreviations}

2NZEF

ATL

BATNZ

BMRC

CHD

HMNZS

lbs

MP

NZEF

NZOYB

NZPD

POW

RCP

Tobacconists' Review

USD

WCTU

YMCA
Second New Zealand Expeditionary Force

Alexander Turnbull Library

British American Tobacco New Zealand

British Medical Research Council

Chronic Heart Disease

Her Majesty's New Zealand Ship

pounds

Member of Parliament

New Zealand Expeditionary Force

New Zealand Official Year Book

New Zealand Parliamentary Debates

Prisoner of War

Royal College of Physicians

The New Zealand Hairdressers' and Retail Tobacconists' Review

United States Dollar

Women's Christian Temperance Union

Young Men's Christian Association 


\section{List of Figures and Graphs}

1. The National Tobacco Company building in Napier in the late 1930s,

1/2-100006-G, Alexander Turnbull Library (ATL).

2. Cable news from the All Blacks, Advertisement - Three Castles, The Press, 14 June 1928, p.12.

3. Graph, Cigarette and tobacco products consumption, 1920-1990, data from Murray Laugesen, Tobacco statistics 1991: trends in tobacco consumption and smoking prevalence in New Zealand, Wellington, 1992, p.12.

4. Tobacconist Shop Window Display, Wellington Region,

c. 1932, EP-0248-1/2-G, ATL.

5. Women and Girls! Here is the key to Pleasant and Profitable employment,

Advertisement - W.D. and H.O. Wills factory, Dominion, 2 March 1946, p.5.

6. It's always time for a Capstan, Advertisement - Capstan,

Listener, 19 July 1946, p.48.

7. Half a furlong to go... and then it's time for a smoke of Silver Fern,

Advertisement - Silver Fern, Listener, 5 July 1946, p.48.

8. Cigarette Card showing Jack Lovelock, State Express 333,

c.1934, MSX-2255-062, ATL.

9. The friendly cigarette, Advertisement - Three Castles,

New Zealand Sporting and Dramatic Review. 20 March 1924, p.38.

10. My friends compliment me on my good taste, Advertisement - Ardath, Listener, 27 February 1942, p.12.

11. The right cigarette in the right company, Advertisement - De Reszke,

The Press, 22 March 1929, p.19.

12. Advertisement for Milne and Choyce Department Store, c.1940s, Clifton Firth (photographer), 34-M7E2, Special Collections, Auckland City Libraries, Auckland.

13. Where Fashion decrees Yardley Lavender, Advertisement - Yardley's perfume and bath products, The Mirror, 1 April 1938, p.41.

14. Ngaio Marsh (photographer - Herbert Henry Clifford), 1935, PAColl-8163-04, ATL.

15. Rita Angus, 'Self Portrait', 1937, Dunedin Public Art Gallery, reproduced with permission of the Estate of Rita Angus. 
16. Particular in her tastes - she always smokes Craven " $A$ ",

Advertisement - Craven "A", The Mirror, 1 November 1930, p.1.

17. 'Unconventional', N.Z. Freelance, 6 November 1935, p.42, (C16176, ATL).

18. For many happy rollings, Advertisement - Silver Fern, Listener, 4 April 1941, p.56.

19. You should smoke Silver Fern - Because it's so consistently good, Advertisement - Silver Fern, Listener, 21 December 1945, p.40.

20. Women packing 'comforts' including cigarettes and tobacco during the second world war, PAColl-9150-16, Evening Post Collection, ATL.

21. 'Tobacco for the boys overseas', Patriotic Funds - Postal Tobacco Scheme - For Prisoners of War, c.1943, IA, 1, 3072, 172/24/18, Archives New Zealand.

22. I still Roll-My-Own with Three Castles as I did in 1914, Advertisement - Three Castles, New Zealand Herald, 3 April 1934, p.15.

23. Worthy sons of New Zealand, Advertisement - Silver Fern, Listener, 3 March 1944, p.40.

24. The Superior Smoke for all Service folk, Advertisement - De Reszke, The Press, 23 August 1940, p.9.

25. R. Dysart, Western Desert, North Africa, c.6 November 1942, DA-02713-F, ATL.

26. William Frederick Bell, Aotearoa, Greeting card, 1917, Eph-A-CARDS-Christmas-WWI-1917-01, ATL.

27. Young Men's Christian Association Post-card, Red Triangle Series, 1939-1945, Eph-A-WAR-WII-1940s-04, ATL.

28. World War II Soldiers in the Pacific c.1943, 1/2-041645-F, ATL.

29. 'A Job Well Done - And It's Time For A Capstan', Advertisement - Capstan, Listener, 20 June 1941, p.15.

30. Carol Sladden having a cigarette, Mangaorapa, Hawke's Bay, 1943, 1/4-00732-F, John Pascoe Collection, ATL.

31. He is after the little ones, War Cry, 16 July 1910, p.5.

32. Graph, Lung Cancer Mortality rate, 1940-1988, data from Laugesen, Tobacco statistics 1991, p.22. 
33. Less Nicotine, Therefore Healthier, c.1920s, Eph-C-Tobacco-NTC-1920s-02, ATL. 103

34. Smoke State Express 555 - they're good for you, Advertisement - State Express, Weekly News, 26 September 1934, p.13.

35. Protects your health, Advertisement - Ardath, New Zealand Herald, 2 April 1934, p.15.

36. As a Doctor I cannot recommend any brand, Advertisement - Craven "A", Otago Daily Times, 3 September 1930, p.13.

37. For your throat's sake, Advertisement - Craven "A", Listener, 11 January 1946, p.35. 


\section{Introduction}

In 1962 Peter McKinnon, a fifth year medical student at Otago Medical School, conducted a survey on smoking as part of his dissertation for the Preventive Medicine unit of his medical training. In the foreword to the dissertation he detailed his methodology, explaining that he would have little trouble finding participants:

Today smoking is commonplace, it is socially acceptable and indeed, non-smokers are in the minority. The child often learns the habit at school, increases his [sic] intake as soon as he is earning money and is a confirmed heavy smoker by the time he is 21 years old. For these reasons subject material would be easy to obtain, and as no social stigma is attached to smoking, information would be readily available. $^{1}$

McKinnon's observation of the normal, common and uncontroversial place of smoking in New Zealand society through much of the twentieth century is the subject of this study. This thesis explores smoking practices and patterns as they came to exist in the everyday lives of New Zealanders over the period c.1920-1962, a period which saw a significant rise in tobacco consumption in New Zealand and around the world. Over these years smoking became established as normative, acceptable and popular, occupying an integral part of the daily lives of modern men and women. Opportunities for smoking expanded from the 1920s - smokers were to be progressively found 'lighting up' on the tram, the train, in the office, the eating house, the picture theatre, the sports ground, the beach, the dance hall, the street, and around the dinner table.

Smoking became so pervasive, 'commonplace', and 'socially acceptable', as McKinnon observed, that the distinctive haze and odour of tobacco smoke was to permeate the fabric of social life in New Zealand through much of the twentieth century.

In 1962 London's Royal College of Physicians (RCP) released the findings of their report, Smoking and health, the culmination of over a decade's epidemiological and statistical research. ${ }^{2}$ The report established conclusively that there was a strong causal connection between smoking and lung cancer, that smoking was a predisposing cause of chronic bronchitis, and that it was also likely to increase the risk of chronic heart disease. Smokers had far greater rates of lung cancer than non-smokers, and the more a

\footnotetext{
${ }^{1}$ P. A. McKinnon, 'Survey on smoking', preventive medicine dissertation, Otago Medical School, University of Otago, 1962, pp.3-4.

${ }^{2}$ Royal College of Physicians, Smoking and health: a report of the Royal College of Physicians of London on smoking in relation to cancer of the lung and other diseases, London, 1962.
} 
person smoked, the greater their chance of contracting lung cancer. ${ }^{3}$ Two years later, in 1964, the Surgeon General of the United States reiterated the RCP's findings in his report Smoking and health. ${ }^{4}$ Together the two reports represented a watershed in tobacco related research, alerting the public and the press to conclusive evidence of the health risks of smoking. The 1962 and 1964 reports proved to be a crucial turning point in the history of smoking and tobacco control in New Zealand as they were internationally; smoking was no longer an uncontroversial and benign habit. In the wake of the reports, and continuing into the present, escalating efforts and expenditure have been applied to discourage people from taking up smoking, and to encourage those who did smoke to give up.

This thesis asks why and how tobacco consumption increased so significantly over the period 1920-1962. Recognising the wider international context of increasing consumption, this study explores the advent of a smoking culture in New Zealand, looking at what New Zealanders smoked, where they smoked, how they smoked, and what smoking might have symbolised for men and women. What was the role of advertising in this change? What was the effect of the second world war on smoking consumption and take-up in New Zealand? The thesis pays particular attention to the specific arguments or negotiations which took place around smoking. When did arguments arise over the rights and wrongs of smoking, who could smoke and where smoking could occur? Were these different for men, women or children, and how did arguments differ around leisure or work spaces? How did these arguments shift and what was the reaction to opposition to smoking? The study also explores how smoking became part of popular culture, of aesthetic visual culture, and of social and working life, as well as examining the knowledge, understanding and beliefs that New Zealanders developed in relation to their smoking habits over the twentieth century. ${ }^{5}$

The discussion is primarily concerned with the period from 1920 and 1962. However, as this is a study in the history of patterns of change in the consumption of a commodity, the discussion necessarily strays beyond these parameters on occasion in order to highlight the much longer term trends in behavioural changes and continuities. The return to peacetime following the end of the first world war and the return of soldiers to New Zealand, represents the beginning point. The 1920 s was also the time

\footnotetext{
3 Ibid., pp.1, 43.

${ }^{4}$ Dr Luther L. Terry, Surgeon General of the United States of America, et al., Smoking and health, Washington, 1964.

5 This study deals with the history of tobacco use, for discussion of the history of marijuana use in New Zealand see Redmer Yska, New Zealand green: the story of marijuana in New Zealand, Auckland, 1990.
} 
when increases in tobacco consumption became pronounced for the first time, and saw the establishment of a domestic tobacco growing and manufacturing industry. 1962 is the end point to this study as it marks the point at which the RCP published their groundbreaking report Smoking and health. Although the reports acted to reinforce each other, it is suggested that the College's report, rather than the later 1964 publication by the United States Surgeon General, had a greater bearing on New Zealand doctors in the 1960 s as many were members of the College and were likely to have been more familiar with its work. ${ }^{6} 1962$ was also the highest point of New Zealand's twentiethcentury tobacco consumption; in the rising prevalence of smoking, 1962 represents the zenith of this trend.

The pattern of overall tobacco consumption is included in the New Zealand Official Yearbooks (NZOYB), calculated from the quantity of manufactured cigarettes and loose tobacco (for pipe and roll-your-own cigarette smoking) imported and domestically manufactured in New Zealand each year. ${ }^{7}$ The yearbook charts the trend in overall sales of the commodity rather than smoking behaviour, mapped through who smoked and at what levels. The breakdown of the population showing those who smoked - men, women, youth, Maori and non-Maori, or New Zealand as a whole - is not included in the NZOYB tables. Until a smoking question was included in the New Zealand Census of Populations and Dwellings in 1976, the smoking behaviour as against total commodity consumption was not known. The absence of such statistics is a common obstacle faced by historians dealing with this subject in other countries. ${ }^{8}$ Non-collection of incidence of smoking (as opposed to tobacco production) is symptomatic of the normative nature of smoking in this era - by and large the habit was not problematic or remarkable. Where government statisticians might collect incidence of tuberculosis for example, there was no reason, health-related or otherwise, to collect smoking prevalence rates. The result is that the history of the rise in tobacco consumption remains undefined and poorly understood, and therefore presents a key rationale for this study. This thesis extends its gaze beyond aggregate consumption statistics, tracing the detail and character of the changing trend in tobacco consumption through an investigation of the social, cultural and economic context of the period 1920-1962.

\footnotetext{
${ }^{6}$ See appendix 1 - 'A conversation with Sir David Hay', 30 January 1992, Sarah Thomson, 'Stubbing out the social cigarette', MA research essay in History, University of Auckland, 1992, pp.1xviii-1xix.

${ }^{7}$ Consumption statistics are compiled from the NZOYBs in Murray Laugesen, Tobacco statistics 1991: trends in tobacco consumption and smoking prevalence in New Zealand, Wellington, 1992, pp.12-3.

${ }^{8}$ Matthew Hilton, Smoking in British popular culture 1800-2000, Manchester and New York, 2000, p.140; Jarrett Rudy, The freedom to smoke: tobacco consumption and identity, Montreal, 2005, p.10.
} 
Though source material for this topic is fragmented, some key sources have revealed a rich archive for the study of the social aspects of smoking. These include military files from the first and second world wars, records from government involvement in the tobacco industry, newspapers, popular magazines and periodicals, and public health dissertations used with the generous help and consent of the Otago Medical School. Some questions have been easier to answer than others. While differences between patterns of male and female smoking emerge as a clear theme in the available sources, differences between ethnic groups, and in particular Maori and Pakeha, are less evident. As such, this thesis says little about the smoking patterns of different ethnic groups for the mid-twentieth century, while recognising that in the post1962 era this has become a major area of policy concentration. It is noted however that Maori and non-Maori patterns of consumption have distinctive characteristics, which were more pronounced in the nineteenth century and in very recent years, both periods where Maori women in particular are reported as having higher than normal consumption rates. ${ }^{9}$

Visual images are key sources in exploring the history of smoking and smokers. They are especially valuable in the period where the habit was normalised and incidence of smoking did not hold a prominent place in more traditional historical sources or more explicit social commentary. Bronwyn Dalley's Living in the twentieth century: New Zealand history in photographs 1900-1980, offers a useful opening point for the use of visual sources as a way of revealing 'ordinary activities' in the 'daily lives of people.' Dalley argues such areas 'remain both unexamined and sometimes inaccessible historically. ${ }^{10}$ Like the themes in Dalley's book ('eating, drinking, dressing, or working, activities of the home, the workplace, the street or the sports field') smoking is an activity that is not widely found in conventional historical sources (government records, published sources, newspapers and periodicals). ${ }^{11}$ Smoking is captured, however, in commercial and non-commercial visual sources such as photographs, advertisements,

\footnotetext{
${ }^{9}$ See John Broughton, Puffing up a storm: “kapai te torori!”, Dunedin, 1996, pp. 38-9; John Broughton and Mark Lawrence, Maori women and smoking: a Maori health research project - Nga wabine Maori me te kai paipa: he rangahau hauora, Dunedin, 1993, pp.10-11; Ministry of Health, New Zealand tobacco use survey 2006, Wellington, 2007, available from http://www.moh.govt.nz/moh.nsf/indexmh/nz-tobacco-use-survey2006, accessed 23 February 2009; Paparangi Reid and Robert Pouwhare, The gift from a distant place: te taonga mai tawhiti, Auckland, 1991; Murray Laugesen and Mark Clements, Cigarette smoking mortality among Maori, 1954-2028, Wellington, 1998.

${ }^{10}$ Bronwyn Dalley, Living in the twentieth century: New Zealand history in photographs 1900-1980, Wellington, 2000, p.12. See also Bronwyn Dalley, 'Chance residues: photographs and social history', Tony Ballantyne and Brian Moloughney, (eds.), Disputed histories: imagining New Zealand's pasts, Dunedin, 2006, pp.169-90. ${ }^{11}$ Dalley, Living in the twentieth century, p.12.
} 
art work, and other related ephemera - for example, postcards, cigarette cards and packaging.

Dalley's work aims to highlight 'the commonplace in photographs that were not necessarily taken to exemplify such things. ${ }^{12}$ Similarly, in a reading of photographs, advertisements and other representations of people smoking in packaging and promotional material, it is important to note the difference between images in which the subject(s) are smoking alongside other activities, and those in which the cigarette or pipe is deliberately placed - the latter is most apparent in posed portraiture. British historian Penny Tinkler uses 'visual culture' as the key organising principle for her study, Smoke signals: women, smoking and visual culture. ${ }^{13}$ Tinkler argues that visual representations are not just a way of examining female smokers in the absence of other sources during the normative phase, but also that smoking was an act or habit which was overtly visual that 'smoking practices were perceived and used by women as visual statements about status and identity. ${ }^{14}$ The use of visual sources is particularly important in the social and cultural context that will be explored in chapter two, given the fragmented nature of other source material through the phase where smoking became normal and popular.

Smoking has received little historical attention in New Zealand. Two longer research essays written as part of a University of Auckland MA study by Sarah Thomson in 1992 provide the most comprehensive coverage of the history of smoking thus far. In the first study Thomson examines the history of the 1903 Juvenile Smoking Suppression Act, passed in an effort to curb juvenile delinquency problems around the turn of the century. ${ }^{15}$ Thomson argues that while issues were raised about the possible negative health effects of smoking on young people, in the rhetoric surrounding the passage of the Act, 'ultimately the evils of the fragrant weed attached not to ill health but to juvenile delinquency. ${ }^{16}$ Thomson's second research essay focuses on the 'enlightenment' of the medical profession to the dangers of smoking in the second half of the twentieth century and resulting tobacco control activities in New Zealand. ${ }^{17}$ Thomson's studies fall a little outside the time limits of this thesis, addressing the periods when cigarette smoking was still a marginal activity in the very early years of the twentieth century, and

\footnotetext{
12 Ibid., p.21.

${ }^{13}$ Penny Tinkler, Smoke signals: women, smoking and visual culture, Oxford and New York, 2006.

14 Ibid., p.2. (Italics in original)

${ }^{15}$ Sarah Thomson, 'Evils of the fragrant weed: a history of the 1903 Juvenile Smoking Suppression Act', MA research essay in History, University of Auckland, 1992.

16 Ibid., p.viii.

17 Thomson, 'Stubbing out the social cigarette'.
} 
into the later period when it had clearly become a target for health campaigning. As such, the studies provide useful bookends to this thesis. The majority of existing literature on smoking in New Zealand dates from the period when smoking was identified as a health risk. George Thomson and Nicholas Wilson are among those who have contributed to a large body of work dealing with the issue of tobacco control in the post-1960s era. ${ }^{18}$ Murray Laugesen has compiled extensive statistical studies of smoking with a tobacco control and health costs focus. ${ }^{19}$ Brian Easton also offers some comprehensive analyses of the economic impact of smoking in New Zealand. ${ }^{20}$ Finally, Patricia O'Shea provides a useful and thorough historical study of tobacco growing in New Zealand which provides much necessary context to this thesis. ${ }^{21}$

Another source which is not currently in the public domain, but may well be available in future years, is the evidence and examiners' reports from New Zealand's first tobacco litigation case, Pou vs. British American Tobacco New Zealand (BATNZ). ${ }^{22}$ The 2006 case heard in the Auckland High Court found that BATNZ was not liable for damages caused by their tobacco products to the plaintiff, Janice Pou, an Invercargill beneficiary who died in 2002 from lung cancer. The defence's case largely rested on establishing that the risks of smoking were 'common knowledge' in 1968 when Mrs Pou started smoking. ${ }^{23}$ The defence commissioned Dr Jenny Carlyon, an Auckland historian, to conduct an historical investigation into 'the New Zealand public's knowledge of the health hazards of cigarette smoking and the difficulties of quitting in the period 1900 to $2000 .{ }^{24}$ Unfortunately at the time of researching and writing this thesis access to Dr Carlyon's report was restricted by the defendant and plaintiff's lawyers, and the Auckland High Court. The report was commissioned by BATNZ and correspondence with their lawyers indicates that they wish for the report to remain for in-house use only.

\footnotetext{
${ }^{18}$ See for example, George Thomson and Nicholas Wilson, Resource document: a brief history of tobacco control in New Zealand, Wellington, 1997; George Thomson and Nicholas Wilson, 'Tobacco control in New Zealand from 1945 to 1961', New Zealand Medical Journal, vol. 112, no. 1084, 1999, pp.101-3; George Thomson and Nicholas Wilson, 'Rethinking the regulatory framework for tobacco control in New Zealand', New Zealand Medical Journal, vol. 118, no. 1213, 2005, available from http://www.nzma.org.nz/journal/118-1213/1405/content.pdf, accessed 10 April 2009.

${ }_{19}$ See, for example, Laugesen, Tobacco statistics 1991; Laugesen, The big kill continues: the buman cost of smoking in New Zealand in the 1990s, Wellington, 1996.

${ }^{20}$ See Brian Easton, The economic regulation of tobacco consumption in New Zealand, Wellington, 1998; Brian Easton, The social costs of tobacco use and alcohol misuse, Wellington, 1997.

${ }^{21}$ Patricia K. O'Shea, The golden harvest: a bistory of tobacco growing in New Zealand, Christchurch, 1997.

22 Justice Graham Lang, Judgement, Pou vs. British American Tobacco (NZ) Ltd, Auckland High Court, Civ2002-404-1729, 3 May 2006.

${ }^{23}$ Kate Tokeley, 'Case note: Pou v British American Tobacco (NZ) Ltd - a comprehensive win for the New Zealand tobacco industry', Waikato Law Review, vol. 14, 2006, p.136.

${ }^{24}$ Lang, paragraph 65.
} 
While the focus of this thesis differs in scope and purpose from Dr Carlyon's task, the report would have further illuminated discussion of health knowledge and government intervention in the period immediately before the 1962 and 1964 reports were published. Access is likely to be possible at a later date and will be of use to future historians interested in this topic.

The increase in tobacco consumption over the first half of the twentieth century occurred in most Western countries and as such New Zealand's experience is comparable and finds parallels in tobacco consumption trends in countries including Britain, the United States, Canada and Australia. ${ }^{25}$ This study attempts to place its discussion of the social history of smoking within a small but significant existing historiography which has emerged over the past ten years. The topic has arisen within the context of the rising popularity of the history of commodities, consumption and advertising, and also health, gender and social history. The changing trend in smoking consumption patterns is the main premise of each of these studies, however each work differs in its focus. This thesis draws on diverse aspects of each of the existing studies in order to look to where New Zealand's experience mirrors international trends, and where it diverges. The study of New Zealand's smoking patterns through much of the twentieth century adds to this growing international body of work.

One dominant feature of the international studies is that the pattern of smoking around the world in the twentieth century was heavily marked by gender. Tobacco consumption trends were staggered for men and women - smoking was primarily a male activity in the nineteenth century and this continued to be the case through the first half of the twentieth century. However, the period from the 1920s also saw women beginning to take up smoking in greater numbers. The nature and timing of this shift in New Zealand is a key concern of this thesis. The gendered difference is the central organising idea for Rosemary Elliot and Penny Tinkler who have both recently published studies, with slightly different focuses, on the smoking patterns of British

${ }^{25}$ For comparative consumption statistics across these countries see P. N. Lee, (ed.), Tobacco consumption in various countries, $4^{\text {th }}$ edition, London, 1975. 
women through the twentieth century. ${ }^{26}$ Elliot is concerned to chart the rise of smoking among women, looking for trends and continuities through the second half of the twentieth century. Tinkler looks at women smokers through the lens of visual culture assessing not only depictions of female smoking, but also arguing for the significance of the increased visibility of the female smoker in public space over the period 1920-1950. Matthew Hilton's study of British smokers, and Jarrett Rudy's study of smokers in Montreal also address the gendered dimension of smoking but with a greater focus on male smokers. ${ }^{27}$

In the nineteenth century smoking was almost exclusively a male practice. Hilton and Rudy both argue that in the nineteenth century upper-class men established a bourgeois-liberal culture of smoking. ${ }^{28}$ This culture was 'liberal' in the sense that men made rational self-possessed choices as to what they smoked. Based around a 'hierarchy' of smoking tastes which elevated particular brands and mixtures, the bourgeois-liberal culture of smoking was also reinforced in the upper-class periodical press. Writers exalted the role of smoking as an aid to relaxation and as a 'retreat from the world' suggesting luxury of both time and space which were exclusive to the upper-class. ${ }^{29}$ Good tobacco was a luxury, privilege and pleasure of the elite and was positioned in distinction from working or lower-class smoking habits. In the late nineteenth century however, industrial developments made tobacco much cheaper to manufacture, opening up the production of different forms of tobacco to a much wider market. ${ }^{30}$

Female smoking followed a similar pattern to male smoking, in that upper-class, wealthy or bohemian women were the first to risk smoking without jeopardising their respectability in a period where smoking was still a morally dubious activity for women. Elliot identifies the first world war as a key phase in the changing economic status of young women, when the appropriation of the cigarette as a luxury item upon which to spend disposable income became a powerful symbol of economic autonomy. ${ }^{31}$ Economic independence achieved through paid employment made young, single and

\footnotetext{
${ }^{26}$ Rosemary Elliot, Women and smoking since 1890, New York and London, 2008; Tinkler, Smoke signals. See also Penny Tinkler, 'Refinement and respectable consumption: the acceptable face of women's smoking in Britain, 1918-1970', Gender and History, vol. 15, no. 2, 2003, pp.342-360; Penny Tinkler, 'Red tips for hot lips': advertising cigarettes for young women in Britain, 1920-70', Women's History Review, vol. 10, no. 2, 2001, pp.249-272; Penny Tinkler, 'Rebellion, modernity, and romance: smoking as a gendered practice in popular young women's magazines, Britain, 1918-1939', Women's Studies International Forum, vol. 24, no. 1, 2001, pp.111-122; Rosemary Elliot, 'Everybody did it' - or did they?: the use of oral history in researching women's experiences of smoking in Britain, 1930-1970', Women's History Review, 2006, vol. 15, no. 2, pp.297-322.

${ }^{27}$ Hilton, Smoking in British popular culture; Jarrett Rudy, The freedom to smoke.

${ }^{28}$ Hilton, p.3; Rudy, p.5.

${ }^{29}$ Hilton, p.34.

${ }^{30}$ Hilton, p.5.

${ }^{31}$ Elliot, Women and smoking since 1890, p.64.
} 
socially mobile women the targets of marking in the interwar era. Campaigning for political assertions of emancipation and independence were a strong feature of this era in Britain and the United States, with long-running campaigns for women's political rights finally gaining success in 1918 when women over the age of 30 won the right to vote in Britain, and in 1920 when American women over the age of 18 won the vote. In Britain Elliot asserts that female smoking must be viewed as inseparable from emancipatory politics... as emancipation changed the landscape in which life choices could be made. ${ }^{32}$ Tinkler too notes the symbolic value of the cigarette as an outward show of women's independence and modernity, altering how they 'looked, moved, and occupied space. ${ }^{33}$ While women's emancipation campaigns occurred earlier in New Zealand and Australia (with women gaining the vote in 1893 and 1902 respectively), the interwar era saw a strong convergence of economic and social factors for women, such as greater participation in paid work, into which cigarettes were marketed and became a symbol for young 'modern' women.

The other key factor identified in the existing historiography surrounding the rise in female smoking, is a reworking of gender identities and feminine respectabilities which enabled smoking to become a more socially and culturally acceptable activity for women. Hilton and Rudy argue that notions of the liberal smoker expanded in the twentieth century with increasing consumption, and came to include women. However, Tinkler and Elliot argue that women sought to incorporate the cigarette in a redefinition of existing feminine identities and respectabilities. Notions of respectability were fluid and intrinsically tied to class, time and place. ${ }^{34}$ The cultural and social shifts which saw female smoking become more acceptable involved a renegotiation of what the cigarettes was associated with or represented. Encouraged by advertisers' messages, women sought to build stronger associations between smoking and their everyday activities. Patterns of female smoking expanded firstly into leisure spaces and activities such as dances, parties and sporting events. As chapter two charts women then sought to align their smoking habits with their participation in paid work, underlining both the function of smoking as a source of refreshment and relaxation, but also as a very visual and definite marker of modern female identities.

\footnotetext{
${ }^{32}$ Elliot, Women and smoking since 1890, p.6.

33 Tinkler, Smoke signals, p.215. Further studies examining outward expressions of economic independence displayed by young women in the interwar era include Kathy Peiss' study of cosmetics and young working women in the United States. See Kathy Peiss, Hope in a jar: the making of America's beauty culture, New York, 1998.

34 Tinkler, Smoke signals, p.133.
} 
Space is a key organising concept used by historians to analyse smoking through the normative era of tobacco consumption in the first half of the twentieth century. Jarrett Rudy, in particular, emphasises the centrality of space in his study of smoking practices in Montreal, assessing the extent to which a 'separate spheres' ideology was applicable to smoking practices. ${ }^{35}$ In the nineteenth century when smoking was still principally a male practice, Rudy argues that smoking 'gave odour and visible shape to spaces socially constructed as male. ${ }^{36}$ This study seeks to understand the spaces and times in which smoking expanded, in order to reveal a more nuanced picture of New Zealand's smoking culture over the middle of the twentieth century. The process by which tobacco smoking became normative was largely aided by the negotiation and consolidation of spaces where smoking was acceptable and assumed. Primarily space is addressed in its geographical or physical sense, yet this discussion also looks to the cultural, social and commercial meanings which were attached to space. Negotiations of smoking in different spaces were directly affected by who occupied the space, who had a claim to the space, and how the space was being used at different points in history.

The significance and role that advertising played in the take-up and rising consumption of smoking in New Zealand is a central focus in this study. As both a widespread visual source, and a key driver of smoking patterns, the thesis asks how advertising was deployed to produce a smoking culture. What can advertising tell us about the construction of smokers and the wider ideas and beliefs that New Zealanders held about smoking? Most historians researching the history of tobacco as a consumer item address and use advertising in some form, however the significance of tobacco advertising in the context of mass consumer culture and rising tobacco consumption patterns in the early twentieth century is most comprehensively covered by Hilton. ${ }^{37}$ The key moment in the history of tobacco advertising, according to Hilton, was the invention in 1883 of the Bonsack cigarette machine, patented in the United States by James T. Bonsack. Previously 'tailor-made' cigarettes had been hand rolled by women in factories. The Bonsack revolutionised this process, initially being capable of producing 300 cigarettes a minute. ${ }^{38}$ Promotion became a vital element of the tobacco industry which needed to recruit customers and raise tobacco consumption up to a level where it generated good profits for the industry.

\footnotetext{
${ }^{35}$ Rudy, pp.13-45.

36 Rudy, p.6.

${ }^{37}$ See also Judy Vaknin, Smoke signals : 100 years of tobacco advertising, London, 2007.

${ }^{38}$ Hilton, p.83.
} 
Tobacco was among many consumer items to benefit from improvements in industrial production in the late Victorian era. The availability of cheaply produced products, and particularly repeat-purchase products such as tobacco or soap, saw the rapid expansion of the advertising industry in the late nineteenth and early twentieth centuries. T. R. Nevett argues that by the interwar era, following the advances of mass consumer culture in the United States, Britain entered a 'golden age' of advertising - a new era of 'powerful personalities, of exciting new media, of improved precision and effectiveness. ${ }^{39}$ Advertisers built on the popularity of magazines, and used local and national newspapers to target particular groups. Until the 1930s print advertisements were dominant, and given their accessibility remain the key source for analysis of how advertising operated within society over the period 1920-1962. Billboards, placards, and advertising at point-of-sale were also important during this period, but do not occupy nearly so great a place in the historical record. The interwar period also saw advertisers take to new media. In 1936 the New Zealand government passed the Broadcasting Act which allowed, for the first time, advertising on commercial radio stations. Television advertising would follow much later in the 1960s. Cinema increased in popularity in the interwar era, and New Zealanders, like others, became enraptured with the latest films and movie stars emerging from Hollywood. Direct and indirect advertising was a key feature of this new medium. ${ }^{40}$ Film companies were paid to use particular products such as tobacco in their movies. Movie stars smoked cigarettes on the screen, as well as providing paid testimonials which manufacturers then used to advertise their products. This practice was particularly prominent with tobacco companies in the 1930s. In their 1937-8 'Lucky Strike' campaign, American Tobacco paid movie starts the present day equivalent of USD $\$ 3.2$ million for their testimonials. ${ }^{41}$

In his analysis of the rise of the 'mass market' in Britain, Hilton argues that advertising was essentially the means through which tobacco manufacturers sought to control the tastes and desires of its consumers in order to meet the manufacturers' own needs - 'dictated by motives of profit. ${ }^{, 2}$ Whether advertisers controlled/shaped or followed/reflected consumption patterns is a central issue in the study of advertising. This question is particularly pertinent in the study of female smoking patterns. Tinkler

${ }^{39}$ T. R. Nevett, Advertising in Britain: a bistory, London, 1982, p.161.

${ }^{40}$ For more on the significance of smoking, advertising and cinema in this era see Hilton, pp.149-50. See also Wayne Brittenden, The celluloid circus: the heyday of the New Zealand picture theatre 1925-1970, Auckland, 2008, on New Zealanders movie going habits, and Patrick Day, The radio years: a bistory of broadcasting in New Zealand, volume one, Auckland, 1994, on the development of radio over the first half of the twentieth century.

${ }^{41}$ K. L. Lum, J. R. Polansky, R. K. Jackler and S. A. Glantz, 'Signed, sealed and delivered: "big tobacco" in Hollywood, 1927-1951', Tobacco Control, vol. 17, 2008, p.313.

42 Hilton, pp.85, 92. 
observes that 'cigarette advertising was particularly keen to construct the cigarette as a passport [for women] to public spaces and, especially, modern ones. ${ }^{43}$ Yet whether this was already occurring, or would have occurred despite advertisers' efforts, is difficult to determine. Similarly Rosemary Elliot argues that advertising sought to 'locate smoking within the boundaries of gendered societal norms, whereas in reality, women's smoking was much more associated with financial independence and social autonomy. ${ }^{, 4}$ The question of influence is a problem faced by all historians working with advertising sources. While this study acknowledges the limits of interpretation posed by this dilemma, it also suggests that advertising was both shaped by existing trends, and played a central role in shaping the increase in consumption patterns in New Zealand through much of the twentieth century.

When Peter McKinnon embarked on his survey in 1962, the findings of the RCP's report were very new and had not been fully absorbed by the participants in his study. McKinnon considered that smoking was still socially acceptable and normative. However, there were times at the beginning and end of the study period when there were debates about smoking, when arguments about the rights and wrongs of smoking, and the risks and dangers of the habit were voiced. Understandings of health are central to discussions of controversies and campaigns around smoking. If we are to understand the rising popularity and consumption of smoking in New Zealand over the period 1920-1962, this thesis must also ask what was the specific nature of the discussions that took place around smoking and what was the basis for these discourses? This study is particularly concerned to unravel the extent and grounds of 'health' discourses in the period prior to smoking being identified as a health issue strongly linked to disease and mortality. What was the public understanding of this discourse by the turning point in 1962 when the health risks of smoking were realised?

While many historians situate their analysis of the 'health' issue firmly in the second half of the twentieth century, Ian Tyrrell, who has written the Australian case study, is much more concerned to address health rhetoric in the pre-1950s era. Tyrrell's main work, Deadly enemies: tobacco and its opponents in Australia, has a much stronger focus

43 Tinkler, Smoke signals, p.92.

${ }^{44}$ Elliot, Women and smoking since 1890, p.51. 
on the negotiation between pro and anti-smoking campaigners in Australia. ${ }^{45}$ Tyrrell, much more than other historians such as his British or Canadian equivalents, is concerned to acknowledge and accentuate the presence of a real and heated debate promoted by anti-smoking campaigners right throughout the twentieth century. Tyrrell argues for the significance and presence of a strong anti-smoking message based on moral and health concerns through the late nineteenth and twentieth centuries, arguing that the shifts and negotiations which took place in public smoking sites 'account much better for the anxieties about smoking than do increases in per capita consumption. ${ }^{46}$ He argues however, that health concerns were known and warned against through the period 1900-1950, yet did little to stem the rising popularity and prevalence of smoking in Australia.

Other international studies focus on the period before the first world war as the main period of activity for anti-smoking campaigners. Anti-smoking activities had a much smaller presence in Britain after the first world war yet lobbyists continued to campaign against smoking in the United States well into the 1920s and 1930s. Allan Brandt and Cassandra Tate both chart the anti-smoking message through the history of smoking in the United States, stressing the influence of well-known personalities who campaigned against smoking, such as car manufacturer Henry Ford who published a book in 1916 entitled The case against the little white slaver. ${ }^{47}$ Such opposition was grounded in moral rather than health concerns. This thesis is more concerned to establish how smoking was discussed and understood, particularly within a wider health framework, in the normative era when smoking was unremarkable and common. Within the changing health context in New Zealand over the period 1920 to 1962, successive governments took a much greater interest in the lives of their citizens. Health administrators successfully controlled, to a great extent, the spread of communicable diseases as well as improving a wide range of other health concerns. ${ }^{48}$ This context is integral to our understanding of how the reports of the Royal College of Physicians and United States

\footnotetext{
45 Ian Tyrrell, Deadly enemies: tobacco and its opponents in Australia, Sydney, 1999. See also, Robin Walker, Under fire: a history of tobacco smoking in Australia, Melbourne, 1984; Ian Tyrrell, 'The limits of persuasion: advertising, gender and the culture of Australian smoking', Australian Historical Studies, vol. 114, 2000, pp.27-48; Ian Tyrrell, 'Before the Surgeon General's report: public discourse in Australia over tobacco addiction to 1964', Australian Journal of Politics and History, vol. 44, no. 2, 1998, pp.177-90.

46 Tyrrell, Deadly enemies, p.116.

${ }^{47}$ Allan M. Brandt, The cigarette century: the rise, fall, and deadly persistence of the product that defined America, New York, 2007; Cassandra Tate, Cigarette wars: the triumph of the 'little white slaver', New York, 1999, p.55.

48 See Derek Dow, Safeguarding the public health: a history of the New Zealand Department of Health, Wellington, 1995; Linda Bryder, (ed.), A bealthy country: essays on the social history of medicine in New Zealand, Wellington, 1991.
} 
Surgeon General were received in New Zealand in the early 1960s by health officials, health professionals and the public.

The discussion is organised into three chapters, each focusing on different but related aspects of the rise in popularity and prevalence of smoking over the period 1920-1962. Chapter one examines the establishment of a local tobacco growing industry, aided in large part by government investment and administrative support from the 1920s. The chapter discusses the wider economic and political factors which shaped the activities of growers, manufacturers and retailers and which propelled the availability and affordability of tobacco over the study period. Chapter one also acts as a chronological and contextual overview for chapters two and three. The ability of the industry's widespread promotional activities to drive the sustained upward trajectory of tobacco consumption in New Zealand is the focus of chapter two. The chapter assesses the spatial and gendered expansion of smoking, looking to how, encouraged by advertisers, smoking became more acceptable and normal in the smoking spaces and activities of leisure, work and war. Through most of the period 1920-1962 smoking was uncontroversial and normative, however chapter three looks at two distinct phases at the beginning and the end of the study period when smoking became something questionable or controversial. The chapter looks at the shifting nature of discourses surrounding smoking, including the presence of a 'right to smoke' rhetoric in New Zealand's smoking culture. 


\section{Chapter One}

\section{Growing, selling and smoking: the development of the tobacco industry and the long term consumption trends}

In March 1953 Major Spraggon, sales manager of the National Tobacco Company, visited his local Rotary Club in Napier, boasting to its members that New Zealanders were among the heaviest smokers in the world. Spraggon claimed that they smoked more tobacco than their Australian or British counterparts. In that year, New Zealanders consumed 7.4 lbs per adult head of population (over 15 years of age), where the Australians smoked only $6.8 \mathrm{lbs}$ and the British 6 lbs each. ${ }^{1}$ New Zealanders were the forth highest consumers, per capita, of tobacco in the world. ${ }^{2}$ This high consumption did not come by chance, but rather as a result of over thirty years of hard work in the development of a domestic tobacco industry. Spraggon asserted that to grow tobacco successfully in New Zealand required 'intelligent care, adoption to soil, climate and the best seed.' Getting the right blend of tobacco for New Zealanders' tastes was also important - the National Tobacco Company had a 'sampling panel' of around forty people across New Zealand trialling their product. Lastly Spraggon stressed the importance of packaging - the right 'design, colour scheme and [a] brand name... with punch... which could not be mispronounced or misspelt' were crucial. ${ }^{3}$

This study is primarily interested in smokers and tobacco consumption. In order to understand this trend we must also look at the people, companies and events which established a tobacco industry in New Zealand in the first half of the twentieth century, enabling tobacco to become a widely available consumer item which was affordable to a large proportion of the population of New Zealand. This chapter will introduce the three main elements of the tobacco industry - growers, manufacturers and retailers, charting the development, with government support, of a domestic industry. The interplay of government and industry and how it affected what New

${ }^{1}$ Daily Telegraph (Napier), 17 March 1953, in Annual Reports Press Reports, 1941-1954, TB, W2303, 2, 1/7, part 2, Archives New Zealand, Wellington.

${ }^{2}$ Lee, (ed.), pp.9, 59, 81. In 1953 only Canada, the Netherlands and the United States had higher per capita consumption levels than New Zealand.

${ }^{3}$ Daily Telegraph (Napier), 17 March 1953, in Annual Reports Press Reports, 1941-1954, TB, W2303, 2 , 1/7, part 2, Archives New Zealand, Wellington. 
Zealanders smoked over this period will be a particular theme. The industry is then placed within the context of tobacco consumption trends, focussing in particular on three noticeable dips in the overall upward trend - the economic depression of the early 1930s, the years within the second world war, 1939-1945, and the 1958 'black budget'.

Tobacco growing in New Zealand remained experimental in the 1910s and early 1920s, as manufacturers trialled areas of the country which provided conditions suitable for growing good tobacco leaf. Hot, dry areas were sought - Hawke's Bay, North Auckland and the Nelson region quickly proved suitable, yet other areas with similar climates were less successful at yielding good quality leaf - Hokianga, Rotorua, and Marlborough. ${ }^{4}$ The most prosperous and enduring area for cultivation was Motueka, near Nelson, where tobacco was grown through most of the twentieth century, only ceasing production in 1995 . In the 1920s the government encouraged farmers to experiment with tobacco leaf in such areas, hopeful that it might prove to be a successful export product. Under the imperial preference scheme Britain allowed its colonies and dominions to enjoy special reduced tariffs on tobacco imports. ${ }^{5}$

Despite such encouragement, initial shipments of New Zealand leaf were not well received in London. In March 1929 W.D. and H.O. Wills sent 10,000 lbs of leaf to London to be tested on the British market. When it arrived in London in November however, 27 of the 42 bales were totally destroyed by dampness. The rest were deemed low grade tobacco, some only fetching a token $f_{1}$ per $340 \mathrm{lb}$ bale. Only one of the bales was deemed to be 'first grade. ${ }^{6}$ British manufacturers were wary to introduce new leaf which might alter the taste of their tobacco. ${ }^{7}$ Growers were guaranteed a minimum price for their crop from 1926, however by the end of 1929, as the economic depression set in around the world, the government retracted this offer, unsure of how New Zealand leaf would continue to fare on the British market. ${ }^{8}$ The government's dreams of tobacco as a valuable export crop faded. The Department of Agriculture issued a notice that it did 'not advise persons to embark on tobacco growing as a sole means of livelihood, unless they are working under contract to a company."

${ }^{4}$ The Press, 22 March 1929, p.16; 26 November 1928, p.10.

${ }^{5}$ Ibid., 17 January 1928, p.6.

${ }^{6}$ Ibid., 22 March 1929, p.16; 23 December 1929, p.12.

${ }^{7}$ Ibid., 20 November 1929, p.12.

8 Ibid., 1 November 1929, p.12.

${ }^{9}$ Ibid., 1 November 1929, p.12; 20 November 1929, p.12. 
While New Zealand might not have found a place for its tobacco crop on the international market, the potential for locally grown leaf to be absorbed into the domestic tobacco market was realised. Tobacco growing in New Zealand remained, through much of the 1920s and early 1930s, a largely experimental venture. Farmers were more likely to convert a couple of acres to tobacco than to make it their sole crop. In 1925, for example, 160 independent growers in the Motueka area cultivated just 450 acres of tobacco between them, averaging just 2.8 acres each. ${ }^{10}$ By 1935 the number of growers in the area had increased to 499, cultivating around 3.9 acres each; however by 1945 the number of growers had risen only slightly to 553 but they were each responsible for, on average, just over 6 acres each. ${ }^{11}$ The large number of growers, all contracted to different manufacturers, were united under the Tobacco Growers Association in the 1920s and early 1930s, and then the Tobacco Growers Federation from 1938. The Federation was supported by the Tobacco Board, a government committee brought into being in 1935 by the Coalition Government at the end of its administration (billed by some as an election stunt), to oversee the licensing of growers and the warranting of buyers, though its mandate was later significantly widened throughout its 50 year existence. ${ }^{12}$ Under the organisation of the Tobacco Growers Federation working with the Tobacco Board, growers had a strong platform from which to demand minimum prices and government support for capital purchases.

Commercial production and manufacturing of tobacco leaf in New Zealand first began when Gerhard Husheer, a German immigrant, set up the New Zealand Tobacco Company in 1912 and began growing tobacco for production in Napier. Following the first world war, Husheer left the company, a victim of 'anti-German feeling engendered by the war', and started a tobacco plantation in Riverhead, North of Auckland. ${ }^{13}$ Husheer returned to the New Zealand Tobacco Company after it went into liquidation four years later, and with the assets formed the National Tobacco Company. Husheer was to become an important figurehead of the local tobacco industry. During the second world war, despite his German origins, Husheer was permitted to retain his position as head of the National Tobacco Company - tobacco was a 'key revenue earner' and Husheer was 'trusted. ${ }^{14}$ The second major producer and manufacturer in these early years was W.D. and H.O. Wills, a British company which

\footnotetext{
10 O'Shea, p.214.

11 Ibid.

12 Ibid., pp.73-4.

13 Ibid., pp.15-6.

${ }_{14}$ David McGill, The guardians at the gate: the history of the New Zealand Customs Department, Wellington, 1991, p.118.
} 
began manufacturing from their Wellington factory in $1919 .{ }^{15}$ Until this point, New Zealanders had, by and large, smoked imported tobacco products mainly from the United States and Britain. However tobacco shortages and increasing prices by the end of the first world war meant that it became increasingly profitable to import untreated tobacco leaf for local manufacture, and better still to support the establishment of a local tobacco growing industry.

Wills and the National Tobacco Company were the two main manufacturers through the 1920s and early 1930s. Other smaller companies such as the Nelson Tobacco Company and Consolidated Tobacco also enjoyed some success in the 1930s, yet without the backing of a larger British parent company, were not in a position to recover from business setbacks and poor growing seasons. The Nelson Tobacco Company, founded in 1934, produced tobacco and cigarettes made from only locally grown leaf (i.e. it was not blended with imported leaf), but when a kiln fire destroyed the premises in 1948, the company lacked the capital to restore business, going into liquidation that year. ${ }^{16}$ Consolidated Tobacco's short existence also ended in a fiery blaze - when the company went into liquidation in 1937 it was forced to dispose of $£ 1,500$ of tobacco which was deemed unfit to be sold, destroying it in a bonfire at its Mt Eden factory. ${ }^{17}$ Other minor companies were absorbed, with their growers, into larger companies, for example the St James Tobacco Company was bought out by Wills in the early 1960s. ${ }^{18}$ More contemporary companies such as Phillip Morris and Rothmans entered the New Zealand market toward the end of the study period, with Rothmans forming a merger with the National Tobacco Company in Napier in 1957 and Phillip Morris buying out Godfrey Philips in the early 1960s. ${ }^{19}$

Retailers were the final group in the tobacco industry, linking production with consumption. Through much of the twentieth century the independent tobacconist was the main retailer of tobacco products and was often combined with a men's hairdressing salon. Though the name of the organising body changed often, independent tobacconists began to organise themselves in regional divisions from the mid-1920s. In April 1932 The Tobacconist and Hairdresser put out a call to form a federation of tobacconists and from 1934, regional organisations united as divisions of

\footnotetext{
15 O’Shea, pp.15-19.

16 Ibid., p. 102; Tobacco and cigarettes - Manufacture of by Nelson Tobacco Company Limited, Nelson, IC, 1, 17/3/8, Archives New Zealand, Wellington.

17 The New Zealand Hairdressers' and Retail Tobacconists' Review, 15 October 1937, p.14.

18 O'Shea, pp.102-3.

${ }^{19}$ Ibid., pp.137, 160 .
} 
the 'New Zealand Tobacconists' and Hairdressers' Federation. ${ }^{, 20}$ The newly formed Federation held annual conferences, published a monthly trade journal, The New Zealand Hairdressers' and Retail Tobacconists' Review, and petitioned government on issues affecting their business. ${ }^{21}$ Analysis of the Tobacconists' Review and minutes of the Otago Southland division of the Federation reveal that the independent tobacconist was in continual competition with larger retailers who sold tobacco within a wider general trade, such as grocers, hotels, and later, department stores.

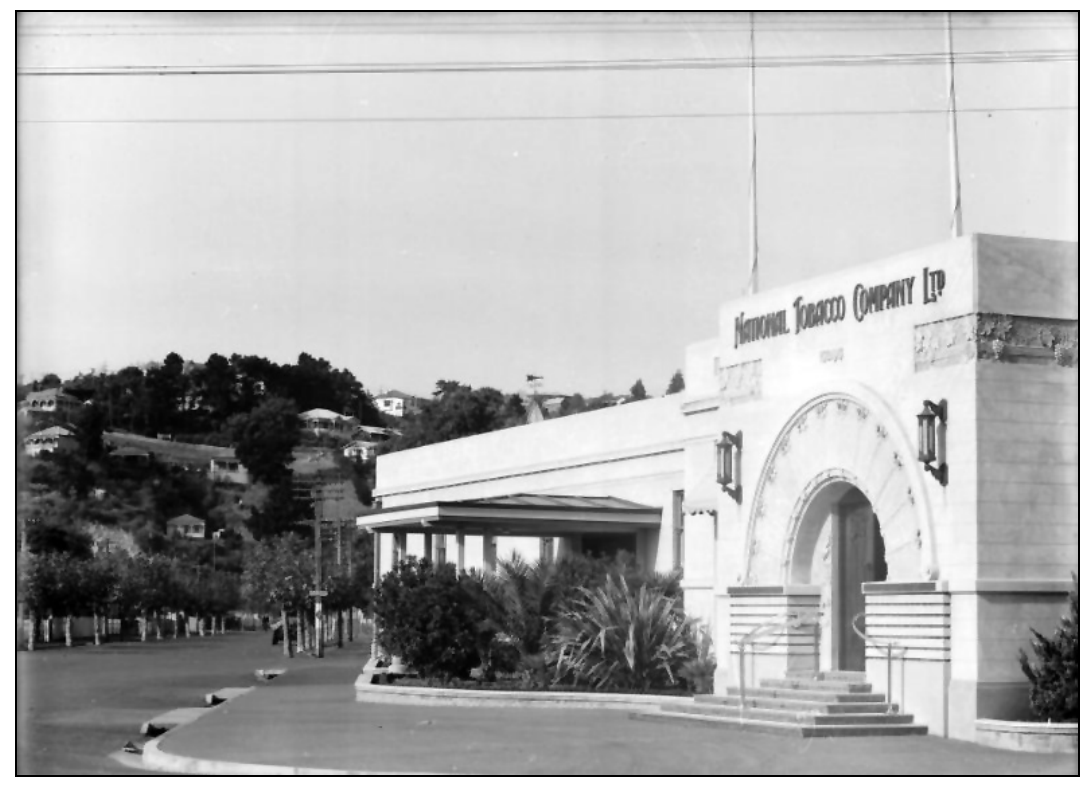

Figure 1

Built in 1925, the external walls of the National Tobacco Company building in Napier collapsed in the Hawke's Bay earthquake of 1931. Company director Gerhard Husheer commissioned architect Louis Hay to design the new entranceway - an elaborate façade in the art-deco style which characterised much of Napier's post-earthquake building. ${ }^{22}$ 1/2 -100006-G, late 1930s, ATL

Throughout the years of this study, the major source of agitation for tobacconists was the issue of price cutting by larger retailers who, through the sale of other products, could afford to cut their prices on popular lines of tobacco in order to attract customers to their shops, thereby making a smaller profit on tobacco and cigarettes. As early as 1927 W.D. and H.O. Wills held a conference for representatives of the tobacco trade, primarily about price cutting. The Otago Southland representative reported back to his association that the practice of price cutting is

20 The Tobacconist and Hairdresser, 21 April 1932, p.11. The Tobacconist and Hairdresser ran throughout 1932. It is not clear from surviving records whether a trade journal existed in 1933.

${ }^{21}$ The New Zealand Hairdressers' and Retail Tobacconists' Review will hereafter be referred to in short form as the Tobacconists' Review. Copies of the trade journal for the years 1934 to 1938 are held in the Alexander Turnbull Library. The final edition of the Tobacconists' Review refers to its takeover by a new journal however copies of this have not been located.

${ }^{22}$ For more detail on the design aspects of the building see Julia Gatley, (ed.), Long live the modern: New Zealand's new architecture 1904-1984, Auckland, 2008, p.19. 
being indulged in freely throughout the Dominion. ${ }^{23}$ From the 1930s, retailers called for a repeal of the Commercial Trusts Act 1910 which legislated against price-fixing of commodities such as tobacco, coal, petrol, and food, by the manufacturer or distributor. ${ }^{24}$ Tobacconists saw this as 'antiquated wartime and civil legislation,' which was 'stifling trade, causing unemployment, loss of rates, rents and taxes, and heading us directly on the path of national dishonour and bankruptcy. ${ }^{25}$ In 1933, after much petitioning the tobacconists were finally successful in their bid to have the Commercial Trusts Act amended and for the first time could standardise retail profits on tobacco and cigarettes. ${ }^{26}$ However, tobacconists still had to negotiate the scale of profits with the larger retailers, and in the first few years, the move did not lead to significant increases in trade or profit for the independent tobacconist. ${ }^{27}$ While they may have won the right to price-fix, tobacco and cigarette price-lists and margins continued to be contested between large and small retailers, the independent tobacconists fighting to defend their place in the tobacco trade well into the 1950s and 1960s.

The standardisation of opening hours for retailers stocking tobacco and cigarettes was another legislative move won by tobacconists in the fight to maintain their sales against the threat of the larger retailer. In 1927 the Shops and Offices Act was amended, effectively enabling tobacconists to enforce, by a two-thirds majority ruling, the hours of trade for any retailer stocking tobacco. The change meant that grocers and department stores had to close at the same time as tobacconists if they wished to stock tobacco. ${ }^{28}$ However, such rules made it more difficult for those who worked during shop hours or did not work near a retail outlet, to purchase tobacco. In April 1927, Auckland magistrate J. H. Luxford exempted two Onehunga tobacconists from the new legislation, arguing that workers, who are 'the largest buyer[s] of tobacco and cigarettes' find it difficult to purchase tobacco during the day. ${ }^{29}$ Negotiations of this Act, along with the administration and control of price-fixing occupied the Federation over the study period. The main outcome of these battles by early members of the Federation, however, was that the independent tobacconist survived though much of the twentieth century, and the tobacconist shop remained an important space in the history of smoking in New Zealand.

\footnotetext{
23 Special Meeting, 12 July 1927, 'Minutes 1924-1961', Otago and Southland Retail Tobacconists' and Registered Hairdressers’ Association, MS-1028, 1924-1976, Hocken Library, Dunedin.

24 The Tobacconist and Hairdresser, 21 April 1932, p.2.

25 The Tobacconist and Hairdresser, 21 March 1932, p.2.

26 Tobacconists' Review, 15 February 1937, p.12; 'The Commercial Trusts Act 1910', The Public Acts of New

Zealand 1908-1931, vol. 8, Wellington, 1932, pp.713-7.

27 Tobacconists' Review, 15 February 1937, p.12.

28 The Press, 20 January 1928, p.8.

${ }^{29}$ Ibid., 30 April 1928, p.8.
} 
An area where all three parties in the tobacco trade met, and where government intervention was most obviously felt, was the issue of excise taxation on domestically produced tobacco and customs tariffs on imported tobacco. Like alcohol, tobacco has long been a lucrative form of revenue for government, with New Zealand's first tax laws regulating tariffs on these items as early as $1841 .^{30}$ Since the 1970 s, the government has clearly enunciated that the rationale for high goods taxation on tobacco is firstly a deterrent to start or continue smoking, and secondly, a way to offset the resulting burden on the public health system that tobacco use causes. ${ }^{31}$ Until this point however, alcohol and tobacco were primarily seen as high revenue-generating goods. Through the period of this study New Zealand governments successively moved away from a reliance on indirect forms of taxation such as customs and excise duty, toward direct taxation such as income, profits and wealth taxes. ${ }^{32}$ Total government revenue from customs tariffs was reduced in the first two decades of the twentieth century by measures which removed import tariffs on foodstuffs. ${ }^{33}$ However import tariffs and excise duty on tobacco and alcohol were excluded from such measures, and particularly in times of national crisis such as war, were items which the government could raise taxes on to generate income quickly.

While direct forms of taxation came to be the main source of revenue for government by mid-century, reductions in customs revenue were offset by an increase in taxation at the point of sale - with most consumer goods being subject to a five per cent sales tax from 1933, a tax which was later readily exploited by Finance Minister Walter Nash as a quick way to generate revenue during the second world war, raising the tax to twenty per cent by $1941 .^{34}$ This sales tax excluded essential items such as basic foodstuffs, and during the war clothing and footwear remained at the lower rate. ${ }^{35}$ On the other hand, items such as petrol, tobacco, and alcohol were subject to higher rates of excise duty, rising 25 per cent overnight in September 1939. ${ }^{36}$ Through the period 1920-1962 tobacco's status as 'non-essential' proved to be a highly

\footnotetext{
30 Through much of the nineteenth century and the early years of the twentieth century tobacco and alcohol remained the two main high duty goods in New Zealand and as such, were subject to smuggling and circulation on the black market. See McGill, pp.18, 63-5.

31 Toni Ashton and Susan St John, Insights into excises: a focus on alcohol, tobacco and motor fuels taxation, Wellington, 1985, p.15.

32 Ashton and St John, pp.19-20; Paul Goldsmith, We won, you lost, eat that! a political history of tax in New Zealand since 1840, Auckland, 2008, pp.120, 189-90, 239.

33 Goldsmith, p.154.

${ }^{34}$ Goldsmith, pp.175, 198.

35 Goldsmith, p.200.

${ }^{36}$ J.V.T Baker, War economy, Wellington, 1965, p.262, available from http://nzetc.org/tm/scholarly/teiWH2Econ.html, accessed 12 September 2008.
} 
contentious rationale for high rates of taxation and seemingly at odds with public and government rhetoric.

As a domestic tobacco industry developed, revenue in the form of excise taxes levied on domestically produced goods became more common. Uneven and inconsistent rates of taxation between import and excise tariffs were a persistent source of tension and debate fought between growers and manufacturers. Growers felt that the government should be obliged to protect and nurture the local growing industry, whereas manufacturers resented the increased tariffs on imported tobacco which was, in the 1920s, preferred by most consumers. The growers were often represented by backbench Reform MP Keith Holyoake, who represented Motueka early in his career, and even fought against his government's proposed amendments to tobacco tax on a number of occasions. ${ }^{37}$ In 1930 the directors of the National Tobacco Company protested an import tariff hike, which was seen to favour growers over manufacturers. Husheer argued that by pushing tariffs on imported leaf up, the government was simply making it less profitable to manufacture tobacco in New Zealand and that they may as well import the product in saleable condition. ${ }^{38}$ Despite the development of the New Zealand growing industry, manufacturers primarily used imported tobacco leaf until imports were banned during the second world war. Tariffs needed to be low enough to make the import of raw leaf profitable for the manufacturers to continue to do so.

How then did the internal machinery of the tobacco industry, supported by government, determine what New Zealanders smoked? What people smoked was largely tied to availability, import licenses, and as we will see from the second world war onwards, the ability of the local industry to grow and manufacture enough tobacco to meet demand. Until the second world war, New Zealanders could afford to be selective in what they smoked, favouring British and American tobacco and cigarettes brands over locally made product. In the early years of production in New Zealand, crops were inconsistent and possessed a different taste to the American or British imports. The internationalism of New Zealanders' choices and what was available to them on the local market is perhaps best reflected in the style and content of advertising found in New Zealand through the interwar years 1918-1939.

\footnotetext{
${ }^{37}$ Dominion, 17 February 1933, p.7; Barry Gustafson, Kiwi Keith: a biography of Keith Holyoake, Auckland, 2007, p.26.

${ }^{38}$ Dominion, 2 December 1930, p.13.
} 
Not only were the raw tobacco and manufactured cigarettes imported into the country, but so too were advertising brands, slogans and ideas. American and British brands overwhelmingly dominated the New Zealand market. Tobacco grown in the American state of Virginia was common and brands such as 'Clarence', 'Craven " $\mathrm{A}$ ”, 'Bears', 'Grey's', 'State Express', and 'Ardath' were popular in New Zealand.

Advertising for American imports typically boasted about the quality of the cigarette tobacco and drew on Virginia's long history as a leading producer of tobacco and position as the 'best' in the world. British brands popular in New Zealand were manufactured out of Wills' tobacco factory in Wellington, and included 'Army Club', 'Three Castles' and 'Capstan.' Given the strength of imperial connection in the first half of the twentieth century, British advertisers were well placed to draw on imperial sentiment to promote British tobacco in New Zealand. 'Three Castles', for example, ran 'Leaders of the Empire' advertisements which profiled particular political leaders such as Herbert Morrison, a British MP; following a description of Morrison's political posts, the advertisement trumpets 'and the Unquestioned Leader in Cigarette Tobacco is...The Three Castles Tobacco. ${ }^{39}$ Such statements make implicit inferences about the strength of the British Empire and the obvious parallel in quality tobacco. Similarly, a 1924 advertisement for 'Prince Charming' cigarettes overtly proclaimed that 'The best people smoke them in the Old Country. ${ }^{40}$

This imperial sentiment was employed by advertisers in Britain in an attempt to reach a mass consumer base; symbols of Empire, monarchy, military and health were 'culturally conservative' and had a wide appeal. ${ }^{41}$ This advertising technique was also widely used for other products. Anne McClintock's study of advertising in the Victorian era shows that the use of 'Empire' iconography for commodities and luxuries took 'scenes of empire into every corner of the home, stamping images of colonial conquest on soap boxes, matchboxes, biscuit tins, whiskey bottles, tea tins and chocolate bars. ${ }^{, 42}$ Advertising brands were not the only way that the tobacco industry reinforced ties to Britain and the Empire. In the Tobacconists' Review, Empire tobacco news and consumption statistics were frequently reported, and many articles were pulled straight from the Tobacco Journal (Australia) or Tobacco World (Britain). In 1936 a correspondent to the Tobacconists' Review congratulated the Dunedin tobacconist who dressed his shop window display as a tribute to the recently deceased King George V.

\footnotetext{
${ }^{39}$ Advertisement - Three Castles, Listener, 20 June 1941, p.13.

40 Advertisement - Prince Charming, New Zealand Sporting and Dramatic Review, 27 March 1924, p.2.

${ }^{41}$ Hilton, p. 95 .

42 Anne McClintock, Imperial leather: race, gender and sexuality in the colonial contest, London, 1995, p.209.
} 
He described the scene: 'The whole window was black and sides draped in black velvet, in the centre a large framed picture of the King, from the top of the window purple satin was draped down round the picture and rucked across the black velvet. ${ }^{, 43}$ While the irony that the King died from smoking-related complications is lost on the correspondent (and probably the tobacconist), the symbolic gesture of loyalty to Empire is clear. ${ }^{44}$

Even though most of the American or British brands were manufactured in New Zealand by local divisions of international tobacco companies, advertisements generally did not adopt a distinct New Zealand character, and were replicated straight from their place of origin. Where British or American tobacco advertisers did occasionally attempt to make local references, it was usually by connecting smoking with New Zealand sport. For example in the 1920s, 'Three Castles' ran an advertisement announcing that the All Blacks, on tour in South Africa, were all regular smokers of 'Three Castles' and were relieved to find that they could obtain 'regular supplies of their favourite smoke' in South Africa and would 'continue to smoke "Three Castles" during the period of their tour' (figure 2$).{ }^{45}$ Such assertions fit with the current discussion of national and Empire references in advertising, yet can also be placed in a much longer history of sport sponsorship by tobacco companies in the twentieth century.

In the context of the 'golden age' of advertising through the interwar era, the influence of Hollywood and associations of internationalism and modernity are significant to our understanding of why New Zealanders favoured international brands. ${ }^{46}$ International brands represented, in part, a connection to broader notions of belonging to or participating in international, modern trends. In 1941 an Otago Daily Times article addressed this phenomenon in New Zealand, stating that the 'psychology of the public is most peculiar' - preferring imported goods to locally produced and manufactured goods. ${ }^{47}$ One politician noticed that 'some people were prejudiced

\footnotetext{
43 Tobacconists' Review, 15 February 1936, p.15.

${ }^{44}$ For a further example of imperial sentiment, see also L. Sowman (President of New Zealand United Tobacconists' Movement and President of the United Retailers Protection League), 'The Time for Action', The Tobacconist and Hairdresser, 21 March 1932, p.1.

45 Advertisement - Three Castles, The Press, 14 June 1928, p.12. See also, 'The Australian Cricket team in England state that they smoke only Army Club Cigarettes', Advertisement - Army Club, Weekly News, 20 May 1926, p.85.

${ }^{46}$ Robin Walker notes a similar pattern of internationalisation of taste in Australia through the 1930s and 1940s. See Walker, pp.60-1.

47 Otago Daily Times, 3 June 1941, Miscellaneous Press Cuttings, 1936-1941, TB, W2303, 2, 1/9, part 1, Archives New Zealand, Wellington.
} 
simply because a product was of local manufacture. ${ }^{, 48}$ However wartime conditions would soon drastically reduce New Zealanders' ability to be selective or exclusive about their tobacco preferences.

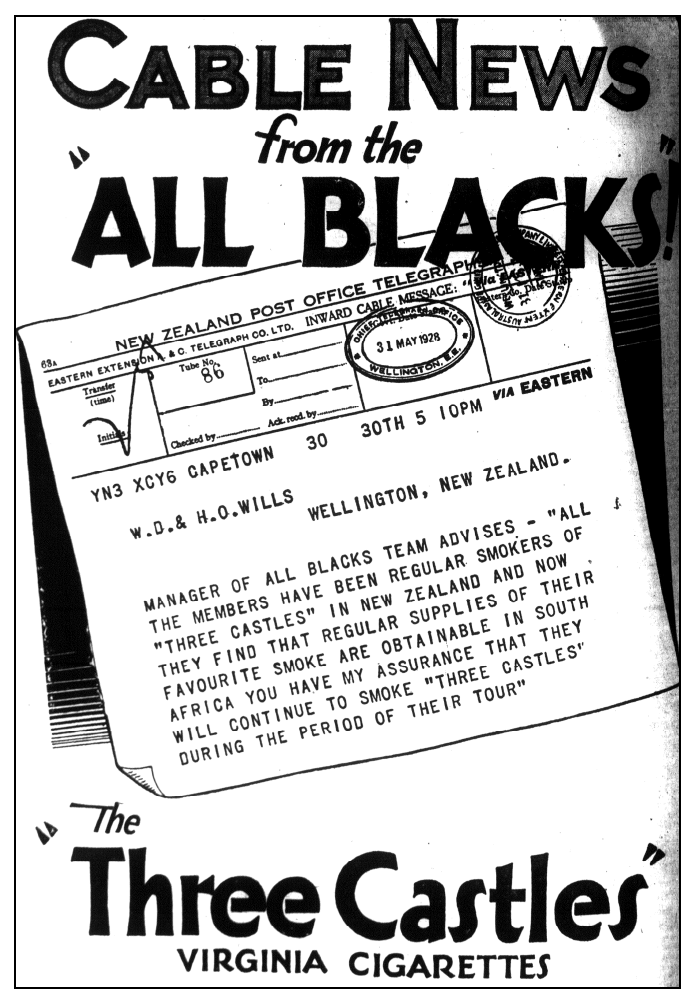

Figure 2

Though local references were relatively uncommon in tobacco advertising in the interwar era, W.D. and H.O. Wills were eager to align their products with popular national figures such as the All Blacks.

The Press, 14 June 1928, p.12

In 1941 licenses for the import of tobacco were cancelled. As a combined result of the shortages and the control of imports, New Zealanders were compelled to smoke more domestically produced tobacco. The Nelson Evening Mail encouraged local growers in 1941, 'it is perhaps not easy to capture the conservative smoker who has long derived a peculiar satisfaction from the aromatic flavour of a particular blend of the weed, but the exigencies of war will doubtless help to break him in. ${ }^{, 49}$ The 'conservative smoker', would no doubt have established his smoking habit during the time when imported tobaccos were cheaply and consistently available. However, if the government and growers were to have their way, the Mail went on, 'we can look forward to the time when the slogan will be, not "made from the best Virginian" but

\footnotetext{
48 Armstrong, New Zealand Parliamentary Debates (NZPD), vol. 271, 21 November 1945, p.650. ${ }^{49}$ Nelson Evening Mail, 12 May 1941, Miscellaneous Press Cuttings, 1936-1941, TB, W2303, 2, 1/9, part 1, Archives New Zealand, Wellington.
} 
"made from the best Nelsonian." "50 Through limited availability and the "exigencies of war' rather than a patriotic localisation of taste, the second world war represented a move toward greater consumption of locally grown and manufactured leaf in New Zealand. International brands still dominated the market in the post-second world war era, yet contained leaf grown in the hot climate of Motueka, and packed by women in factories in Petone.

New Zealand developed its own tobacco industry at the same time as its people began smoking more and in greater numbers. Successive governments saw that while New Zealand's position as a tobacco exporter might not be realised, the domestic market was growing and revenue from excise tariffs might prove just as profitable. This discussion now turns to assess the rise in tobacco consumption in New Zealand. As has been noted, the general pattern over the period 1920-1962 shows a rising consumption trend upwards. However industry and consumers were not isolated from the wider economic and political situation which affected the availability and affordability of tobacco.

In 1953 when Major Spraggon boasted to the Napier Rotary Club that New Zealanders were among the highest, per capita, consumers of tobacco in the world, he claimed that tobacco was used 'more than any other commodity, except tea, sugar and salt. ${ }^{, 51}$ In the post second world war climate of relative prosperity through the 1950s, high consumption of goods indicated that New Zealand had eased out from the economic controls of wartime. Domestic production of meat, butter and wool secured New Zealand's place as a thriving export producer and consumption of these goods was also much higher at home than in Britain. ${ }^{52}$ Brian Easton asserts that this 'rising prosperity' among New Zealanders coupled with the 'momentum of past addiction', particularly among returned servicemen, sustained the high levels of tobacco consumption through the post war era. ${ }^{53}$ A central question therefore is how New Zealanders came to be among the highest consumers of tobacco in the world by the mid-1950s?

\footnotetext{
50 Ibid.

${ }^{51}$ Daily Telegraph (Napier), 17 March 1953, in Annual Reports Press Reports, 1941-1954, TB, W2303, 2 , $1 / 7$, part 2, Archives New Zealand, Wellington.

52 Bronwyn Dalley, 'The golden weather 1949-1965', Bronwyn Dalley and Gavin McLean, (eds.), Frontier of dreams: the story of New Zealand, Auckland, 2005, p.317.

${ }^{53}$ Easton, The economic regulation of tobacco consumption in New Zealand, p.12.
} 
In 1901, the NZOYB reported that New Zealanders consumed $2.31 \mathrm{lbs}$ of tobacco per adult head of population annually for the year $1900 .^{54}$ This figure rose steadily. By the mid-1920s it had doubled to around 4.8 lbs annually. Consumption reached a small peak of 5.0 lbs per year in 1929 but then fell away in the first noticeable decline in the rising consumption trend during the depression following the 1929 stock market crash. Consumption again rose during the mid to late 1930s but declined during the second world war as production failed to keep up with consumer demand. Shortages in the immediate post second world war period were alleviated by 1947 and consumption again began to grow. From the mid-1950s, consumption again plateaued, yet levels remained historically high, between around $7.5 \mathrm{lbs}$ and $8.1 \mathrm{lbs}$ per year until the mid-1970s. Interestingly, consumption peaked in 1962 and 1963 at 8.1 lbs per year, at exactly the moment in the history of smoking when the negative health effects of tobacco were presented to the medical profession and public in conclusive form. As this is a study in the rise in consumption, the normative, it is useful to end the study at a point when consumption was at the highest point it was ever to reach in the twentieth century. It is also important to note that that this high consumption continued through to the mid-1970s and declined slowly from that point. ${ }^{55}$ By 1990 , tobacco consumption was back to the same level as $1920 .^{56}$

Figure 3

Cigarette and tobacco products consumption, 1920-1990 (cigarette equivalents per person aged 15 years and over, per year)

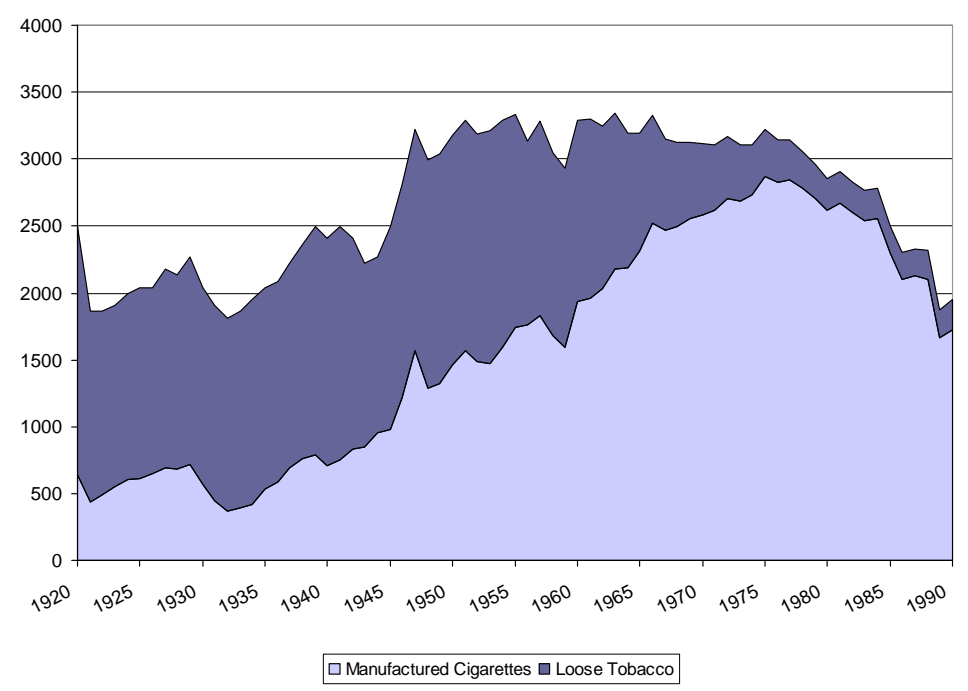

Source: Laugesen, Tobacco statistics 1991, p.12

Note this source states that one cigarette is equivalent to one gram of loose tobacco. One pound of tobacco is therefore equal to around 453.6 cigarette equivalents.

\footnotetext{
${ }^{54}$ NZOYB, Wellington, 1901, p.106.

55 All statistics are taken from Lee, (ed.), pp.58-9; and Laugesen, Tobacco statistics 1991, p.12.

${ }^{56}$ Laugesen, Tobacco statistics 1991, p.12.
} 
Another key component of total consumption that is known is the proportionate consumption of manufactured or tailor-made tobacco as compared to loose-leaf tobacco for pipe or roll-your-own consumption. Statistics are also available for the number of cigarette papers that were manufactured in, or imported to New Zealand. ${ }^{57}$ The sharpest rise in the consumption of manufactured cigarettes occurred between 1940 and 1950. This rise can be attributed to increased numbers of women lighting up during these years, as women smoked almost exclusively tailor-made cigarettes. In 1940 loose tobacco comprised 70 per cent of total consumption, yet by 1950 it had decreased to 54 per cent. In the 1950s and 1960s as prices of manufactured and roll-your-own levelled out, manufactured cigarettes became increasingly popular, and by 1970 loose tobacco products comprised only fifteen per cent of the market. ${ }^{58}$

In 1953 newspapers keenly reported tobacco growth and consumption statistics when they were released annually by the Tobacco Board.$^{59}$ Earlier, in November 1938, Truth similarly trumpeted the fact that tobacco consumption was again on the increase after the depression years. 'Necessity' argued Truth, 'appears to have had some effect on tobacco consumption, at least according to official figures for the depression years, so thank goodness the depression is gone! ${ }^{60}$ The economic depression of the early $1930 \mathrm{~s}$ represents the first noticeable dip in the trend of increasing tobacco consumption. As in other countries, New Zealanders faced large scale unemployment and wage cuts during the early 1930s. In 1929 total tobacco consumption per adult was 5.0 lbs per annum; however over the next six years to 1935, consumption fluctuated between 4.0 lbs and 4.5 lbs. ${ }^{61}$ This decline in consumption is roughly in line with the decline in consumption of food around the same time. James Belich notes that, beyond unemployment levels, consumption levels are a valuable way of assessing the impact of the depression on New Zealanders. The consumption of staple foods such as beef, pork and potatos all fell by about 30 per cent during the depression, and spending on 'luxuries' such as ice cream and alcohol dropped more sizeably. ${ }^{62}$

\footnotetext{
${ }^{57}$ See Lee, (ed.), p.5; Laugesen, Tobacco statistics 1991, pp.12-13.

58 Laugesen, Tobacco statistics 1991, p.12.

59 Te Puke Times, 11 September 1953, in Annual Reports Press Reports, 1941-1954, TB, W2303, 2, 1/7, part 2, Archives New Zealand, Wellington.

${ }_{60}$ N.Z. Truth, 9 November 1938, in Miscellaneous Press Cuttings, 1936-1941, TB, W2303, 2, 1/9, part 1, Archives New Zealand, Wellington.

${ }^{61}$ Lee, (ed.), pp.58-9.

${ }^{62}$ James Belich, Paradise reforged: a history of the New Zealanders from the 1880s to the year 2000, Auckland, 2001, p.255. Paul Christoffel also notes the decline in alcohol consumption during the depression, stating that consumption did not begin to pick up again until the mid-1930s, see Paul Christoffel,
} 
The movement from manufactured cigarettes to roll-your-own cigarettes is also an indicator of the impact that the depression had on smokers in New Zealand. Rollyour-own cigarettes were a much more economical choice, as smokers could roll smaller cigarettes and stretch their supply to last longer. ${ }^{63}$ In the nineteenth century pipe smoking was the most common form of smoking in New Zealand, chewing tobacco also occurred but was nowhere near as widespread. ${ }^{64}$ By the end of the first world war however, the cigarette came to represent the modern form of smoking. Despite the invention of the Bonsack machine in 1883 which made tailor-made cigarette production cheap and efficient, roll-your-own cigarettes remained an important part of smoking in New Zealand. ${ }^{65}$ In John Mulgan's fictionalised account of New Zealand in the interwar period, Man alone, the protagonist, Johnson, is a British soldier who emigrated to New Zealand following the first world war. ${ }^{66}$ Johnson had never rolled his own cigarette before and needed to be shown how to roll one by the other farm-hand he worked with. The farm-hand, Scotty, instructs 'You got to pack it fairly tight,... and roll it round a bit. You want to pull the end off and shake it down. They're better than anything you'll buy. ${ }^{97}$

Loose-leaf tobacco for pipe or roll-your-own smoking held around 70 per cent of the market through the 1920s but rose sharply to dominate about around 80 per cent of total consumption from 1932-1934. ${ }^{68}$ In 1933 a New Zealand manufacturer stated that there was much higher turnover of fine cut tobacco for rolling cigarettes rather than packet cigarettes, as duty was much higher on manufactured cigarettes. ${ }^{69}$ In Australia during the depression a similar pattern occurred - consumption fell as tobacco was too expensive for the unemployed and working people alike, despite prices being reduced slightly, or tobacco companies adding an extra cigarette into packets. Smaller packets with only nine or ten cigarettes grew in popularity as people had less disposable income to buy in bulk. ${ }^{70}$ Roll-your-own cigarettes, as an economically cheaper choice, could be seen to be a lower or working class

\footnotetext{
'Removing temptation: New Zealand's alcohol restrictions, 1881-2005', PhD thesis in History, Victoria University of Wellington, 2006, p.188. In July 1935, Gerhard Husheer, managing director of the National Tobacco Company, donated 14,500 lbs of beef to be distributed among relief workers of Napier, Tobacconists' Review, 15 July 1935, p.11.

${ }^{63}$ O'Shea, p.61.

64 Thomson, 'Evils of the fragrant weed', p.4.

${ }^{65}$ Roll-your-own cigarettes were much more characteristic of smokers in New Zealand, Australia, Canada and Norway. See Lee, (ed.), p.5; Walker, pp.64-5.

${ }^{66}$ John Mulgan, Man alone, Hamilton, 1960 [1939].

${ }^{67}$ Ibid., p.20.

${ }^{68}$ Laugesen, Tobacco statistics 1991, p.12.

${ }^{69}$ Dominion, 9 June 1933, p.10.

70 Tyrrell, Deadly enemies, p.111.
} 
phenomenon. Indeed, during the depression the Newmarket branch of the Amalgamated Society of Railway Servants protested at customs duties levied on cigarette papers for roll-your-own cigarettes, which had recently been increased. Their resolution stated that 'workers were almost the sole users of cigarette tissue papers and it was demanded that the duty placed on papers be removed. ${ }^{, 71}$

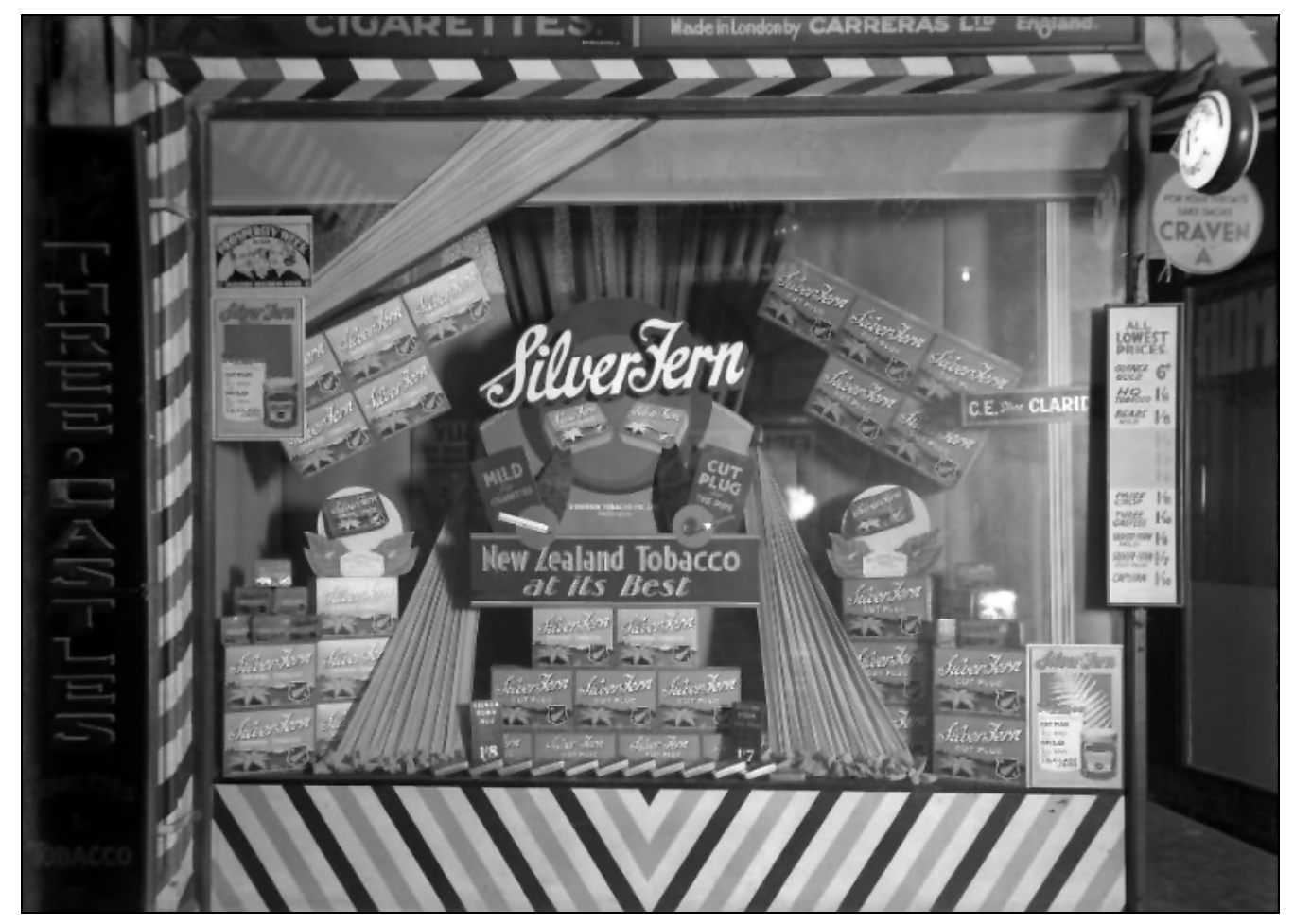

\section{Figure 4}

During the 1930s depression sales of loose tobacco rose as economic conditions impacted on smokers. This Wellington tobacconist's window in 1932 promotes two types of 'Silver Fern' loose tobacco for roll-your-own and pipe smoking.

EP-0248-1/2-G, ATL

In the 1930s tobacco was still, arguably, a luxury item and depending on family or individual circumstances, was one of the first items to go when the economic recession hit. As some New Zealanders lost the economic power to purchase tobacco during the depression, tension mounted over the taxation of tobacco as a luxury item. As a consumer item, tobacco held a somewhat fluid position somewhere between luxury and necessity. Certainly tobacco was taxed as a luxury, yet rising prevalence saw great numbers of New Zealanders reliant on it, long before any knowledge of addiction entered public discourse. Interestingly, in the early 1930s when tobacconists were trying to get price stabilisation introduced, the Commercial Trusts and Food Trusts

${ }^{71}$ Dominion, 19 July 1934, p.4; Tobacconists' Review, 15 September 1934, p.14. 
Acts ensured that retailers could not effect a system of price-fixation as tobacco and cigarettes were categorised as 'necessities of life' under these Acts, seeming to contradict the terms under which Customs was able to impose increased tariffs on tobacco. ${ }^{72}$ In 1936, a correspondent to The Press, with the apt pseudonym 'Lord Nicotine', protested the high duties on tobacco. He argued that the 'working classes' were being 'most heavily hit' by taxes, because 'for revenue purposes politicians hypocritically pretend that tobacco is a luxury.' For the average smoker, Lord Nicotine protested, 'tobacco is as necessary as tea."

The government's role here was complex and contradictory. No matter what other branches of government were saying, Customs were loathe to yield one of their prize items of revenue. Tobacco remained a highly taxed item, despite rhetoric such as that offered in parliament by National MP Sidney Holland in 1942. Though not a smoker himself, Holland protested against increased tobacco taxes, arguing that tobacco was 'a necessity', pleading on behalf of the 'class of the community which I might refer to as the "forgotten man" - that hardworking, self-reliant, thrifty soul who has saved little...That person might be a man or a woman. ${ }^{74}$ Holland clearly saw tobacco as an entitlement for New Zealanders, drawing on an individualist, egalitarian rhetoric which will be further explored in chapter three in the development of a prosmoking discourse in New Zealand through the period when smoking was normative and uncontroversial.

Following the impact of the depression on tobacco consumption, the next noticeable dip in total consumption was much larger and occurred during and immediately following the second world war. The reasons for the decline in consumption however, differed considerably from the economic conditions that dictated the change in the early 1930s. The second world war represents a phase where tobacco supplies were, for the first time, in limited supply to New Zealanders. The tobacco shortages occurred at a point when tobacco smoking was more prevalent and popular in New Zealand than it ever had been, and therefore the number of people vying for a share of the tobacco stock escalated tensions. Social and political commentary in newspapers and parliamentary debates from this period is very telling as to who was smoking, and who was believed to have greater entitlement to limited tobacco stocks.

72 The Tobacconist and Hairdresser, 21 March 1932, p.2.

73 The Press, 4 June 1936, p.9.

${ }^{74}$ Holland, NZPD, vol. 261, 6 May 1942, p.214. 
How then did shortages eventuate when, as we have seen, the New Zealand government was supportive of the industry and there was a growing consumer demand for tobacco? During the second world war, many consumer items were in short supply due to limited shipping, import bans and restrictions, and labour shortages or redirections to essential industries. Rationing of many commodities was introduced in 1939. ${ }^{75}$ Tobacco, however, was dealt with slightly differently. Tobacco was not perceived as a commodity in the same way as basic foodstuffs like flour or sugar might be, and could not be rationed in the same manner, especially given that a section of the population (notably children and to some extent, women) did not smoke. Rationing ran the risk of tobacco becoming a form of currency in itself, as was rife within the armed forces, and between New Zealand armed forces and locals in Europe and at home.

In the context of massive political and social upheaval presented by wartime demands, the necessity of tobacco lay in the connection to wartime conditions and notions of military masculinity, but also in the importance of maintaining continuity and normalcy with pre-war conditions on the home front. A large proportion of New Zealand's tobacco stock was going to troops overseas, and a high percentage of the civilian population left in New Zealand had also become dependent on it. Despite rising demand for tobacco, Customs cancelled import licenses on manufactured tobacco products from 1941, forcing New Zealand manufacturers to take responsibility to fill the tobacco requirements of its domestic and military population. It was decided that New Zealand should eventually be 'self-supporting. ${ }^{76}$ The import of raw tobacco leaf to be treated and manufactured at New Zealand factories was still allowed, however local manufacturers were required to use at least 30 per cent local leaf in the period 1938-1940, rising to 40 per cent by 1944 and remaining above this level well into the post-war era. ${ }^{77}$ Growers therefore were impelled to increase production, many converting acres of other farmland to the increasingly lucrative tobacco crop. In May 1942 representatives of New Zealand's main tobacco manufacturers met with members of the Ministry of Supply in an attempt to figure out how, jointly, manufacturers and the government could maintain tobacco supplies. A representative from Wills suggested that the tobacco industry should be classified as 'essential' to the war effort. Representatives from Godfrey Philips and the Nelson

\footnotetext{
${ }^{75}$ Belich, p.294.

${ }^{76}$ NZPD, vol. 259, 16 July 1941, p.356.

${ }_{77}$ Baker, p.173; During the second world war the National Tobacco Company boasted 75 per cent of locally grown leaf in its tobacco products. See NZPD, vol. 271, 21 November 1945, pp.649-50.
} 
Tobacco Company agreed, stating that in recent weeks engineers and female factory workers had been taken from them for the Army or for other industries. ${ }^{78}$ Factory officials argued that the quickest way to increase tobacco production was to bring experienced labourers back into the industry. ${ }^{79}$ By July the War Council instructed Army officials to release key men from their military duties to return to tobacco farms and factories. ${ }^{80}$

The Department of Labour went about recruiting or redirecting (mainly female) workers to the tobacco fields and into the two major factories based in Wellington. ${ }^{81}$ Housewives were encouraged to participate in relays of evening work as factories increased production hours. ${ }^{82}$ The movement of women away from other industries was not without opposition - the official war histories reported that there was a 'very vocal' opposition to such support of a 'luxury trade', yet in the context of rising smoking rates and scarce tobacco availability such dissent was muted. ${ }^{83}$ Otaki woman Georgina Kiripuai Te Aomarere remembered being called up twice for military service during the four and a half years she spent working in the stemmery (removing stems from the tobacco leaf) of the Wills tobacco factory during the war. However on both occasions Wills' management appealed and kept Te Aomarere based on the factory's status as part of an 'essential industry'. Te Aomarere was amused by these appeals, recalling that management 'said that I was a very good worker, which I wasn't, I was the slowest one there. ${ }^{84}$ Such evidence is very revealing therefore of the extent of the labour shortage - the tobacco industry grappled to retain any manpower it had fought so hard to prise from other industries.

During and following the war, evidence suggests that tobacco found a place in the economy as a valuable item of trade, and in some instances acted as a form of currency. It is also evident in light of increased tariffs and widespread shortages that a black market existed in New Zealand. Servicemen and members of the tobacco

\footnotetext{
78 Meeting of Tobacco Manufacturers' Representatives with officers of the Ministry of Supply, 20 May 1942, Rationing of Cigarettes, 1942-1943, TB, W2303, 13/10, Archives New Zealand, Wellington.

79 Dominion, 8 July 1942, p.4.

${ }^{80}$ Dominion, 8 July 1942, p.4.

${ }^{81}$ In January 1942, after the Japanese entered the war, the New Zealand government passed a regulation which allowed it to direct civilians into essential industries. Women were central to this drive and at the peak of wartime employment, in 1942-3 one-third of factory employees were women. See John E. Martin, Holding the balance: a history of New Zealand's Department of Labour 1891-1995, Christchurch, 1996, p.218.

82 Baker, p.173. Australian producers faced a similar problem and attempted to increase production by forcing Italian aliens into the tobacco fields, however by the end of the war, production was still only around half of its pre-war level. See Walker, p.67. For more on female conscription to essential industries see, Deborah Montgomerie, The women's war: New Zealand women 1939-45, Auckland, 2001. 83 Baker, p.174.

${ }^{84}$ Interview with Georgina Kiripuai Te Aomarere, interviewed by Rachael Selby, 2 March 2002, OHInt0673/08, Otaki Oral History Project, Alexander Turnbull Library (ATL) Oral History Centre.
} 
industry were participants in this informal economy. The supply of American tobacco brands which New Zealanders had access to before the war largely dried up due to the ban on import licenses, yet brands such as 'Lucky Strike', which were particularly fashionable among female smokers, were brought into the country by American troops stationed in New Zealand from 1942. The American troops quickly found that their highly-prized brands 'opened all doors. ${ }^{85}$

Betty Robertson, whose husband served with the 2NZEF in the Pacific remembers her husband having access to a ready supply of American cigarettes through American canteens in the Pacific. Due to the close proximity, he was able to send carton upon carton of cigarettes back to his wife via the frequent planes that travelled from islands in the Pacific to Auckland. ${ }^{86}$ Robertson then used the American cigarettes to trade for pork at the butcher, which was rationed during the war, and for bribing the post boy to go to her house at the start of his run with her parcels from the Pacific, so she did not have to wait around for the post to arrive. ${ }^{87}$ A grocer during the war recalls holding on to a supply of tobacco to pay off ration inspectors. He remembered that 'cigarettes and tobacco were hard to get but not rationed, so we kept them under the counter. ${ }^{88}$ Despite reports of 'record' seasons on the tobacco fields, lack of adequate labour meant that by 1943 retailers around the country were reported to have introduced a self-imposed system of rationing. ${ }^{89}$ Tobacconists generally limited their customer to one or two packets of cigarettes or tobacco per purchase, or only sold to regular customers, thus reducing the success of the 'panic buyer' who would do the rounds of the town, hoarding supplies for themselves. ${ }^{90}$

1945 saw the end of the war in Europe and the Pacific and the return of thousands of New Zealand men and women who served overseas. Their return exacerbated existing shortages and stretched the limited supply of tobacco to a section of the population who had been accustomed to a plentiful and cheap supply of tobacco over the preceding five or six years. Despite production of cigarettes by local manufacturers doubling from 600 million per year in 1938-41, to nearly 1200 million by 1944, government and industry efforts were not sufficient to support the tobacco

\footnotetext{
${ }^{85}$ Harry Bioletti, The yanks are coming: the American invasion of New Zealand 1942-1944, Auckland, 1989, p.47.

${ }^{86}$ cited in Eve Ebbett, When the boys were away: New Zealand women in World War II, Wellington, 1984, p.106.

${ }^{87}$ Ibid., p.106.

${ }^{88}$ Ibid., p.107.

${ }^{89}$ Dominion, 5 June 1942, p.4.

${ }^{90}$ Hawera Star, 1 May 1943, Rationing of Cigarettes, 1942-3, TB, W2303, 17, 13/10, Archives New Zealand, Wellington.
} 
requirements of the New Zealand population. ${ }^{11}$ By the end of 1944 and start of 1945 a tobacco 'famine' was predicted in the press. ${ }^{92}$ Discharged servicemen and women were now competing for the limited tobacco supply available on the open market. Recognising that New Zealand manufacturers would not meet increasing supply demands, the Customs Department lifted the ban on imports of foreign manufactured tobacco, inviting applications for import licenses from the end of $1945 .{ }^{93}$ However, shortages in most commodities, not just tobacco, were a worldwide problem, and lifting import bans did little to immediately alleviate the situation. ${ }^{94}$ The Labour Department and manufacturers continued attempts to direct women to factories and tobacco farms, particularly those from munitions factories which were not needed after the war. ${ }^{95}$

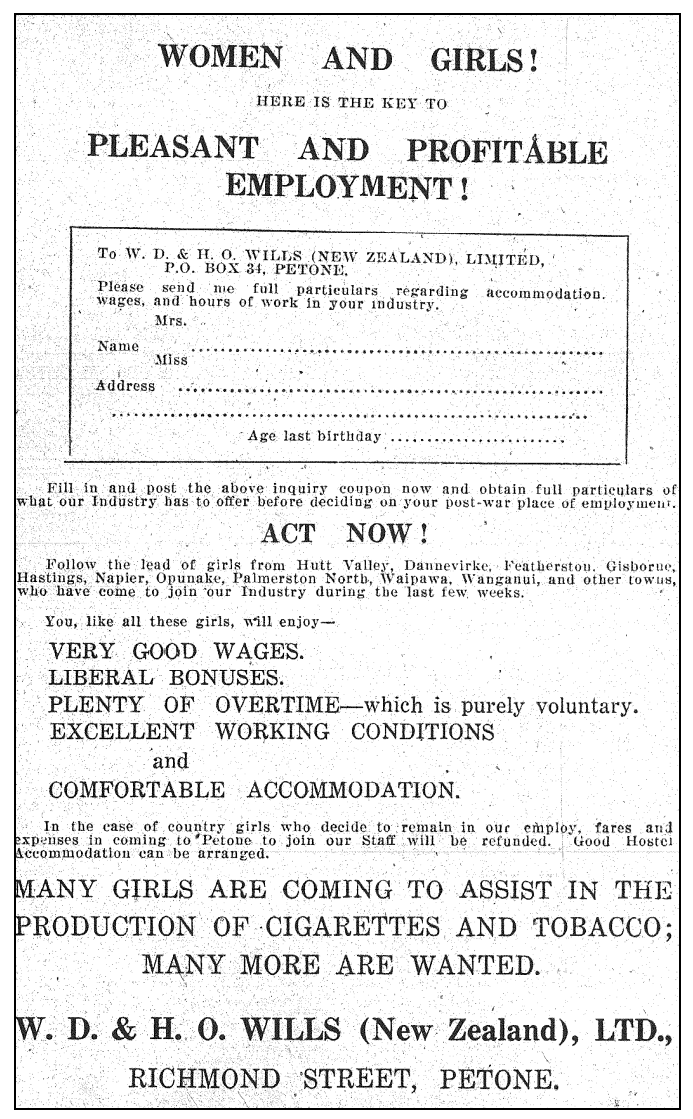

Figure 5

After the war the government could no longer 'manpower' women into the tobacco industry. Tobacco manufacturers struggled to retain their workforce and frequently turned to advertising, such as this advertisement which appeared in the Dominion in March 1946. Dominion, 2 March 1946, p.5

\footnotetext{
${ }^{91}$ Baker, p.174.

92 Dominion, 23 December 1944, p. 6; 4 June 1945, p.6.

93 'Import Licensing - Cigarettes', Comptroller of Customs to the Minister of Customs, 14 July 1949, Import Control Policy - Importation of Tobacco and Cigarettes, 1939-1947, C, 1, 40/55, Archives New Zealand, Wellington; Dominion, 30 November 1945, p.6.

${ }_{94}^{4}$ Harker, NZPD, vol. 271, 14 November 1945, p.420.

${ }^{95}$ See advertisement - W.D. \& H.O. Wills, Dominion, 2 March 1946, p.5; Sullivan, NZPD, 14 November 1945, vol. 271, p.418.
} 
The government therefore was faced with the dilemma of how to distribute the existing stock among the population. The issue generated debate in the House of Representatives in November 1945 when it was reported that returned servicemen were having trouble obtaining tobacco, though the House was assured by Minister of Supply and Munitions Dan Sullivan that the men, including those in mental institutions and hospitals, were not denied cigarettes and tobacco. ${ }^{96}$ Special issues of tobacco were made to seasonal workers who were away from their usual place of residence, such as 'shearing gangs, harvesting groups, timber workers' and miners where new mines had opened up during the war. ${ }^{97}$ In February 1946 the Greymouth Branch of the Amalgamated Society of Railway Servants held a meeting to discuss what they saw as a 'glaring example of class distinction' which was 'contrary to all accepted principles of democracy. ${ }^{98}$ Some members of their industrial group were being offered a weekly guaranteed tobacco ration through a coupon rationing system, but the majority of workers were excluded. The union's protest was directed at government, and they called for a more equitable way of distributing the scarce tobacco supply to be adopted. Sullivan assured the public that the system was working and that all protests were being looked into, furthermore he maintained that factory and labouring workers who had been threatening to strike due to the inconsistent distribution, had not been 'bought off with tobacco so they would return to work. ${ }^{99}$ Civilian supplies were distributed to retailers around the country based on regional population numbers before the war. ${ }^{100}$ However this system of preference was ad hoc and inconsistent and for about twelve months was a constant source of tension between workers, returned servicemen and the government.

Tobacco remained a valuable form of currency, which navy men were still able to exploit once they had returned to New Zealand waters. Though naval officials could not patrol the trade of tobacco, it was assumed that navy men were purchasing tobacco duty-free at their canteens on vessels off the coast of New Zealand and then on-selling it on the domestic market. Customs return records from the Navy Department reveal an inordinate amount of tobacco being 'consumed' by the New Zealand Navy in the

${ }^{96}$ Sullivan, NZPD, vol. 271, 14 November 1945, p.418.

${ }^{97}$ Dominion, 16 February 1946, p. 6. Australia faced wartime shortages much earlier, canteens for workers in munitions factories and essential industries were supplied with special issues as early as 1942, see Walker, p.68.

${ }^{9}$ Dominion, 12 February 1946, p.6. See also The Press, 13 February 1946, p.5, for discussion of the dispute between miners and returned servicemen.

99 Dominion, 16 February 1946, p.6.

100 Hawera Star, 1 May 1943, Rationing of Cigarettes, 1942-1943, TB, W2303, 17, 13/10, Archives New Zealand, Wellington. 
immediate post-war period from 1946 to 1950. In May 1948, for example, the Commanding officer of HMNZS Kiwi reported to the Naval Officer in charge that over the period 24 February 1948 to 31 March 1948 (35 days), the men on board the vessel consumed an average of 1000 cigarettes per man, amounting to approximately 28.6 cigarettes each per day. ${ }^{101}$ If this is assuming that all navy men smoked, these consumption statistics would still be seen as staggering, given that the average per capita consumption across all New Zealanders in 1948 was 2994 cigarette equivalents per year. ${ }^{102}$ However, given their situation, isolated on naval vessels with little to do in domestic waters, it is likely that navy men would have had higher consumption rates than the general population. The Commanding Officer of the vessel was quick to maintain that he was 'satisfied that no abuses of customs privileges are occurring., ${ }^{103}$

Other cigarettes supplies no doubt intended for the black market came to a rather soggy end. In April 1946 a large shipment of Canadian cigarettes was due to arrive in Auckland. Having dropped off a quota of its cargo to the 'nicotine-starved thousands' in Auckland, the Crystal Park was due to visit Wellington after Easter. ${ }^{104}$ However Wellingtonians were denied up to 80,000 of the Canadian cigarettes after crew bungled an attempt to pillage the cargo. On 1 May 1946 The Press reported that police discovered about 30,000 of the pillaged cigarettes tied under the wharf in a large linen sack, where it had been placed by the thieves 'until the hue and cry had died down. ${ }^{105}$ Unfortunately in the intervening time the tide had come in, covering the cigarettes and rendering them worthless. ${ }^{106}$ The long awaited Canadian shipment was effectively ruined and Wellingtonians could not procure a share either on the open or the black market. Shortages following the second world war proved to have a major impact on consumer, government and industry, yet once supply issues were under control, consumption, fuelled by wartime recruitment and relative prosperity, was again on the increase.

From the mid 1950s tobacco consumption levelled out yet remained historically high right through until the mid-1970s. In 1958-9, however, there was another noticeable but brief decline in consumption, attributable to the Labour government's 1958 'Black

\footnotetext{
101 Returns - Consumption of tobacco and cigarettes, 1946-1950, N, 1, 580, 18/36/121, part 6, Archives New Zealand, Wellington.

102 Laugesen, Tobacco statistics 1991, p.12.

${ }^{103}$ Returns - Consumption of tobacco and cigarettes, 1946-1950, N, 1, 580, 18/36/121, part 6, Archives New Zealand, Wellington.

104 Dominion, 17 April 1946, p.6.

105 The Press, 1 May 1946, p.8.

106 Ibid.
} 
Budget. ${ }^{, 107}$ Engineered by Minister of Finance Arnold Nordmeyer, the budget increased indirect taxation on goods such as cigarettes and tobacco, alcohol, cars and petrol. ${ }^{108}$ Tax on cigarettes was raised by 39 per cent, and while motivated by a fiscal measure to reduce inflation, Labour's core blue collar constituents also saw the move as a moral judgement on 'sinful' expenditure. ${ }^{109}$ Nordmeyer, who did not smoke or drink himself, was demonised in the public mind as a 'wowser', and a 'Presbyterian puritan who cheerfully taxed the workers' pleasures - beer and smokes'. ${ }^{110}$

Nordmeyer's biographer was later to write that the public furore in 1958 revealed 'it seemed that beer and tobacco were more essential to the survival of the 'working man' than was a roof over his head and free text books for his children. ${ }^{111}$ Once more, the contentious position of tobacco as a luxury or an essential item divided the government and the public; it seemed Nordmeyer had forgotten the previous Labour government's wartime assertions of necessity which firmly established tobacco as an essential item.

The hugely unpopular budget was quickly retracted in the 1959 and 1960 budgets but these changes were still too late to save the Labour government from losing the 1960 election. Brian Easton considered that the huge increase in tobacco prices may have led more smokers to quit or stopped the younger ones from starting. ${ }^{112}$ A 1970 Consumer smoking survey mentions the 1958 budget as a reason given by some readers for giving up smoking. ${ }^{113}$ However, the decline in consumption was brief and by 1960 tobacco consumption was back at 1957 levels. When back at pre-budget prices, tobacco was still cheaply available on a large scale to maintain the momentum of consumption for almost another twenty years.

\footnotetext{
${ }^{107}$ Laugesen, Tobacco statistics 1991, p.12.

108 Goldsmith, p. 230 .

109 Ibid., pp.230-1.

110 Bruce Brown, 'Nordmeyer, Arnold Henry 1901 - 1989', Dictionary of New Zealand Biography, updated

22 June 2007, available from http://www.dnzb.govt.nz, accessed 11 April 2009.

111 Mary Logan, Nordy: Arnold Nordmeyer a political biography, Wellington, 2008, p.323.

112 Brian Easton, Consumption in New Zealand 1954/ 5 to 1964/5, NZIER Research Paper 10, 1967, cited in Easton, The economic regulation of tobacco consumption in New Zealand, p.13.

113 'Cigarette smoking: is it wise? - we think not', Consumer, vol. 64, 1970, pp.164-175.
} 


\section{Chapter Two}

\section{'Yes thanks - I will!': tobacco advertising and the expansion of smoking among consumers ${ }^{1}$}

In September 1939 the Department of Agriculture and the Tobacco Board prepared an exhibit together on the tobacco industry for the New Zealand Centennial Exhibition. The highly popular Centennial Exhibition, staged in Wellington, opened in November 1939 and ran to May 1940. For their exhibit the secretary of the Tobacco Board requested photographs from tobacco manufacturer W.D. and H.O. Wills showing 'various stages in the production of raw leaf and the manufacture of tobacco and cigarettes. ${ }^{2}$ Wills sent through photos of scenes with titles such as 'Girl holding armful of leaves in Tobacco Field', and 'Photo of cutting machine at work. ${ }^{3}$ When Alfred Cockayne, Director-General of Agriculture, received the photos he was not satisfied with the selection. Beyond the manufacturing side of the industry, he also requested images illustrating consumption of tobacco:

To show the general appreciation of New Zealand tobacco, it is purposed to include pictures of smokers of every class - city men, rural workers, seafaring men, and women. The latter preferably not of the picture-star type, but, say, a hospital nurse who finds more than pleasure in a cigarette after a job of hard work. $^{4}$

The Centennial Exhibition celebrated nationhood and New Zealand's progressive place in the British Empire. It provides a 'unique window' through which to view New Zealand's identity, values and ideals at a particular point in time. Material, social and

\footnotetext{
${ }^{1}$ Advertisement - Three Castles, Weekly News, 13 March 1924, p.67.

${ }^{2} \mathrm{Mr}$ Wise (Secretary of Tobacco Board) to Mr Dallas (Office of the Department of Agriculture), 25 August 1939, Exhibitions, Films and Displays (c), 1937-1959, TB, W2303, 3, 1/18, Archives New Zealand, Wellington.

${ }^{3} \mathrm{Mr}$ W. E. Shore (Advertising Department, W.D. and H.O. Wills (N.Z. Ltd.)) to Mr Wise (Secretary of Tobacco Board), 15 August 1939, Exhibitions, Films and Displays (c), 1937-1959, TB, W2303, 3, 1/18, Archives New Zealand, Wellington.

${ }^{4} \mathrm{Mr}$ A. H. Cockayne (Director General of the Department of Agriculture) to Mr Wise (Secretary of the Tobacco Board), 1 September 1939, Exhibitions, Films and Displays (c), 1937-1959, TB, W2303, 3, 1/18, Archives New Zealand, Wellington.
} 
economic progress were key themes in the celebrations. ${ }^{5}$ The Department of Agriculture's exhibit, combining the commercial interests of Government, the Tobacco Board and its constituents from the growing and manufacturing arms of the tobacco industry, was primarily aiming to publicise agricultural and industrial progress in tobacco production. Beyond this core focus however, Cockayne's request shows that tobacco consumption was also a key concern; his request for photos showing a selection of typical New Zealand smokers underlined an egalitarian view of smoking, accessible to all across class, gender and location.

By the time of the Centennial Exhibition in 1939, both government and industry had a deeply vested commercial interest in the consumption of tobacco by New Zealanders. This chapter explores the commercial influence of the tobacco industry as a key driver of changing smoking patterns in New Zealand through the period 1920-1962, and the wider cultural and social impact of this influence. During this period smoking became popular and normative among both men and women, developing into a common and unremarkable activity in a growing range of public spaces. The chapter initially outlines the tobacco industry's promotional ambitions, and then moves on to focus on three key sites of consumption - leisure, work and war. Three questions are central to this chapter: what were the major changes to smoking patterns in these three sites of consumption? What was the purpose or function of smoking within these spaces and activities, and how was this function promoted and encouraged by the commercial interests of the tobacco industry?

Industry developments through the 1920s and 1930s enabled tobacco and cigarettes to become accessible and affordable commodities to New Zealanders. Availability does not in itself translate into a sustained increase in consumption. The tobacco industry also needed to market its product and recruit new consumers if it was to make profitable a product which was previously unavailable or unused, and which was not directly necessary to daily sustenance in the same way that other basic commodities like bread, flour, meat and milk were. As in Britain, the United States, Canada and Australia, it is evident that New Zealand consumers were also the targets of large-scale, sustained marketing campaigns by the tobacco industry through the first half of the twentieth century. ${ }^{6}$ Marketing and advertising were the key vehicles used by the

\footnotetext{
${ }^{5}$ Jock Phillips, 'Afterword: reading the 1940 centennial', William Renwick, (ed.), Creating a national spirit: celebrating New Zealand's centennial, Wellington, 2004, p.273.

${ }^{6}$ See Hilton, pp.83-115; Elliot, Women and smoking since 1890, pp.58-68; Tinkler, Smoke signals, p.49, Rudy, pp. 126-30; Tyrrell, Deadly enemies, pp.128-37.
} 
industry to communicate the presence, function and brand of their product in order to recruit and retain consumers. Promotion was a separate activity from the commercial manufacture of the product. Detailed commercial records charting the promotional investment by the tobacco industry into the marketing of tobacco in New Zealand over the period 1920-1962 are not available to this study. ${ }^{7}$ However, print advertising was a key medium through which the tobacco industry disseminated its promotional messages and is available for historical analysis to interpret or estimate the scale of local investment. An analysis of the frequency, design and content of print advertising offers an accessible and visual understanding of the industry's promotional investment and activities throughout the twentieth century. This study uses examples of print advertising from a systematic scan of daily and weekly newspapers (The Press, Dominion, New Zealand Herald, Weekly News, Listener), aimed at a general readership, and more targeted and gender specific examples from the popular press (New Zealand Woman's Weekly, The Mirror, New Zealand Illustrated Sporting and Dramatic Review, New Zealand Sportsman). ${ }^{8}$

Local advertising agencies developed in New Zealand from the 1890s and predominantly worked with local brands and companies. Through to the 1930s many international agencies preferred to replicate and export their advertising to New Zealand (and other places) rather than to employ the services of local advertising agencies. One of New Zealand's earliest and pioneering advertising agencies, the Ilott agency, attempted to attract international companies to engage local agencies to handle the promotion of their products in New Zealand, by establishing satellite offices in London and Sydney in the 1920s. ${ }^{9}$ Advertising for tobacco followed this trend, and as noted in chapter one, most advertisements were imported directly from Britain or the United States. The development of advertising as an industry separate from the production of

\footnotetext{
${ }^{7}$ It is not known whether commercial records charting the industry investment into the promotion of tobacco have survived within individual company archives. No industry archives are traceable through archival repositories in New Zealand. Conversely in the United States, over ten million documents 'created by major tobacco companies relating to their advertising, manufacturing, marketing, sales, and scientific research' from the late nineteenth century to the present, are accessible online via the Legacy Tobacco Documents Library, available on http://legacy.library.ucsf.edu/, accessed 15 December 2008. This database was created as a condition in the settlement of major class-action lawsuits against tobacco companies in the United States. As an international subsidiary of British American Tobacco, some documents from BATNZ are found here but are predominantly focused in the post-1962 era. For analysis of British tobacco companies' investment in advertising see Hilton, pp.92-5.

${ }^{8}$ Note also that the scan revealed that the Irish-Catholic newspaper, the New Zealand Tablet did not carry tobacco advertisements in the 1940s. Research methodology for this chapter involved a systematic scan of the weekly and periodical magazines mentioned above. All tobacco advertisements were recorded from a selected full month of publication from every second year from the above titles within the study period. For example the Weekly News was scanned in January 1920, February 1922, March 1924 and so on. Daily papers were also extensively searched on selected dates.

${ }^{9}$ See Jack Ilott, Creating customers: the story of Ilott advertising New Zealand 1892-1982, Auckland, 1985, p.26; Jock Phillips, 'Advertising', Te Ara - the Encyclopedia of New Zealand, forthcoming entry, 2009, available from http://www.TeAra.govt.nz.
} 
goods through the early to mid-twentieth century, led the Association of New Zealand Advertisers to proclaim in 1937 that: 'We are living in the most interesting times the World has ever known. Knowledge and Science, including advertising have combined to provide us with undreamt of luxuries, refinements and conveniences. ${ }^{10}$ Advertising was an integral and contingent element in the growth of the consumer market through the interwar era, and cigarettes and tobacco were key commodities through which modern advertising techniques, focused on the creation of consumer demand, were developed. ${ }^{11}$ Tobacco industry advertisers had a crucial task through this era; firstly to make consumers aware of tobacco as a product, then to show consumers what tobacco could offer or promise them, what its function and use was in modern society, and lastly to alert them to their particular brand or type of tobacco. The massive and sustained investment in tobacco advertising around the world effectively 'made marketing an industry in itself' which 'employed expert systems almost directly comparable with the expertise which went into the technical aspects of production. ${ }^{, 12}$

Tobacco advertising permeated society at many different levels. While print advertising is the main medium of tobacco promotion which remains accessible to the historian, it is important to note that it also worked alongside many other forms of advertising such as show-cards, billboards, point-of-sale signage, and packaging. Cigarette advertisements were also a feature of screen advertising at the picture theatre, typically reminding patrons to enjoy a cigarette at the interval or after the film. ${ }^{13}$ Within this wider ambit and circulation of tobacco promotion, the local tobacconist's shop was a prominent space and was central to the marketing of tobacco through the period of this study. The Tobacconists' Review was an important publication used by manufacturers to guide and influence the dissemination of their marketing messages by tobacconists. Analysis of the content of the Tobacconists' Review offers an inside look at how the tobacco industry sought to control the tastes of smokers. Beyond direct advertising, tobacconists were also directed in every aspect of promotion, from how to choose a site

\footnotetext{
10 A.N.Z.A: The Official Organ of the Association of New Zealand Advertisers, December 1937, p.3. Capitalisation as in original.

${ }^{11}$ Juliann Sivulka, Soap, sex, and cigarettes: a cultural bistory of American advertising, Belmont, California, 1998, p.166. For a comparative discussion of international influences on advertising and the sale of consumer goods in New Zealand department stores in the first half of the twentieth century see Evan Roberts, "DDon't sell things, sell effects": overseas influences in New Zealand department stores, 1909-1956', Business History Review, vol. 77, no. 2, 2003, pp.265-289.

${ }^{12}$ Hilton, p.111.

13 Brittenden, pp.86-7, 104.
} 
for their shop, to how to ensure 'window displays actually sell products', to the importance of 'personality' in tobacco retailing. ${ }^{14}$

Tobacco advertising's central message, driving the spatial and gendered expansion of smoking through the period 1920-1962, was the concept of universality the notion that all adult men and women could smoke in almost all places and at anytime. Advertising sought to promote smoking as a common and acceptable habit in all spaces and times: 'Player's' cigarettes could be smoked 'Whatever the occasion', and it was always 'Time for a Capstan'. ${ }^{15}$ This advertising device was central to the rise of the 'mass market' in Britain at the same time, where the 'language of the many, the world, the universal [and] the mass' was a widespread feature of advertising for all kinds of products. ${ }^{16}$ These messages were reinforced by a core marketing technique of repetition and sustained frequency. For example the same slogan would reappear in the same place on successive pages of a newspaper or magazine, or would dominate the banner line of the weekly radio programming in the Listener, serving as a constant visual reminder to have a smoke. ${ }^{17}$

It is through this key concept of universality that advertisers successfully propelled consumption patterns by reinforcing the normal place of smoking in the daily lives of New Zealanders. A 1946 advertisement for Capstan cigarettes (figure 6) highlights this theme across the activities, spaces and times that this chapter will explore. ${ }^{18}$ Whether it was 'waltztime', 'holidaytime', 'halftime', or 'playtime', smoking was a sociable and pleasurable activity in leisure spaces, offering relaxation and rejuvenation. But smoking was not solely relegated to time out, notions of universality also drew smoking into working time and spaces - 'overtime', and 'daytime', and as a reward or refreshment during breaks from work - 'lunchtime', or 'teatime'. Lastly this chapter looks to how all of these 'times' for smoking were accentuated during the heightened climate of insecurity and tension during 'wartime'. Above all, the frequent use of universality as the dominant theme in tobacco advertising stressed that smoking was always acceptable, whether it was 'next time', 'every time' or 'anytime'.

\footnotetext{
14 See The Tobacconist and Hairdresser, 21 April 1932, p.12; Tobacconists' Review, 15 December 1937, p.14; 15 January 1936, p.11.

15 See for example, Advertisement - Player's Please, New Zealand Woman's Weekly, 21 September 1950, p.65; Advertisement - Capstan, Listener, 19 July 1946, p.48.

${ }^{16}$ Hilton, pp.103-6.

${ }^{17}$ See for example, a series of De Reszke advertisements featuring famous people (Clive Brookes, George Formby, Grace Fields, Leslie Henson, Frances Day) which ran on successive radio listing pages of the Listener through February 1942.

${ }_{18}$ Advertisement - Capstan, 19 July 1946, p.48. See also Advertisement - Capstan, 20 February 1942, p.40.
} 


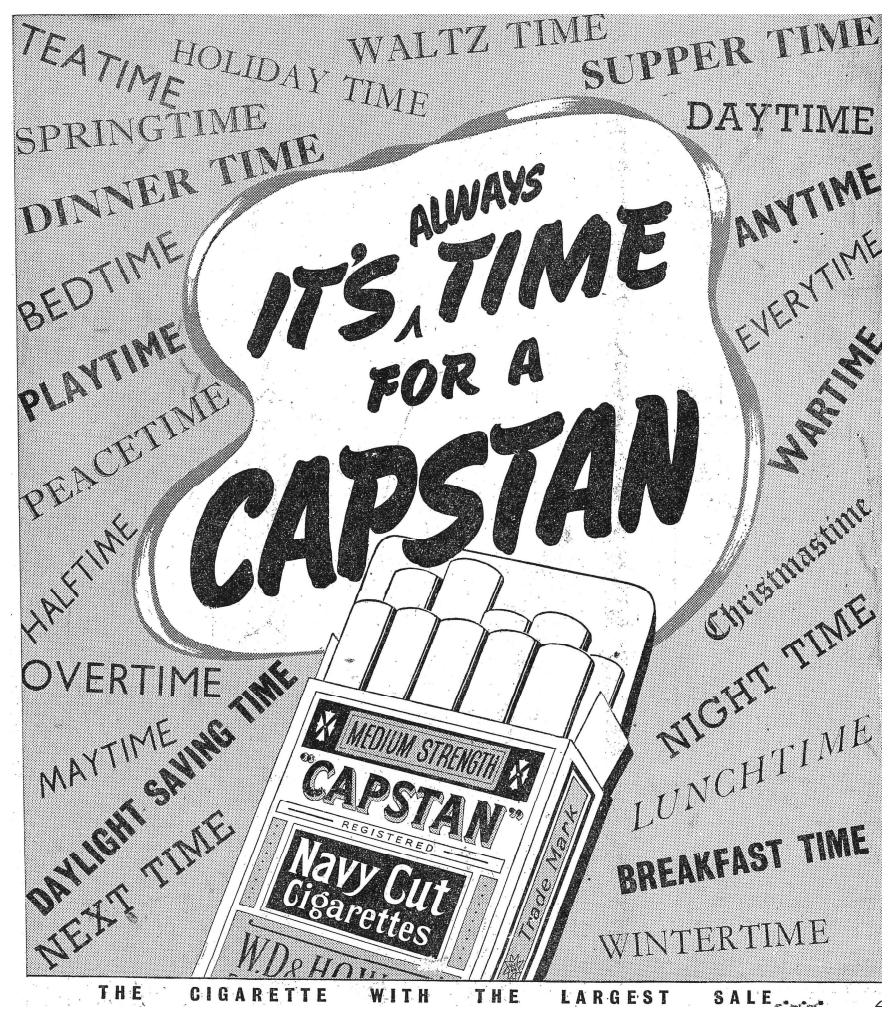

Figure 6

This is one of many Capstan advertisements which underlined the idea that smoking should be practised anywhere, at anytime. Others included images of clocks where the numbers were made of cigarettes, and were promoted through the daily and periodical press, on billboards and cinema screen advertising.

Listener, 19 July 1948, p.48

\section{Leisure}

Tobacco has long been heralded as an aid to relaxation, meditation and contemplation.

In the periodical press aimed at the upper-classes in nineteenth-century Britain, readers were encouraged as they smoked to let their minds drift away to an idealised existence for just a few, brief moments as they rested from the stresses and strains of the real world. ${ }^{19}$ While the link between leisure and smoking was established in the nineteenth century, it remained strong throughout the twentieth century, yet was reworked and redefined by men and women seeking to incorporate smoking into 'modern' gendered identities. In the period 1920-1962, advertisers drew heavily on the multifaceted and versatile function of smoking to promote near universal enjoyment of smoking in leisure spaces, times and activities. Analysis of the daily and periodical press in New Zealand over the study period reveals that leisure received the greatest attention from advertisers seeking to recruit people into smoking and to retain them as consumers.

${ }^{19}$ Hilton, pp.32-4. 
Relaxation, refreshment and pleasure were all key features of this associational link in print advertising; whether smoking occurred in a solitary or sociable setting, smoking promised to put the consumer at ease.

The language and imagery employed by advertisers reinforced the primary purpose of smoking in leisure space and time - as an activity that increased relaxation. In doing so, tobacco advertisers aimed to redefine smoking, attempting to shift tobacco from its luxury status, and more toward its status as a useful, necessary item. Advertising for 'Bears' tobacco in 1936, for example, proposed that smoking a pipe of their tobacco was 'one of the greatest pleasures in life...although one of the simplest. ${ }^{20}$ Another advertisement from 1924 depicts a happy smoker puffing on a 'Three Castles' cigarette, announcing that 'They help me to Enjoy Life'. ${ }^{21}$ By the 1950s 'Matinée' cigarettes, largely marketed at women, were 'unusually pleasing', while 'First Lord' promised 'Deep, deep pleasure and satisfaction renewed with every puff. ${ }^{22}$ Images of 'pleasurable' smoking were often simple and widely applicable, reinforcing and inviting notions of universality. Such images showed as little as a smiling smoker, be it a man or a woman, or an image of a cigarette, such as 'De Reszke's' image showing their three types of filter tip and prompting the consumer to 'please yourself. ${ }^{23}$

The 'pleasure' element in the language used by advertisers to encourage leisurely smoking was also adopted in the language used by smokers to describe their habit. In a letter to his 'chums', Charles Perrin, a retired Wellington grocer, wrote in 1921 of the joy and pleasure he got from smoking:

Most Persons freely make use of this weed

It makes them happy, contented, \& kind It drives away care and composes the mind $\&$ those who know how to value a smoak [sic] Are the best men on earth to enjoy a good joke. I often think of you all \& see your faces framed in Tobacco clouds. \& the scent thereof is grand. ${ }^{24}$

Perrin portrays his smoking as a release and a freedom from everyday life, associated with a contemplative and serene state of being. It is clear that Perrin appreciated both sociable smoking and solitary smoking. He values smokers as peers with whom to 'enjoy a good joke', but also sees 'your faces framed in Tobacco clouds', suggesting a more

\footnotetext{
${ }^{20}$ Advertisement - Bears Tobacco, Weekly News, 21 October 1936, p.63.

${ }_{21}$ Advertisement - Three Castles, Weekly News, 6 March 1924, p.71.

22 Advertisement - Matinée, New Zealand Woman's Weekly, 30 October 1952, p.44; Advertisement - First Lord, New Zealand Herald, 9 October 1956, p.8.

23 Advertisement - De Reszke, The Mirror, 1 April 1938, p.22.

24 'G'Dad' [Charles Perrin], letter to unknown recipient, 23 November 1921, Perrin family papers,

Correspondence, c.1855-1874, MS-Papers-2579-2, ATL, Wellington. Punctuation as in original.
} 
private meditative enjoyment of smoking. ${ }^{25}$ We could imagine Perrin enjoying his pipe as he wrote to his friends and family, or reading the newspaper, showing that while tobacco smoking was a pleasurable activity in its own right, smoking also served to complement other leisure activities.

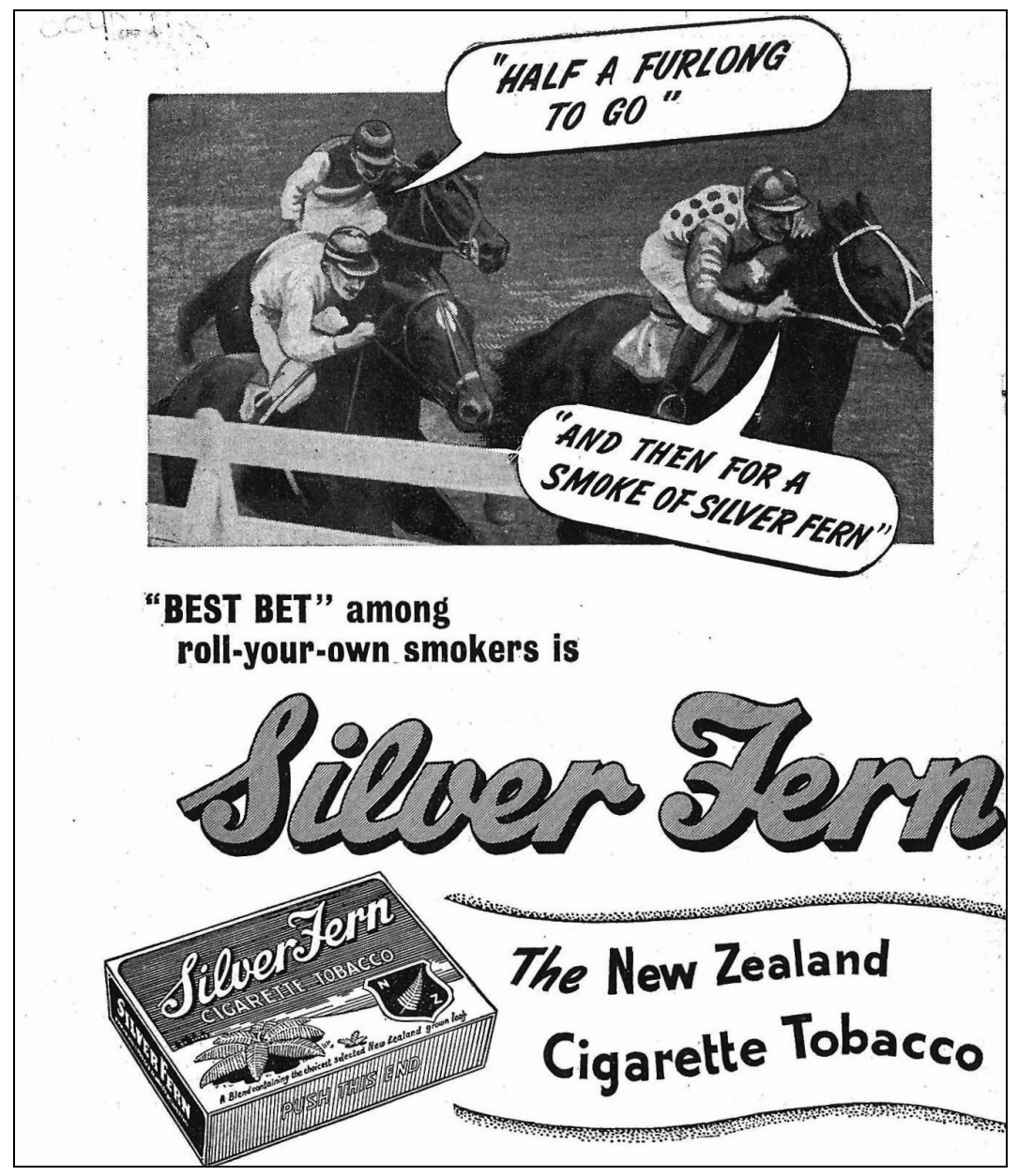

Figure 7

This 1946 advertisement for 'Silver Fern' reinforces a strong association between watching or participating in sporting activities and smoking. The 'smoke of Silver Fern' is positioned as a reward for the jockeys' efforts.

Listener, 5 July 1946, p.48

Advertisers also sought to strengthen the idea of smoking complementing sport and recreational activities. Tobacco advertisements were a prominent feature of both the New Zealand Illustrated Sporting and Dramatic Review and the New Zealand Sportsman. ${ }^{26}$ For example, in 1926 'Spinet' cigarettes were marketed as 'The Sportsman's Favourite.' ${ }^{27}$ Both those watching and those participating in sport were encouraged to associate their

\footnotetext{
25 Ibid.

${ }^{26}$ In contrast the short run of women's sports magazines in the late 1940s, N.Z. Sportswoman (1949) and Women in Sport (1948-9) did not carry any tobacco advertisements.

${ }^{27}$ New Zealand Illustrated Sporting and Dramatic Review, 15 April 1926, p.1.
} 
activities with the enjoyment of smoking. Depictions of spectators combining these activities are exemplified in images of men and women smoking while watching horse and greyhound races. ${ }^{28}$ The jockeys too looked forward to a cigarette together after their race, a 1946 advertisement for 'Silver Fern' depicted jockeys chatting as they raced, one declaring 'half a furlong to go', and another replying 'and then it's time for a smoke of Silver Fern' (figure 7). ${ }^{29}$ Similarly, a 1950 advertisement for 'Greys' tobacco used sports star endorsement to reinforce the connection between playing sport and smoking. The advertisement portrayed a caricature of Alex Murray, New Zealand professional golfer, stating that he enjoyed 'the pleasure of smoking Greys tobacco... on and off the course. ${ }^{30}$ Many other advertisements simply portrayed men and women in sporting attire or with sporting equipment, smoking on a break from their game of golf or tennis. Smoking combined well with sport as well as with sociability in broader leisure times and spaces.

Beyond such direct appeals in print advertisements, enjoyment of sport was also reinforced by manufacturers through marketing schemes. Cigarette cards which were distributed in cigarette packets were highly coveted by adults and children as collector items. ${ }^{31}$ The popularity of cigarette cards peaked around the mid-1920s, but had largely disappeared by the second world war. Sports stars like New Zealand middle-distance runner Jack Lovelock appeared on the 'State Express 333' cards in the mid-1930s (figure 8). ${ }^{32}$ Wills' 50 card collection of 'real photographs' of New Zealand footballers from around 1928 was a highly prized set. ${ }^{33}$ Certificates were also included in some brands of cigarettes which, once the consumer had collected enough certificates, could be exchanged for 'gifts' like photograph albums, golf balls or children's toys. ${ }^{34}$ Advertising in sports programmes and on billboards at sporting events also reinforced the notion that smoking could complement both spectating and participating in sport. The

\footnotetext{
${ }^{28}$ See for example, Advertisement - Army Club, New Zealand Sportsman, April 1951, back cover. ${ }^{29}$ Advertisement - Silver Fern, Listener, 5 July 1946, p.48. See also, Advertisement - Embassy, Evening Post, 8 January 1938, p.10.

${ }^{30}$ Advertisement - Greys, Otago Daily Times, 1 March 1950, p.3. See Barbara Keys for discussion of the internationalisation of sport during the interwar years in which American culture and the rise of international sports stars became more prominent. Barbara J. Keys, Globalizing sport: national rivalry and international community in the 1930s, Cambridge, Massachusetts, 2006, pp.64-89.

${ }^{31}$ Bruce Isted, 'The history of cigarette and trade cards', New Zealand Memories, vol. 18, 1999, pp.206-8; Wayne King, 'Smoke clouds over New Zealand', New Zealand Memories, vol. 53, 2005, pp.31-2.

32 Cigarette card showing Jack Lovelock (State Express 333), c.1934, MSX-2255-062, ATL, Wellington.

${ }^{33}$ W.D. \& H.O. Wills: New Zealand footballers - a series of 50 real photographers, c. 1928, Eph-APicture-Cards-Wills-Footballers-Selection, ATL, Wellington.

${ }^{34}$ See for example, 'Player's Gifts' campaign which ran through the 1930s, advertised in the New Zealand Illustrated Sporting and Dramatic Review, 5 June 1930, p.21. See also a Capstan campaign in 1928 which offered a 'free photogravure of the All Blacks' in return for six lids from Capstan Navy Cut tobacco tins, Advertisement - Capstan, The Press, 1 September 1928, p.5.
} 
presence of other smokers was an equally powerful reminder for patrons to smoke. The extent of the connection between smoking and sports spectating is described in an article in the Tobacconists' Review in 1934:

Manufacturers and sellers of tobacco would have been pleased to see the embankment at Lancaster Park, Christchurch during a recent rugby match...Innumerable whiffs of smoke rose steadily from the closely packed rank of spectators, and mingled to form a distinct blue haze which drifted away before the light easterly breeze. ${ }^{35}$

The influence and company of fellow smokers, coupled with the constant visual reminders in tobacco advertising, reinforced the importance of smoking to the spectating and sporting experience.

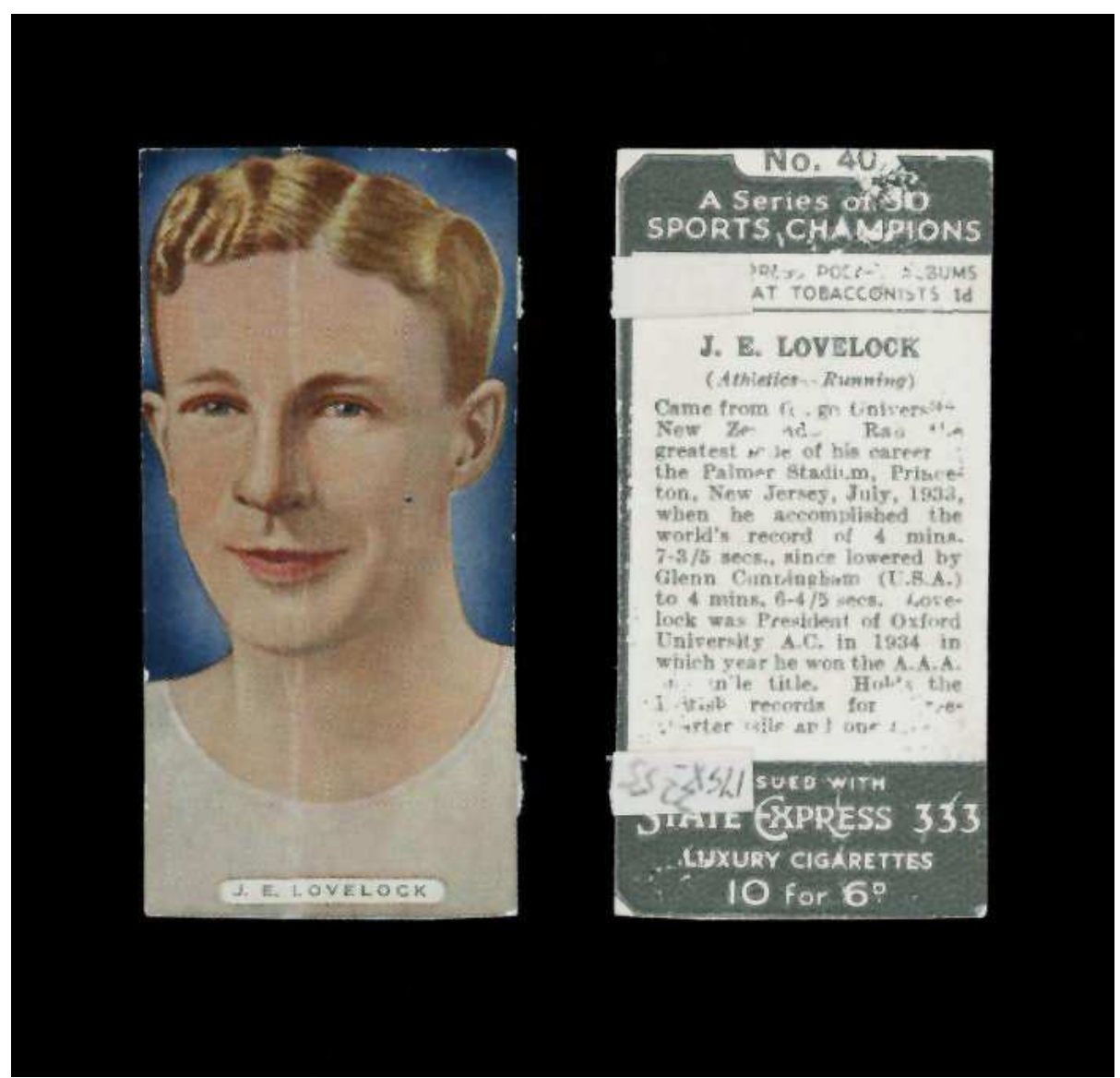

Figure 8

Jack Lovelock was at the peak of his career in the mid-1930s when he appeared on numerous cigarette cards. Lovelock's fame as an international sports star was reinforced not only by the use of his image on New Zealand cigarette cards, such as this example from State Express 333's 'Sports Champions' series, but also in other countries - a Danish cigarette card also depicted Lovelock following his 1936 Olympic win. ${ }^{36}$

MSX-2255-062, ATL

35 Tobacconists' Review, 15 October 1934, p.10.

${ }^{36}$ David Colquhoun reproduced examples of cigarette cards featuring Jack Lovelock in his edited edition of Lovelock's journals. See David Colquhoun, (ed.), As if running on air: the journals of Jack Lovelock, Nelson, 2008, pp.9, 253. 
Smoking's potential to complement playing and watching sport in leisure time and space was heavily promoted by the tobacco industry. This connection is also reflected in the language used by one of New Zealand's most recognised smokers mountaineer, photographer and writer, John Pascoe. Pascoe was rarely photographed without his characteristic pipe hanging from his mouth. Pascoe and his fellow mountaineers often took massive supplies of tobacco on their expeditions, which at times outweighed their dried food allocation. ${ }^{37}$ In 1937 Pascoe wrote an article for the British journal Tobacco about the 'odd places' and 'varied occasions' that he has 'found peace and contentment in a smoke. ${ }^{38}$ Pascoe's language echoes that of Charles Perrin in his description of the joys of smoking:

From personal experiences any New Zealand mountaineer whose briar [pipe] is as indispensable to him as the shaft of his ice axe, may recall the pleasant hours when tobacco smoke was merged into the luxurious image of a perfect view or set in a relief against the savage banners of a nor' west cloud bank. ${ }^{39}$

Pascoe goes on to describe particular expeditions and places where he has fond memories of smoking, including mention of 'Our Lady Nicotine' acting as a calming influence in situations where the climbing conditions were difficult. ${ }^{40}$ For Pascoe, leisure, recreation and smoking were intrinsically linked - smoking helped him to enjoy the mountains, and likewise the climate and scenery helped him to enjoy his smoking. There appeared to be no sense in Pascoe's article of the contradiction between mountaineering being a physical activity requiring extreme exertion which demanded participants economise as much as possible in what they carried, and his (and others) heavy use of tobacco and cigarettes on these expeditions. The language used by smokers such as Charles Perrin and John Pascoe also reiterates the central message put forward by advertisers eager to reinforce the universality of smoking: smoking was both a pleasurable activity and a solitary activity and was something that served to complement and enhance other activities.

Tobacco promoters also advanced the importance of sociability and the promise of glamour and sophistication as key features of leisure spaces and activities which were

\footnotetext{
${ }^{37}$ Chris Maclean, John Pascoe, Nelson, 2003, p.119.

${ }^{38}$ John Pascoe, 'Tobacco in the Mountains', Tobacco, 1 November 1937, pp.49-50, ATL, Wellington.

39 Ibid., p.49.

${ }^{40}$ Ibid.
} 
enhanced by smoking. A focus on sociability offers a way of looking at how tobacco was promoted and used or how it functioned in social settings. Tobacco advertisers were eager to convey what smoking could offer consumers as relaxed and attractive social beings in social spaces such as dances, picnics, parties, restaurants and in sporting and transport spaces. Smoking promised to put the consumer at ease, to make them more popular and attractive, and to provide them with a sense of belonging. The custom of offering a cigarette or 'a light' in social activities and spaces worked as a way of meeting new people, of initiating conversation or breaking the ice, and was emphasised and encouraged by cigarette advertisers throughout the period of this study. The commercial impetus driving the promotion of smoking in such spaces lay in both the importance of legitimising and encouraging smoking in social settings, and the massive potential such spaces held as recruitment grounds for new smokers.

The custom of offering and sharing cigarettes was a key feature of print advertising from around the 1920s. 'Three Castles' was dubbed the 'friendly cigarette' and as shown in figure 9, advertisements typically featured hands offering and accepting cigarettes. The detached hands reinforce the idea of universality - that the bodies attached to them could be anybody, in any social situation. ${ }^{41}$ A 1942 advertisement for 'Ardath' cigarettes, on the other hand, features a glamorous young woman, declaring: 'My friends compliment me on my good taste, particularly when I offer them one of my Ardath Cigarettes' (figure 10). ${ }^{42}$ This image suggested a greater degree of exclusivity in the brand, yet the social custom of offering remains central to the advertisement. 'Sobranie' Cocktail Cigarettes were 'A joy to offer, a delight to smoke'; the use of 'cocktail' in the brand name itself indicates a social setting and strong suggestion of glamour. ${ }^{43}$ The advertising industry was also keen that the custom of offering and sharing cigarettes should also extend to gifts - frequently suggesting boxes of cigarettes as suitable Christmas gifts. A 1928 'Craven "A" advertisement depicted a young woman proclaiming 'Craven " $\mathrm{A}$ " for Christmas! that's my motto, I know the boys like them. ${ }^{, 4}$ In addition advertisers also promoted the importance of offering cigarettes in private social settings, such as the home. In 1929 'Craven " $\mathrm{A}$ "” advertisers again depicted a young woman, this time smoking herself and stating the importance of keeping 'a generous supply of Craven " $\mathrm{A}$ " in the house' to offer to her guests. ${ }^{45}$

\footnotetext{
${ }^{41}$ Advertisement - Three Castles, Weekly News, 13 March 1924, p.67.

${ }^{42}$ Advertisement - Ardath, Listener, 27 February 1942, p.12.

43 Advertisement - Sobranie, Listener, 7 December 1956, p.30.

${ }^{44}$ See Advertisement - Craven "A", The Press, 7 December 1928, p.15.

45 Advertisement - Craven "A", The Press, 12 July 1929, p.18.
} 


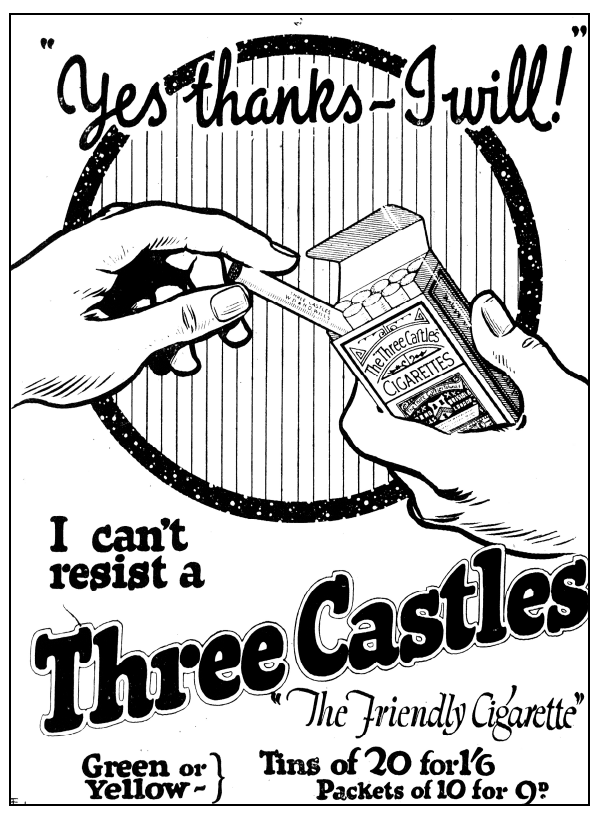

Figure 9

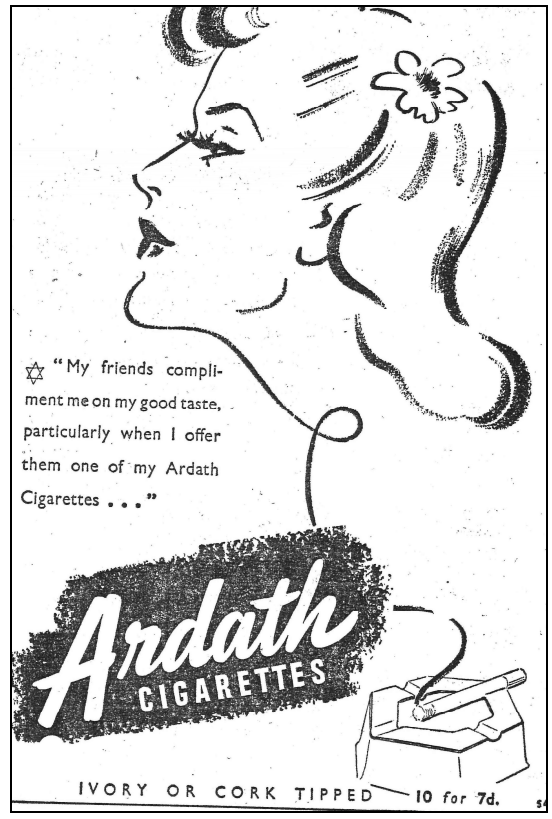

Figure 10

These simple yet effective advertisements for 'Three Castles' cigarettes from 1924, and 'Ardath' cigarettes from 1942 encourage the custom of offering a cigarette.

Weekly News, 13 March 1924, p.67;

Listener, 27 February 1942, p.12

Offering and sharing cigarettes was increasingly suggested as something to be expected in both mixed and single-sex company. Among men the custom was grounded in 'ideas of reciprocity', not dissimilar to a pub 'shout' or round of drinks. ${ }^{46}$ However in mixed company men often carried cigarettes in the expectation that they would produce them to offer to women. ${ }^{47}$ In Edison Hobson's 1962 study of smoking motivation among New Zealand women, his subjects all reported that they 'smoked more when taking part in social activities such as dancing, parties, and visiting. ${ }^{48}$ Hobson's interviewees attributed this to the 'symbolic' gesture of offering a cigarette, which served as an 'offering of friendship and hospitality' in social settings. He also noted that the women found that smoking acted as a way of relieving nervousness and tension at social occasions. Above all, he argued that the 'social acceptability of smoking' coupled with

\footnotetext{
${ }^{46}$ Tyrrell, Deadly enemies, pp.143-4.

${ }^{47}$ For example Don, a character in Bill Pearson's classic novel, Coal flat, continued to purchase cigarettes, even when he had given up smoking for financial reasons, so that Myra could borrow them when she did not have any. See Bill Pearson, Coal flat, Auckland, 1963, p.94.

${ }^{48}$ Edison. R. Hobson, 'Cigarette smoking motivation in women', preventive medicine dissertation, Otago Medical School, University of Otago, 1962, p.19.
} 
the 'presence of other smokers', promoted social spaces in which smoking was expected and normal. ${ }^{49}$

In 1934 the Tobacconists' Review ran a short article on 'Smoking by Women', stating that 'there appears to be little objection now to women smoking in restaurants, theatres, motor cars and at dances. ${ }^{50}$ While the Tobacconists' Review had a commercial agenda in supporting the widening of its consumer base, other source material suggests that by the mid-1930s it was increasingly acceptable and normal for women, as well as men, to smoke in social settings such as at dances, parties and at the theatre. However in 1935, a Wellington ballroom dancing teacher was quoted in the Dominion complaining that 'some of our younger people don't seem to realise that...[smoking] is an objectionable practice and it flouts etiquette.' She despaired that, 'There is a dance number called, "I'm dancing with tears in my eyes"-everyone knows it,... and a more modern version could be "I'm dancing with a cigarette in my hand." However, the Dominion noted that the practice of dancing and smoking was 'fairly common these days, ${ }^{51}$ The view of the dancing teacher was regarded as antiquated within the wider trend and acceptability of smoking by both men and women on social occasions. Indeed the only real opposition to smoking in such spaces came from fire officials. In 1946 the Opunake Municipal Fire Brigade wrote to the Wellington Town Clerk asking for guidance on how to control the fire danger posed by smoking, anxious that

the practice of smoking in public halls on the occasion of dances, meetings, lectures etc., [sic] is one which has been in operation for so long that it has become an accepted fact, and that it would be now extremely difficult, if not impossible, to stop such practice. ${ }^{52}$

Smoking became a common feature, and 'accepted fact', of social occasions, despite fire danger. Encouraged by the strong association suggested in modern advertising between smoking and social activities and occasions, the practice of sharing a cigarette proliferated and increasingly became an important ritual in mixed socialising.

Although shifts in acceptability saw women openly lighting up in social spaces by the 1930s, there was still a strong distinction in both the rate of smoking and how smoking was perceived for men and women. For women, smoking in public spaces

\footnotetext{
${ }^{49}$ Hobson, p.20.

50 Tobacconists' Review, 15 December 1934, p.15.

${ }^{51}$ Dominion, 30 August 1935, p.6.

52 Opunake Municipal Volunteer Fire Brigade to Town Clerk, 2 July 1946, Wellington, Bylaw: Town Hall, No Smoking and Consumption of Liquor Bylaw, 1929-1968, item registration 00001:88:5/90, Wellington City Archives, Wellington.
} 
such as trains and trams was still seen to be 'not quite nicee. ${ }^{53} \mathrm{~A}$ different standard existed concerning the demarcation of where it was 'respectable' and 'unrespectable' to smoke in public. The place and time for smoking was 'contentious and as much about the gendered division of space as about shifting norms of respectable femininity. ${ }^{, 54}$ Smoking outside of socially sanctioned space was still a powerful way to endanger respectability. The smoking section of public transport was one of the most obvious and clearly demarcated smoking spaces in the period 1920-1962. Public transport had a much longer history as an exclusively male space.

Through the period of this study rail travel was a popular and common mode of transport in the everyday lives of both men and women. The rail carriage and the railway station were in themselves sites of sociability. In his history of railways in New Zealand Neill Atkinson observes that

With their wall-mounted match-strikers, brass spittoons and enamelled notices asking passengers not to 'expectorate' on the floor, 'smokers' [i.e. smoking carriages] were exclusively male bastions until the 1920s, when women began to light up in larger numbers. ${ }^{55}$

From the 1920s advertisers sought to construct the smoking section of rail carriages as a space where men and women could both enjoy smoking. A 'De Reszke' advertisement in the series 'The right cigarette in the right company', which ran through the 1920s and 1930s, depicts a man smoking and lighting a cigarette for his female companion in the smoking section of the train (figure 11). ${ }^{56}$ Despite the gesture of the offering and shared enjoyment of smoking suggested in the De Reszke advertisement, a steady stream of letters to the editors of daily newspapers and letters of complaint to rail and city council officials throughout the period of this study, suggests that men were loathe to permit women entry into these 'male bastions. ${ }^{57}$

\footnotetext{
53 Tobacconists' Review, 15 December 1934, p.15.

54 Tinkler, Smoke signals, p.91.

${ }_{55}$ Neill Atkinson, Trainland: how railways made New Zealand, Auckland, 2007, p.148.

56 Advertisement - De Reszke, The Press, 22 March 1929, p.19.

57 Women and children travelling in smoking carriages, 1907-1962, AAEB, W3199, 112, 07/3088, 1, Archives New Zealand, Wellington; Car Accommodation on Mixed Trains Proportion of Smoking to Non Smoking cars on All Services, 1907-1959, AAEB, W3199, 108, 07/1177, 1, Archives New Zealand, Wellington. Earlier examples include, 'Smoking on tramcar', H. L. James, 12 October 1909, item reference number 00233:177: 1909/1842, Wellington City Archives, Wellington. See also, The Press, 7 May 1929, p.10.
} 


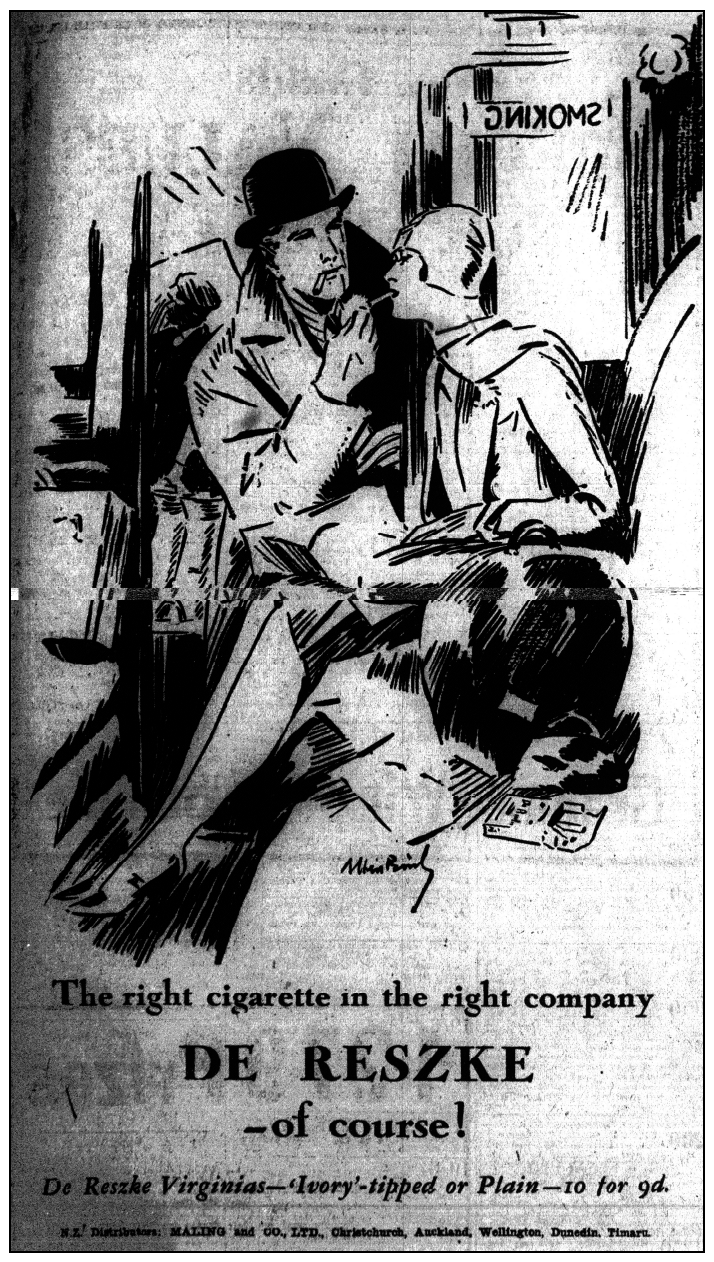

Figure 11

This 1929 advertisement is an example of the De Reszke series 'The right cigarette in the right company', which typically depicted men and women enjoying a cigarette together whether it was in a restaurant, at the races, at the theatre, or in the smoking section of the train.

The Press, 22 March 1929, p.19

Smoking space on long distance and suburban trains, as well as on urban trams increasingly came under pressure as the distribution of smoking and non-smoking space failed to keep up with the rising number of smokers among train users. The basic premise of these complaints was that women were occupying valuable and limited space in smoking carriages, 'to the exclusion of male passengers. ${ }^{58}$ The complaints were directed at both smoking and non-smoking women, though the latter caused greater frustration. It was an offence to smoke in the non-smoking section of transport. In 1943 a Lower Hutt judge stated that he had little sympathy for non-smokers when a charge was brought before him of a person accused of smoking in a non-smoking car.

\footnotetext{
58 R.W. McVilly, General Manager Government Railways New Zealand to District Traffic Managers (South Island), 30 June 1920, Women and children travelling in smoking carriages, 1907-1962, AAEB, W3199, 112, 07/3088, 1, Archives New Zealand, Wellington.
} 
The judge commented that the charge should also apply to non-smokers who occupied smoking cars. ${ }^{59}$ This practice was already in force in Victoria, Australia where rail authorities brought in a regulation in 1924 stipulating that women were only allowed to occupy seats in the 'smoker' if they 'lit up' themselves. ${ }^{60}$

Despite spatial limits for smoking on trains, it was not often decided there was sufficient demand for extra smoking carriages to be added to many services. One such exception was a recommendation from the Auckland District traffic manager in 1925 requesting a change in the configuration of the Huntly to Glen Afton train. Of the seven carriages, only one was a smoker, and he recommended that this be changed to five smokers and two non-smokers, probably reflecting the high proportion of male miners who were travelling out to the new mining areas that were opened up during the first world war to the west of Huntly. ${ }^{61}$ However, over the 1930s and 1940s rail officials gradually reconfigured the distribution of space and by the 1950s there were on average four to five smoking carriages to every one non-smoking carriage on New Zealand trains. ${ }^{62}$ This ratio is a very strong indicator of the high rate of smoking among New Zealanders, both men and women, by the 1950s. The decline in complaints by this time also suggests that men became more accepting of female smokers on the trains; female presence became unproblematic, as long as the men could smoke themselves.

Beyond instances of negotiation over particular sites of smoking, leisure places and activities were the most important spaces in the expansion of female smoking over the period of this study, and were a key target of promotional activity aimed at increasing consumption. Not only did smoking in leisure spaces offer a shared activity for interaction, but leisure spaces and leisure activities also promised glamour and sophistication for women. The visual function of the cigarette was very important in the outward expression of what it was to be a young woman in the interwar era. Advertising of cigarettes promised women that if they used the product it would make them more desirous, attractive and modern; cigarette smoking was 'the fashion that never changes. ${ }^{93}$ The cigarette, like other consumer products such as make-up and

${ }^{59}$ New Zealand Herald, 20 December 1943, in Women and children travelling in smoking carriages, 19071960s, AAEB, W3199, 112, 07/3088, 1, Archives New Zealand, Wellington.

60 The New Zealand Times, 15 March 1924, in Women and children travelling in smoking carriages, 19071962, AAEB, W3199, 112, 07/3088, 1, Archives New Zealand, Wellington.

${ }^{61}$ Car Accommodation on Mixed Trains Proportion of Smoking to Non Smoking on All Services, 19071959, AAEB, W3199, 108, 07/1177, 1, Archives New Zealand, Wellington.

${ }^{62}$ Atkinson, p.148.

${ }^{63}$ Advertisement - Player's Please, 12 August 1948, p.49. 
fashionable clothing, became synonymous with a contemporary glamorous look. The influences of Hollywood, fashion and film stars were prominent in the promotion of smoking to a female market. Film stars were portrayed smoking on screen and were also paid to endorse cigarettes in advertisements for particular brands. ${ }^{64}$ As David Lascelles asserts, films emerging from the United States in the interwar era taught New Zealanders 'how to dress, how to kiss, and how to light a cigarette; they gave us style and class, fashion and elegance. ${ }^{65}$

Cigarette smoking became a central accessory used by the glamorous Hollywood star. The commercial impetus behind the representation of smoking in the film industry was colossal. K. L. Lum et al.'s recent investigation into industry records from American tobacco companies is very revealing of the massive financial power that the tobacco companies wielded. ${ }^{66}$ The study highlights the extent of the 'mutually beneficial commercial collaborations' between 'big tobacco' and the film industry and how these were multi-faceted and sustained over a long period from the beginning of the 'talkies' in the late $1920 \mathrm{~s}$ through to the $1950 \mathrm{~s} .^{67}$ There was no mystery as to who the tobacco companies' efforts were aimed at. Lum et al. found that the tobacco companies reported targeting women 'to increase the size of the cigarette market', and 'used female film stars to model behaviour and increase social acceptance through testimonial advertising and onscreen smoking. ${ }^{68}$

The promise of glamour, sophistication and modernity offered by smoking was also a prominent feature of print advertising. Images drawing on expressions of 'glamour' were a feature of advertising in the daily press from the early 1920s and began to appear in papers like The Mirror from the late 1920s. Women were targeted in the Listener from the 1940s though cigarette advertising was not a prominent feature of the New Zealand Woman's Weekly until the 1950s. Cigarette advertisements typically portrayed fashionably dressed women with make-up, jewellery, evening gown or hat and of course a lit cigarette. Collusion between the fashion industry and the tobacco industry can also be seen as a feature of the commercial impetus driving patterns of female consumption

\footnotetext{
${ }^{64}$ Sivulka, pp.167-8.

${ }^{6}$ David Lascelles, 80 turbulent years: Paramount theatre Wellington 1917-1997, Wellington, p.189, cited in Charlotte Burgess, 'Looking to the heart: young people, romance and courtship in interwar New Zealand', MA thesis in History, University of Auckland, 2007, p.54.

${ }^{66}$ Lum, et al., pp.313-323.

67 Ibid., p.313.

68 Ibid., p.321.
} 
in the period 1920-1962. ${ }^{69}$ Throughout this period, the cigarette was not only a feature of tobacco advertisements but was heavily used as a prop in advertisements for beauty products, clothing, gloves, hosiery and underwear. ${ }^{70}$

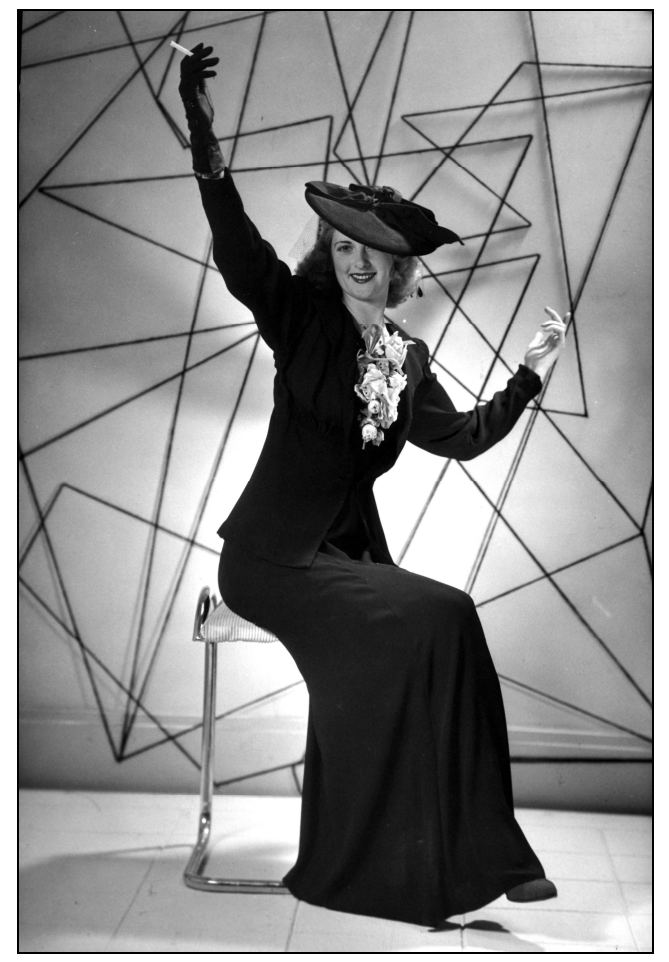

Figure 12

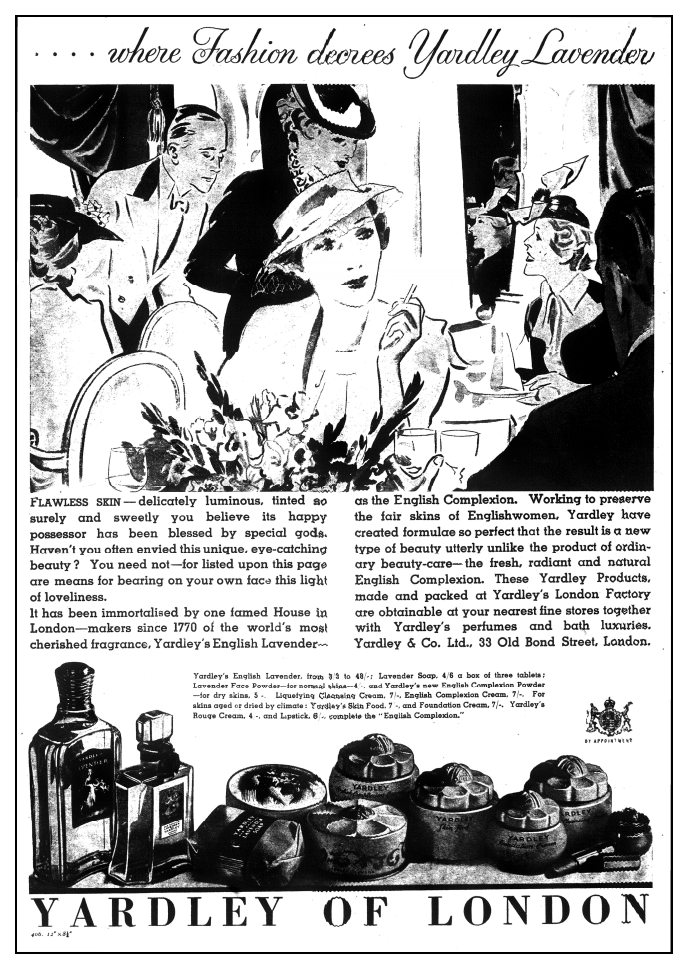

Figure 13

In advertisements for women's products and clothing the cigarette represented a modern and fashionable look.

Clifton Firth, 34-M7E2, Special Collections, Auckland City Libraries, Auckland (reproduced with permission of Auckland City Libraries); The Mirror, 1 April 1938, p.41

Auckland photographer Clifton Firth characteristically used this device in his studio portraits for department stores and clothing companies. Firth's photographs were glamorous and theatrical. For example, his 1940s portrait for the Milne and Choyce department store depicted a woman modelling a dress and hat with a cigarette in her

\footnotetext{
${ }^{69}$ The cigarette or pipe was also widely used as a device in advertising for men's products, predominantly clothing. Danielle Sprecher suggests that the cigarette was often used 'strengthen the manliness' of advertisements for clothing such as woollen underwear. See Danielle Sprecher, 'The right appearance: representations of fashion, gender, and modernity in inter-war New Zealand, 1918-1939', MA thesis in History, University of Auckland, 1997, pp.87-8. See also, Advertisement - Kilpper dressing gowns for men, New Zealand Sportsman, July 1946, inside cover.

${ }^{70}$ See for example, Advertisement - Bonds Arrow Point Hosiery, The Mirror, 1 November 1928, backcover; Advertisement - Selby Slenderized Shoes, The Mirror, 1 March 1936, p.36.
} 
hand; the modern woman is set against an abstract background of intersecting geometrical shapes (figure 12). ${ }^{71}$ The connection between sophistication and smoking was made even more overt in advertisements portraying sociable smoking. A 1938 advertisement for Yardley's perfume and bath products in The Mirror depicted a sophisticated, fashionable woman dining in a restaurant - her cigarette is prominently placed in her hand as she turns toward her male companion (figure 13). ${ }^{72}$ The function of smoking was multi-faceted in social spaces, promising glamour and sophistication as well as acting as a tool for offering and social interaction with men. Smoking was not only acceptable but was also fashionable and desirable.

The strong association between glamour, modernity and smoking was not only promoted through commercial means, but also through non-commercial images in the creative sphere. Clifton Firth and Gordon Burt typically used the cigarette as a prop in both their photography for advertisements, and also their studio portraits. Following a growing international trend, the cigarette became an important element for both male and female cultural symbols in New Zealand through the 1930s and 1940s in creative industries. As Vita Cochran notes, smoking 'was once considered a stimulator of thought and creativity', and the cigarette was used in portraits as an 'external emblem of a vigorous intellectual life. ${ }^{73}$ Photographs and paintings of female writers and actresses are typical of this genre. Henry Herbert Clifford's 1935 photograph of crime writer Ngaio Marsh (figure 14), and artist Rita Angus' 1937 self-portrait (figure 15), exemplify this medium. ${ }^{74}$ Both women prominently hold a lit cigarette, and stare defiantly at the viewer. The cigarette is a striking marker of their modernity and independence.

\footnotetext{
${ }^{71}$ Clifton Firth (photographer), Milne and Choyce Department Store, 1940-1949, 34-M7E2, Special Collections, Auckland City Libraries, Auckland.

72 Advertisement - Yardley of London, The Mirror, 1 April 1938, p.41.

${ }^{73}$ Vita Cochran, 'What the pyramid contains - the early self portraits', William McAloon and Jill Trevelyan, (eds.), Rita Angus: life and vision, Wellington, 2008, p.42. See also the prominence of smoking in a portrait of the authors of 'Murder by Eleven', taken in Pat Lawlor's study in 1936, in Chris Hilliard, The bookmen's dominion: cultural life in New Zealand 1920-1950, Auckland, 2006, p.38.

74 Ngaio Marsh, (photographer Herbert Henry Clifford), 1935, PAColl-8163-04, ATL, Wellington, (published in the N.Z. Freelance 3 April 1935); Rita Angus, 'Self Portrait', c.1937, Dunedin Public Art Gallery, Dunedin. For a wider discussion of Angus' self-portrait see Cochran, 'What the pyramid contains', p.42. For other examples of this genre see also a later studio portrait of Ngaio Marsh "Ngaio in the spotlight", (photographer unknown), 194-, ADQ-4294, Christchurch City Libraries, Christchurch; Louise Henderson's 'Portrait of Betty Curnow', 1954, Christchurch Art Gallery, Christchurch; May Smith, 'Characterisation in colour', 1941, Auckland Art Gallery, Auckland.
} 


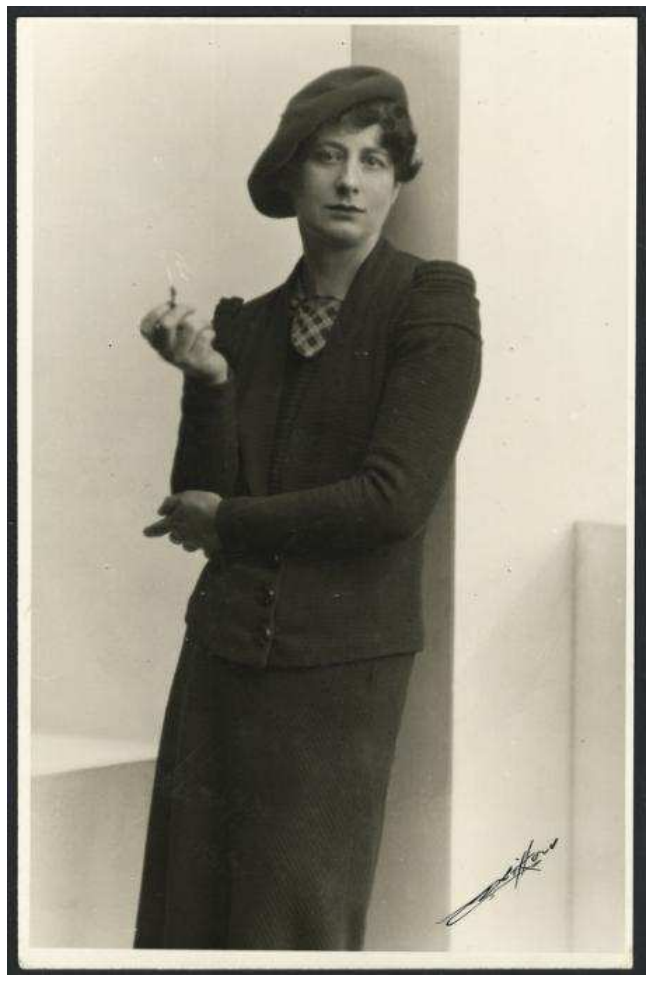

Figure 14

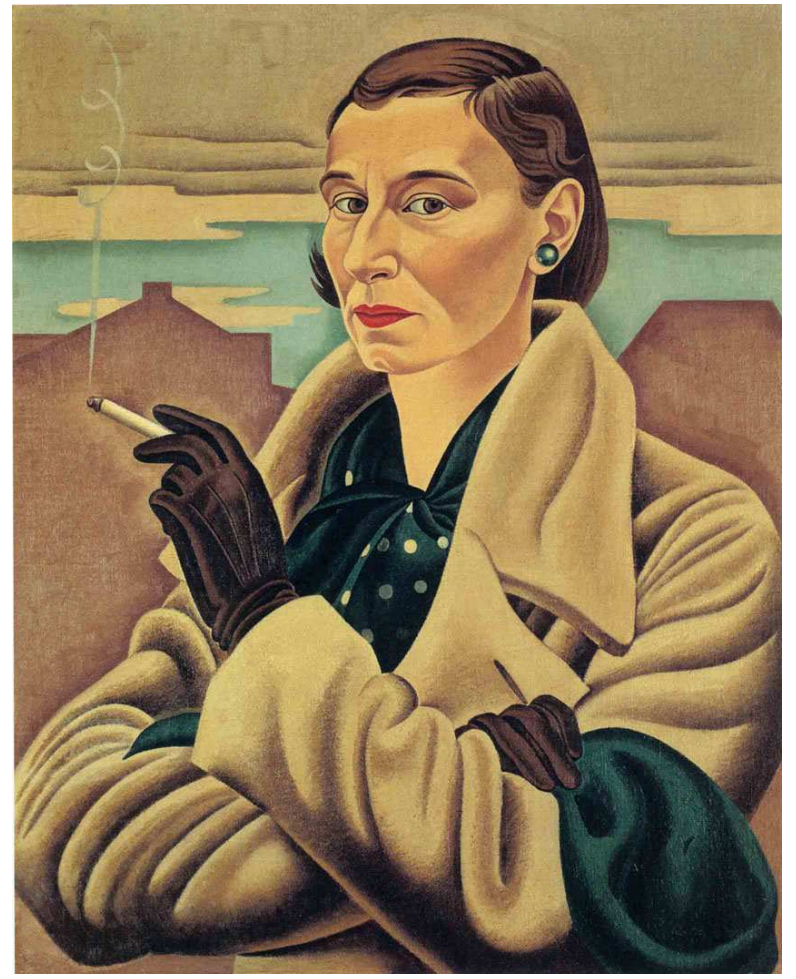

Figure 15

These iconic portraits of Ngaio Marsh and Rita Angus from the mid-1930s are powerful images where the cigarette is prominently positioned as a marker of their place as 'modern' cultural figures.

Ngaio Marsh (photographed by Herbert Henry Clifford), 1935, PAColl-8163-04, ATL; Rita Angus, Self Portrait, c.1937, collection of the Dunedin Public Art Gallery, reproduced with permission of the Estate of Rita Angus 
Throughout the period 1920-1962 the tobacco industry marketed the function of smoking in leisure spaces and activities as an aid to relaxation, as a complement to playing and watching leisure activities such as sport, and as a social accessory for offering and sharing in mixed and single sex social spaces. Beyond these core functions, smoking was portrayed in commercially driven representations such as film and advertising as attractive, modern and glamorous. These representations were prolific and pervasive. While the promise of glamour portrayed through commercial media was most likely more symbolic than the reality of female smokers in New Zealand, its significance lay in the commercial impetus to influence and drive the attitudes and behaviours of consumers, increasing the acceptability of a previously marginal and male-focused habit. This commercial agenda worked alongside other non-commercial means, and was successful in shaping the way that men and women smoked in leisure spaces, times and activities.

\section{Work}

When Alfred Cockayne described his ideal of the worker who finds 'more than pleasure' in a cigarette 'after a job of hard work', he positioned the cigarette as a recompense for work, as much as a solely pleasurable and sociable activity. The connection made between smoking as a universal entitlement and beneficial accompaniment to a job of hard work' is the second key focus of this chapter. Indeed leisure and work are so interlinked that it is often difficult to make the distinction between what was pleasurable smoking and what was viewed as a reward or chance to relax before or after work. Work, as a space and as an activity, was also a major target for tobacco industry advertisers. Working time represented a considerable period of the day in which consumers could be smoking, and it was in the interest of the tobacco industry to encourage workers to view smoking as an entitlement or a reward for paid employment, and as a psychological and physical break from that work. The widespread promotion of smoking during both leisure and work reinforced both spatial and temporal universality, the idea that smoking could be practised anywhere at anytime.

Workers were a lucrative market for the tobacco industry, as they were more likely to possess the disposable income which made smoking affordable. Young, socially mobile women who joined the work force in clerical or office jobs in the 1920s and 1930s were particularly targeted by promoters. Danielle Sprecher charts the movement 
of women into office roles through the 1920s against changing ideas of feminine respectability. She argues that a

young woman sitting behind a typewriter became the emblem of this changing femininity; she was represented as being young, 'modern', earning her own living, freer and more independent than her mother. $^{75}$

Financial independence and greater freedom over what they bought and consumed made these women a focus for tobacco advertisers. The cigarette was a convenient and powerful visual symbol for the image of the young modern worker. The cover of The Mirror in November 1930 offers a striking illustration of such advertising. Unusual for this period, the whole cover was dedicated to an advertisement for "Craven " $\mathrm{A}$ " corktipped cigarettes (figure 16). The image shows a young, sophisticated woman in an elegant coat and cloche hat, wearing lipstick, and graciously holding a cigarette as she stares off into the distance. ${ }^{76}$ The image is not only an attractive and alluring advertisement for the brand of cigarettes, with a full page advertisement on its cover, but also had a high design (as well as revenue) value for the publishers to sell copies of their magazine. Notions of independence and modernity are strongly evident in this image, yet such images also had the power to overstate or draw attention to what could have still been seen as a risqué public behaviour.

${ }^{75}$ Danielle Sprecher, 'Good clothes are good business: gender, consumption and appearance in the office, 1918-39', Caroline Daley and Deborah Montgomerie, (eds.), The gendered Kiwi, Auckland, 1999, p.152. See also Sprecher 'The right appearance.'

76 Advertisement - Craven "A", The Mirror, 1 November 1930, p.1. 


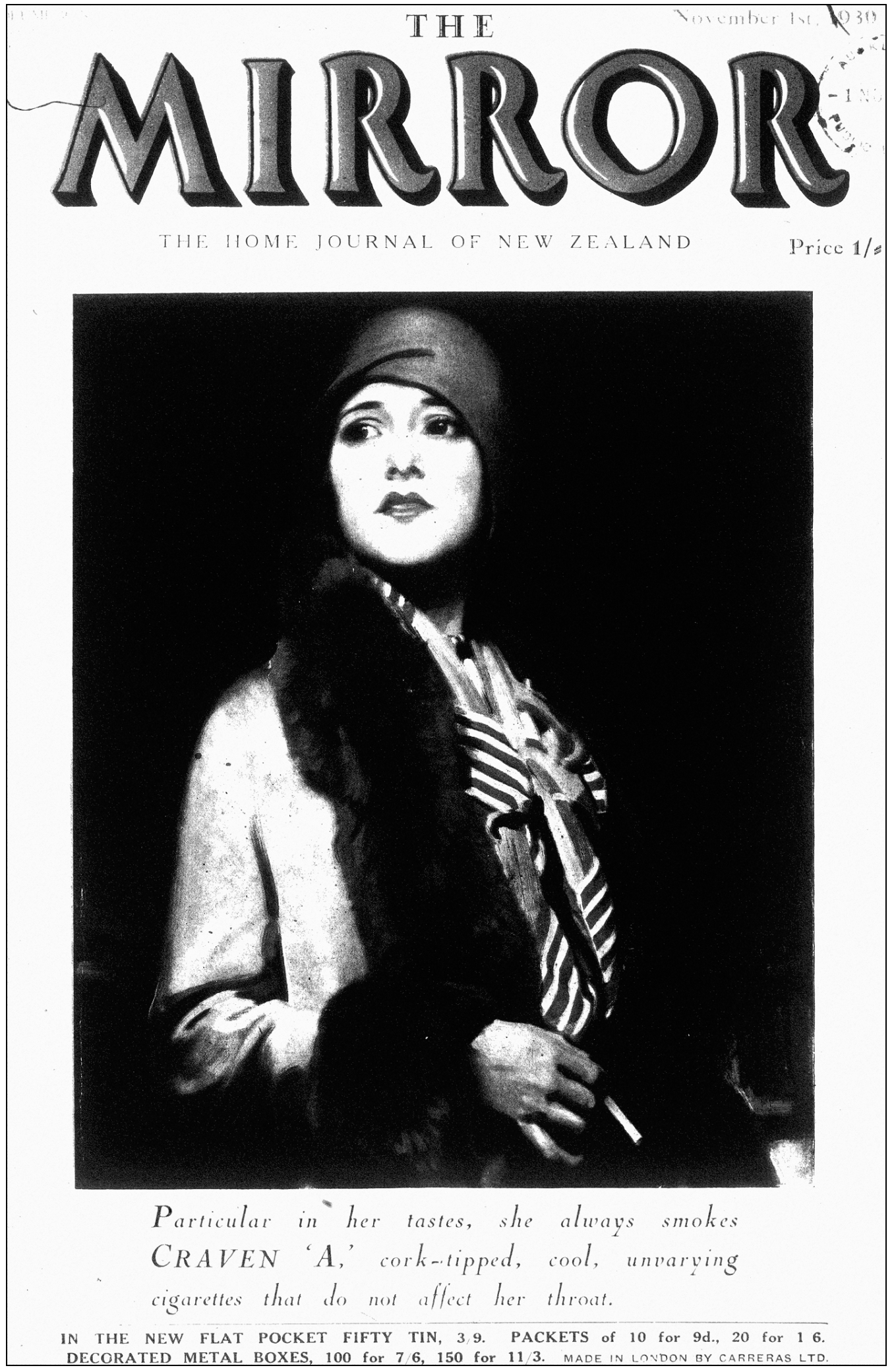

Figure 16

Though women's magazine The Mirror frequently carried cigarette advertisements from the late1920s, it was very rare to dedicate a whole front cover, as in this 1930 cover advertising 'Craven "A" cigarettes. 
The independent smoking woman might have raised more eyebrows than the tobacco companies were willing to admit. In 1935 a photograph appeared in the pictorial pages of the N. Z. Freelance, showing two Christchurch women walking in the street on Labour Day (figure 17). They are wearing berets, trousers and one of the women is smoking a cigarette. The caption labels the women 'unconventional', and mentions the fact that they are 'garbed in men's trousers. ${ }^{77}$ That such an image was chosen as a noteworthy inclusion in the popular weekly periodical indicates the novelty of such appearance - trousers combined with smoking - in public, indicating a breach of convention. Work gave women the economic opportunity to take up smoking yet women were still tasked with negotiating the habit and the cigarette within existing notions of feminine identity.

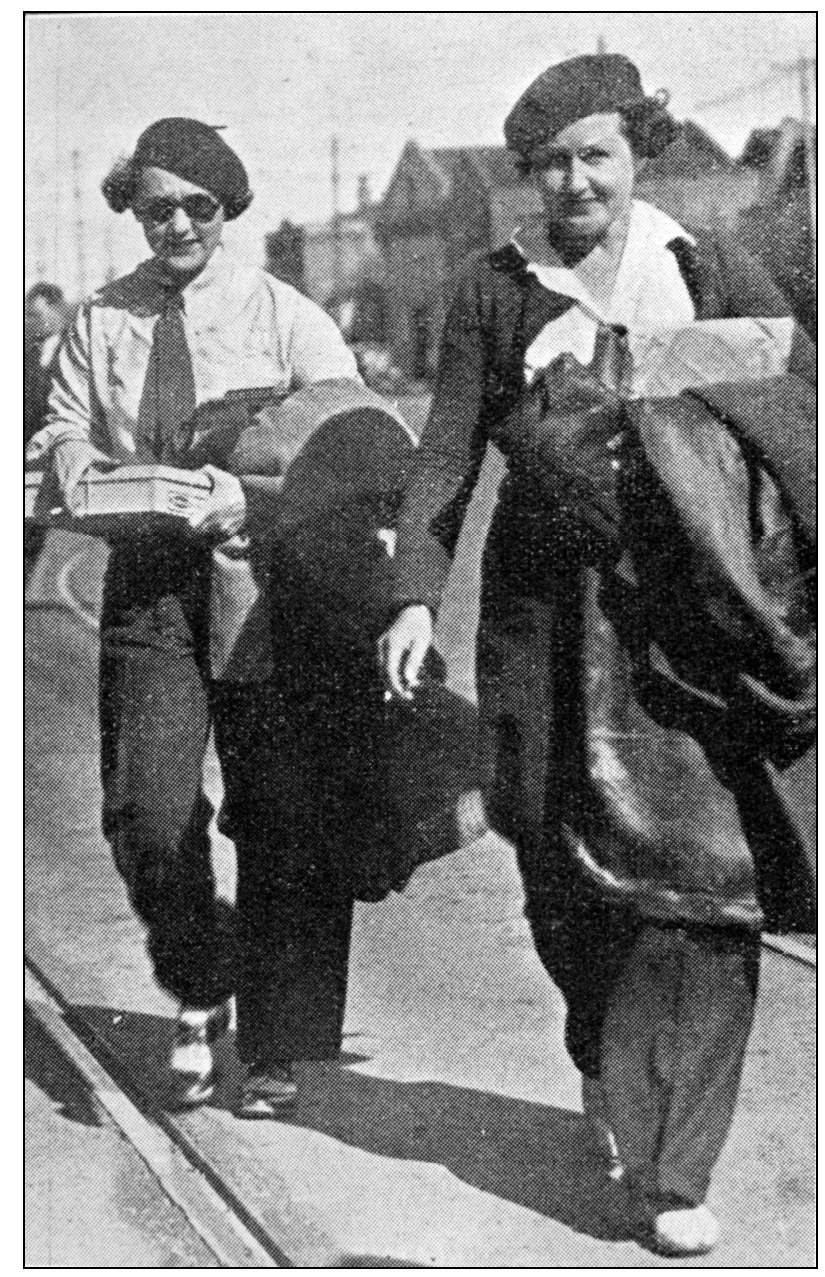

Figure 17

When the N.Z. Freelance carried this photograph in 1935, where one of the women is openly smoking on the street, it ran the caption 'Unconventional - These two Christchurch girls garbed in men's trousers enjoy a Labour Day outing'.

N.Z. Freelance, 6 November 1935, p.42, (C16176, ATL)

${ }_{77}$ N. Z. Freelance, 6 November 1935, p.42. 
Shifts in feminine identities and respectabilities cannot be easily plotted along a straight line, but rather differed across time, place, and class. It is evident from Sprecher's analysis that 'modern' young women within feminised office work were a key consumer target for products such as make-up and clothing, items which were central to providing an appearance as 'professionals. ${ }^{, 78}$ However, cigarette advertisers could extend their focus to female shop or factory workers who also had greater independence and discretionary income. Cigarette advertisers' images of young women suggested a degree of universality - emphasising youth and glamour but not specific working groups. Some women were noticeably absent from cigarette advertising. While the housewife might have been the target of other consumer products emerging in this era, particularly for household appliances and products for children, she was never depicted as a smoker. ${ }^{79}$ No advertising images exist showing a woman casually smoking in her kitchen or back step as she waits for the dinner to cook. As smoking was closely aligned with discretionary spending, waged female workers were much stronger targets for the tobacco industry. The image of the modern woman, particularly as constructed in advertisements, was emphasised in her participation in paid work.

Whether smoking was permitted 'on the job' or during breaks from work depended on the type of work and on gender divisions in the work place. As the Tobacconists' Review was keen to suggest in 1934, smoking was acceptable among men in many work places:

In many offices nowadays the male members of staff are allowed to smoke sometimes during the whole of office hours and sometimes only after certain hours, but in the majority of cases under no circumstances are the women allowed to smoke at all. ${ }^{80}$

Advertisers were particularly keen to push the idea that people of all occupations should be able to smoke 'on the job'. In the 1940s 'Silver Fern' tobacco ran advertisements stressing the universal appeal of their product. One example, shown in figure 18, depicts a well groomed man in a suit, an office worker or 'city man', happily smoking a cigarette. The second depicts a linesman working up a power pole, simultaneously repairing power lines while he smokes 'Silver Fern' tobacco (figure 19). ${ }^{81}$ The dual aim

\footnotetext{
${ }^{78}$ Sprecher, 'Good clothes are good business', pp.151-7.

${ }^{79}$ For a thematic analysis of the promotion of household appliances to women through the period 19351956 see Jean-Marie O’Donnell, “Electric servants', and the science of housework: changing patterns of domestic work, 1935-1956', Barbara Brookes, Charlotte Macdonald and Margaret Tennant, (eds.), Women in History 2, Wellington, 1992, pp.168-183.

80 Tobacconists' Review, 15 December 1934, p.15.

${ }^{81}$ Advertisement - Silver Fern, Listener, 4 April 1941, p.56; Advertisement - Silver Fern, Listener, 21

December 1945, p.40.
} 
of these advertisements was firstly to stress the universality of their product, appealing across all classes of men and worker, and secondly showing that their product could and should be smoked 'on the job'. However, the right to smoke on the job was not a universal entitlement, some jobs were far more conducive to workplace smoking, such as office work, where a pen in one hand and a cigarette in the other were easily juggled, whereas manual work in factories or in labouring jobs would have precluded smoking on the job.

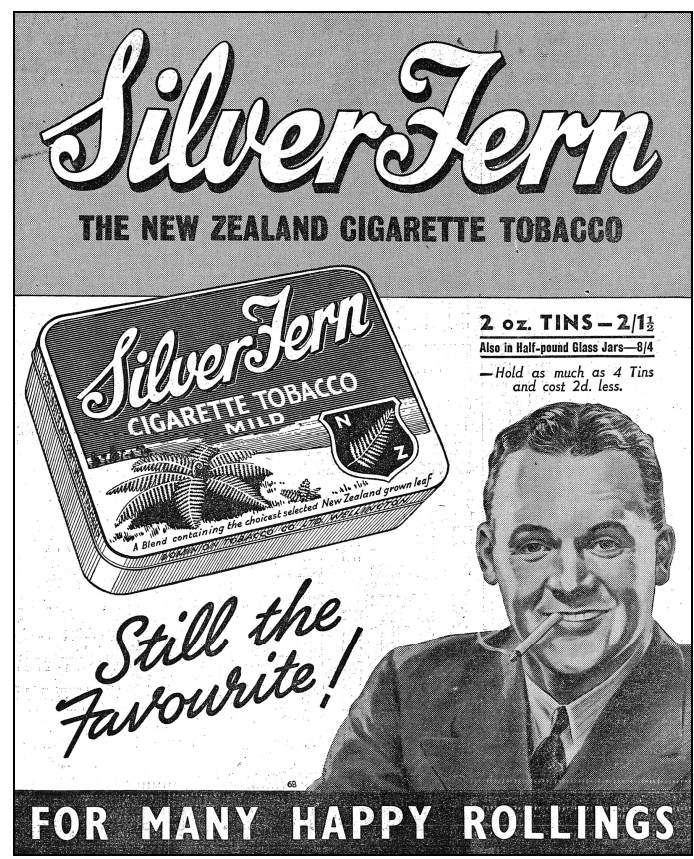

Figure 18

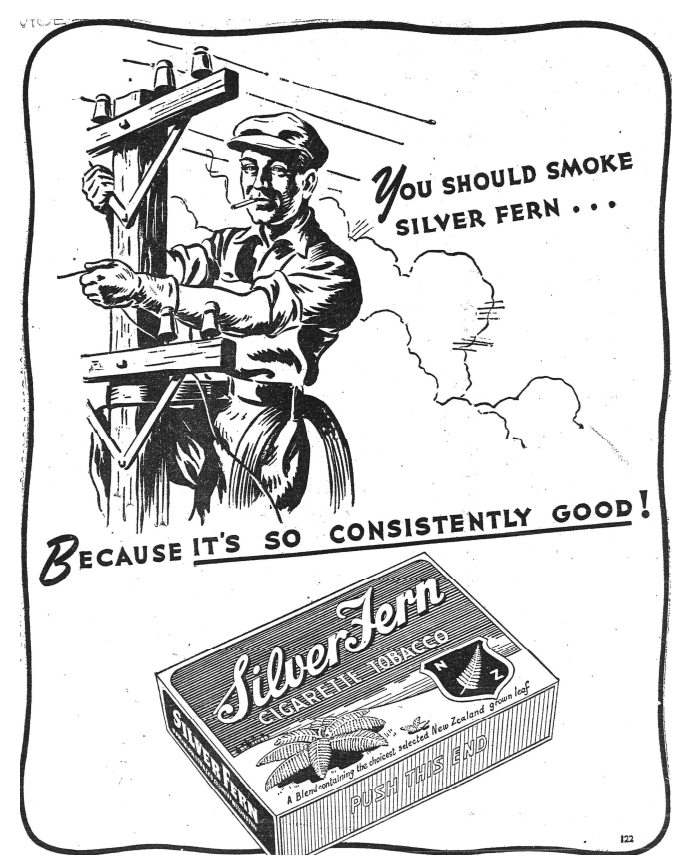

Figure 19

These Silver Fern advertisements from the early 1940s were aimed at men of all classes. Other examples from this series include depictions of a man smoking while driving a car, a train driver and an aeroplane mechanic. ${ }^{82}$

The right to smoke on the job was won by railway workers employed by the Government Railways Department in the 1920s. Men were first allowed to smoke in the railway workshops during the 1918 Influenza Epidemic due to the belief that smoking acted as a personal preventive against influenza. ${ }^{83}$ Permission to smoke was again granted in August 1923 when another, smaller influenza epidemic broke out but the right was revoked when the danger had passed a month later. Following this episode the

${ }^{82}$ Listener, 23 November 1945, p.40; Listener, 15 February 1946, p.40; Listener, 18 January 1946, p.40.

${ }^{83}$ See Geoffrey W. Rice, Black November: the 1918 influenza pandemic in New Zealand, 2 ${ }^{\text {nd }}$ edition,

Christchurch, 2005, p.152. 
General Secretary of Railways wrote to the General Manager of Railways requesting that the men continue to be allowed to smoke in the workrooms. He argued that 'the men are more contented and more attentive to their work when allowed to do so, and that if the request were to be granted it would be in the interest both of the Department and the men. ${ }^{84}$ A few weeks later the Chief Mechanical Officer wrote to the General Manager stating that 'the desire for a smoke comes at any time, and it is preferable to satisfy it then instead of trying to restrict it to stated periods, as the latter method will no doubt be defeated by a visit to the latrine. ${ }^{85}$ Later that year it was agreed that the Government Railways implement the suggested scheme, as it had been found that many large firms had allowed smoking on the job since the 1918 epidemic on similar grounds of fewer breaks being taken for smoking, and productivity had increased. As soon as one group was granted the right to smoke, others steadily voiced their right for equality, arguing for their entitlement to smoke on the job. Throughout the 1920s to the 1930s requests for the provision to be extended to other working groups within the railways were received by the Government Railways head office in Wellington from all around the country. Generally the requests were granted so long as the smoking was not in view of the public', suggesting that while the railways were keen to increase productivity and workplace harmony, there was still an element of propriety which precluded smoking in front of the public for whom they were providing a service. ${ }^{86}$

For workers whose jobs expressly denied the option of smoking during working hours, the entitlement to smoke was constructed within their right to scheduled breaks from work. The regulation of work breaks was a central issue in industrial legislation in New Zealand in the early twentieth century. ${ }^{87}$ The term 'smoko' persisted through the twentieth century as a term for a break from work for refreshments. ${ }^{88}$ While the origin of the term is not known, it is supposed that it derived from a call to stop work for smoking, but also applied to tea and food breaks. Smoking remained a key feature of

\footnotetext{
${ }^{84}$ General Secretary Government Railways Department, to General Manager Government Railways Department, 29 August 1923, Smoking in the Workplace, 1904-1988, ABJP, W4098, 33, 04/399, 1, Archives New Zealand, Wellington.

${ }^{85}$ Chief Mechanical Officer, Government Railways Department, to General Manager, Government Railways Department, 23 October 1923, Smoking in the Workplace, 1904-1988, ABJP, W4098, 33, 04/399, 1, Archives New Zealand, Wellington.

${ }^{86}$ Smoking in the Workplace, 1904-1988, ABJP, W4098, 33, 04/399, 1, Archives New Zealand, Wellington.

${ }^{87}$ In the 1908 Blackball strike miners were successful in getting their 'smoko' or 'crib' mealbreak extended from 15 minutes to half an hour. See Melanie Nolan, 'Introduction', Melanie Nolan, (ed.), Revolution: the 1913 great strike in New Zealand, Christchurch, 2005, pp.21-2.

${ }^{88}$ Elizabeth Orsman and Harry Orsman, (eds.), The New Zealand Dictionary, Auckland, 1994, p.257.
} 
these breaks and smoko-rooms or smoko-sheds also became synonymous with this daily ritual. ${ }^{89}$ The term 'smoko' is also used in Australia where it became a 'ritualised' behaviour among workers where men adapted to the smoking habits of their coworkers, leaving little room for 'radical changes in smoking behaviour' such as the movement toward smoking manufactured cigarettes. ${ }^{90}$

Smoking as a reward or entitlement aligned with participation in paid work was, however, not universally acknowledged by employers. While the Government Railways allowed smoking among their male staff employed in workshops, a different standard existed for their female clerical employees at their head office in Wellington. In $1940 \mathrm{a}$ complaint was received by the Staff Superintendent of the railways from B.B. Bradshaw and C.F. Olsen on behalf of their fellow clerical workers. The women felt that there should be a specific space in the cafeteria set aside for them to smoke on their lunch and tea breaks, as they currently only had the option of a small veranda off the tea room which was rarely suitable for smoking due to Wellington's blustery weather. ${ }^{91}$ The women felt particularly slighted that their male colleagues were permitted to smoke during working hours, in the office, as well as on their breaks. They also knew that the practice of having smoking space for female employees was common in other organisations 'both Government and private', and that the 'girls of this Department do not see any reason why this same privilege should not be accorded them. ${ }^{92}$ This idea of smoking as a 'privilege' is couched in language showing that the women felt quite justified in claiming smoking as a right they were entitled to, supporting their request with a petition signed by 47 female co-workers.

The clerical workers' request was grounded in their appropriation of smoking as modern, working women, not seeking to have equal rights as men to smoke across all times and spaces at work, but rather 'room where they can meet socially and smoke in their lunch hours' within female company. ${ }^{93}$ It appears that no immediate action was taken to meet the women's request in 1940 and no records exist documenting further action by either the workers or the Railways. The situation of the women at the Government Railways echoed that of female students at Auckland University five years earlier, whose indignation at being denied the right to smoke in their common room

89 Ibid.

90 Tyrrell, Deadly enemies, p.150.

${ }^{91}$ B.B Bradshaw and C.F. Olsen to Staff Superintendent, Government Railways Department, 19 March 1940, Smoking in the Workplace, 1904-1988, ABJP, W4098, 33, 04/399, 1, Archives New Zealand, Wellington.

92 Ibid.

${ }^{93}$ Ibid. 
elicited considerably greater attention. Young, educated female university students might equally have found themselves the target of cigarette advertising in the study period, as women who were eager to express their independence. A young Betty Hurst recalled starting at Victoria University in the 1930s where around twenty per cent of the student population were female. She found that it really mortified me to go into the common room and see sophisticated young women sitting on the edges of chairs and tables, puffing cigarettes and looking superior. ${ }^{94}$ Smoking, it appears, was a habit that women picked up at university, and was a powerful symbol of adulthood.

At Auckland University in 1935 however, the Professorial Board saw fit to reinforce a ban on smoking in the women's common room. Women had never been allowed to smoke anywhere at the university but it appears that the rule was not strictly adhered to. Female students smoking at the university had probably raised little concern through the 1910s and 1920s as the female student population (and the rate of female smoking) was much smaller. Men had been allowed to smoke in their common room at the university since 1905, when they petitioned against the prohibition using the argument that smoking would allow them to establish 'a corporate life and feeling of esprit de corps. ${ }^{95}$ In 1935 the ban on women's smoking was upheld on the grounds that it was seen as inappropriate for women to smoke, regardless of place or company. One member of the Professorial Board, Dr Burbridge, declared 'just imagine that the mother of one of the girls calls and finds her smoking. ${ }^{96}$ It appears that Dr Burbridge was concerned for the respectable appearance and behaviour of the young women of his university, as a parent would be, and that such conduct might be seen as indecorous for these women. He was concerned not just for their academic education but for their status as 'young ladies' attending the university. However much like the female clerical workers at the Government Railways Department in 1940, young female university students positioned their smoking within their identity as young, independent women. One student campaigning for the student association in 1935 considered that 'university women are old enough to judge for themselves on such a purely personal matter as smoking. ${ }^{, 97}$ Smoking was also similarly positioned as a reward and pleasure for their hard work at university, one female student protesting that: 'Some of us often have four

\footnotetext{
${ }^{94}$ Quoted in Beryl Hughes and Shelia Ahern, Redbricks and bluestockings: women at Victoria 1899-1993, Wellington, 1993, p.61.

95 Secretary Students Association/O’Rorke, 19 April 1905, GC 1905/172; CM, 20 June 1905, p.48, cited in Keith Sinclair, A history of the University of Auckland 1883-1983, Auckland, 1983, p.64.

96 Sinclair, p.185.

${ }_{97}$ Craccum, Election Issue, 1935, Auckland University Library, Auckland.
} 
or five lectures almost on end and after that one can find more than a little comfort in a smoke. ${ }^{98}$

Paid employment was an activity which the tobacco industry was keen to associate with smoking. The central themes through which this association were constructed were the ideas of universality and entitlement; promoters aimed to make smoking acceptable across greater space and time. Young, 'modern' working women in the 1920s and 1930s were the new targets for advertising - these women, based in clerical or office work (and beyond in shop and factory work), earned enough disposable income to purchase cigarettes. Tobacco promoters aimed to construct the cigarette and smoking as a display of independence and modernity, epitomising what it was to be a young, modern woman. However while advertising stressed a strong connection between work and smoking, both men and women in New Zealand were also tasked with negotiating their individual right to smoke, both on and off the job, within their particular working conditions.

\section{War}

The second world war proved to have massive and lasting implications for the sustained upward tobacco consumption trend in the post-war years. 'War' as a space and as a time stands slightly apart from the discussion so far, in that wartime was a special, unusual event with different social, economic and political condition from peacetime. During wartime the values of national unity, thrift, and hard work were emphasised. War had a huge impact both on those directly involved in New Zealand's military campaign, and those people on the home front. The final section of this chapter considers the second world war as a specific phase in the wider time period of the thesis, in which imperatives toward smoking accelerated. Although the second world war saw an overall decline in consumption, this was due to a lack of available tobacco and had there been sufficient supplies, smoking would have been more prevalent. Beyond the overall consumption pattern, however, the war served to shift and intensify the function of the cigarette for both men and women.

As an essential industry, tobacco industry promoters continued to be focused on supply, recruitment and branding during the second world war. The tobacco industry and government had mutually vested interests in supplying New Zealand servicemen with

${ }^{98}$ New Zealand Herald, 6 July 1935, p.12. 
tobacco and cigarettes throughout the war. It is difficult to determine the extent of the tobacco supplied to New Zealand troops in either the first or second world wars, as tobacco and cigarettes were distributed through both formal and informal channels. ${ }^{99}$ However it is evident that tobacco supply was sustained and on a large scale. From the outset of the second world war, New Zealand troops were supplied with tax-free loose tobacco and cigarettes sold through Army and Navy canteens. Tobacco was also a main component of care packages sent to troops through the Patriotic Funds Board, which also established a duty-free postal tobacco service allowing friends and family of serving men and women to place tobacco and chocolate orders with their local tobacconist. Tobacco and chocolate were bought duty free and were packaged and posted by volunteers (figure 20). In total the postal tobacco service dispatched a massive $34,500,500$ cigarettes and 54,200 lbs of tobacco to New Zealand military and navy serving during the second world war. ${ }^{100}$ New Zealanders patronised the funds heavily and, as in Britain, the donation of cigarettes 'provided a powerful symbol to rally support for the war effort. ${ }^{, 101}$ The New Zealand Government also supplied either 400 cigarettes or 16 ounces of tobacco per month to New Zealand prisoners of war (POW) interned in enemy camps. ${ }^{102}$ Beyond these official channels, tobacco was also supplied through private donations by friends and family members, and via organisations such as the Red Cross and the Young Men's Christian Association (YMCA). For example, Captain Hutchison's camp diary from Capua, Italy, where New Zealand troops were

\footnotetext{
${ }^{99}$ At different stages during both wars cigarettes may have formed part of official troop rations, however a selective analysis of ration schedules at Archives New Zealand do not mention cigarettes or tobacco. See Supplies - Returns - Rations - Actual number issued, 1918, AD, 1, 995, 50/595, Archives New Zealand, Wellington; Supplies - Rations- NZEF camps - Cost per head per day, 1918-1919, AD, 1, 994, 50/359, Archives New Zealand, Wellington; Mobilisation - ASC [Army Service Corps] 2nd line rations etc., 1941, AD, 1, 1253, 271/22/5, Archives New Zealand, Wellington. Note that some references to cigarette distribution in the official war histories refer to smoking as an ration, such as two ounces per week as part of the ration scale 'Food Ration Scale, Middle East, 1940', in T. Duncan M. Stout, New Zealand Medical Services in Middle East and Italy, Wellington, 1956, p.92, available from http://nzetc.org/tm/scholarly/tei-WH2Medi-c3-55.html, accessed 12 April 2009.

100 Department of Internal Affairs, New Zealand's patriotic war effort: 1939-1946, Wellington, 1946, p.18; New Zealand sent around 140,000 men and women to serve overseas in the second world war. See Ian McGibbon, (ed.), The Oxford companion to New Zealand military history, Auckland, 2000, p.484.

101 Elliot, Women and smoking since 1890, p.46.

102 Patriotic Funds - Postal Tobacco Scheme - For Prisoners of War, c.1943, IA, 1, 3072, 172/24/18, Archives New Zealand, Wellington. Note that POWs in Japanese Camps were not sent rations as it was unlikely that they would reach the desired recipient. Also note that in the official history, the tobacco allowance is stated as being 200 cigarettes (or equivalent) per month. In all 355,315 ounces of tobacco and 49,191,178 cigarettes are reported to have been sent to New Zealand men in prisoner of camps. Under the Hague convention, all prisoners of war were entitled to three ounces of tobacco per week. See Walker, p.69.
} 
based in 1942, documents the arrival of frequent Red Cross parcels primarily comprised of food and tobacco. ${ }^{103}$

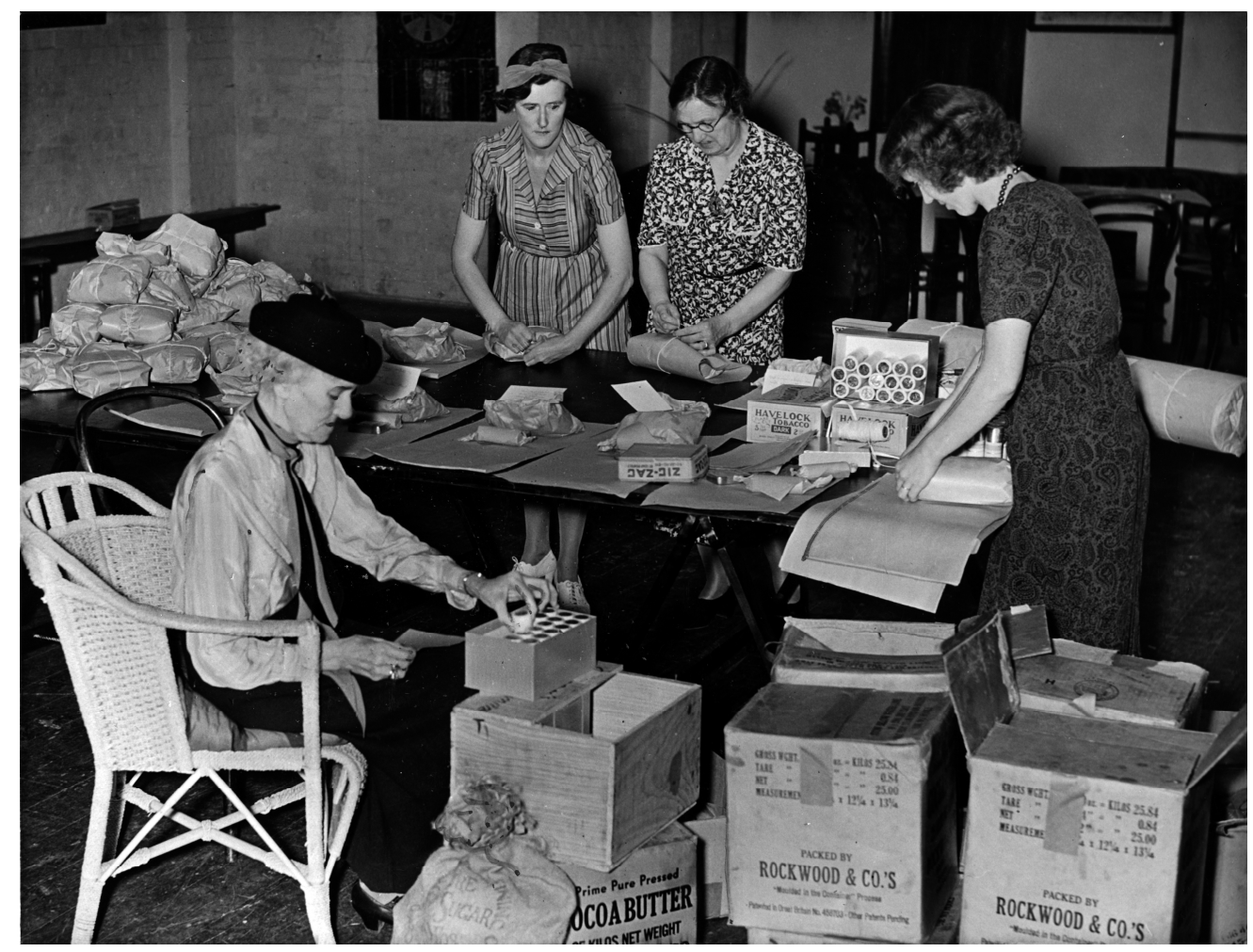

Figure 20

Women of the Overseas Seamen's Gift Committee packing items, including Zig-Zag papers and Havelock tobacco for New Zealand merchant seamen.

PAColl-9150-16, Evening Post Collection, ATL

The scale of the supply of tobacco is a powerful indicator of the centrality of smoking to New Zealand men by the 1940s, and of the importance of smoking to the military experience. From the perspective of tobacco manufacturers war provided a highly effective vehicle for the recruitment of new smokers. War effectively gave manufacturers free access to a large group of young consumers who were a key market for the take-up of smoking, and who, it was hoped, would continue to smoke after the war. Branding and brand names therefore became a central preoccupation of tobacco promoters in wartime. By the second world war there were considerably more brands available on the New Zealand market. Tobacco promoters had to work harder to ensure that their brand was prominent and that troops were being supplied with their tobacco.

\footnotetext{
103 Captain C. P. Hutchinson, 'Camp office Diary, 1 July 1942 - 7 February 1943', ABIA, W3918, 1, 1,
} Archives New Zealand, Wellington. 


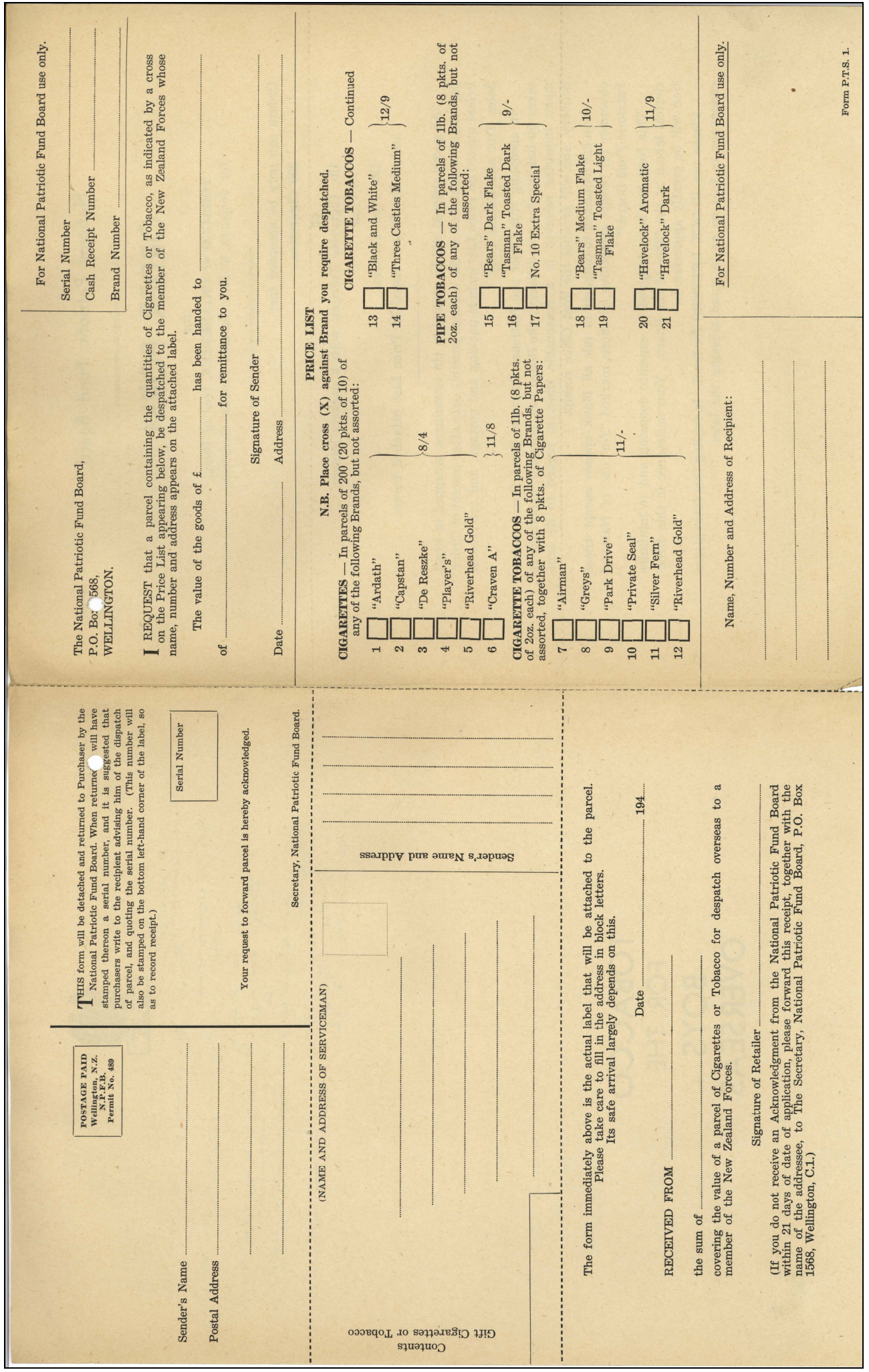

Figure 21

The cover for this order form reads 'Tobacco for the Boys overseas'. Organised by the Patriotic Funds Board during the second world war, the scheme allowed friends and family to place orders for the duty-free tobacco at their local tobacconist which would then be wrapped and dispatched by volunteers.

Patriotic Funds - Postal Tobacco Scheme - For Prisoners of War, c.1943, IA, 1, 3072, 172/24/18, Archives New Zealand 
Recruiting new consumers of tobacco was not new to the second world war but built on trends established in the first world war. It is evident from source material that a wide variety of brands of tobacco and cigarettes were also highly accessible to New Zealand troops in the first world war. Walter Nicholls, a New Zealander who served in the first world war, wrote a poem during the war recounting his experience of smoking the many different brands and types of tobacco available to him. An excerpt reads:

Say in your idle moments you should read the Daily Rag

You're almost sure to want a smoke presumably a "Flag"

And after bayonet exercise, with parries, points and jabs,

You'll find a great consolation in a puff of "Ogden's Tabs". ${ }^{104}$

Nicholls' poem goes on to offer numerous other examples of brands of tobacco of which he had constant supply. Bert Hughes, a Wellingtonian who served with the $32^{\text {nd }}$ reinforcements near the end of the first world war, also found that New Zealand troops were supplied with superior brands of cigarette to their British counterparts. He remembered that the 'tommies' had 'little wee cigarette[s], you'd have two or three draws and it was finished', whereas the New Zealand troops got 'Three Castles cigarettes...they were in a tin and they were beautiful cigarettes', which the New Zealanders saw fit to share with the 'poor old tommies. ${ }^{105}$ The fact that Bert Hughes remembered, over 70 years later, the specific brand which he favoured during the first world war, underlines the importance of brands and the massive incentive of the tobacco industry to push particular brand names within the military.

Tobacco supply remained plentiful following the first world war, with patriotic organisations continuing to distribute donations to returned servicemen and to injured men in hospitals or homes. Records of the Otago Provincial Patriotic Society document large quantities of tobacco and cigarettes being supplied to returned servicemen in Otago regional hospitals and mental institutions between 1916 and 1922. ${ }^{106}$ It appears that the supply and range of tobacco was steady enough that in some instances the Patriotic Society received complaints or requests from the hospitals. In 1919 the Patriotic Society received a letter from an ex-serviceman at the Seacliff Mental Hospital, requesting that the Society 'send Capstan instead of Three Castles as it smokes better

\footnotetext{
104 Walter Nicholls, 'Issue Cigarettes', Poems, 1914-1919, MS-Papers-5727, ATL, Wellington. 105 3"30, Interview with Herbert Thomas Hughes, interviewed by Nicholas Boyack, Jane Tolerton, 4 November 1989, OHInt-0006/38, World War One Oral History Archive, ATL Oral History Centre, Wellington.

${ }^{106}$ Record book of tobacco issued to ex-servicemen in individual hospitals, 1916-1922, AG-113/182, Otago Provincial Patriotic Council records, ARC-0514, Hocken Library, Dunedin.
} 
and is not so injurious to our health. ${ }^{, 107}$ However, in 1920 the Sister in charge of Waikari Hospital telephoned the society stating that the men 'would not smoke Capstan cigarettes.' The men would rather buy their own cigarettes than smoke the Capstans and 'would smoke nothing but Three Castles. ${ }^{108}$ These examples suggest that New Zealand troops were not passive recipients of tobacco donations but rather actively sought out brands and tastes which they had grown accustomed to over the war years. During the second world war the New Zealand High Commission in London surveyed New Zealand troops in prisoner of war camps, in order to find out how the government could better provide comforts for them. As part of the survey prisoners were asked what type of tobacco they preferred, allowing the High Commission to compile a list of each prisoner and their preferences. Most, like the men in the Otago hospitals, were quite specific, requesting for example, 'Craven " $\mathrm{A}$ ” Square Yellow', or a variety of brands, such as 'Players alternating with Capstan. ${ }^{109}$

The second key feature of tobacco promoters' agenda during wartime was to build a strong and overt association with positive elements of the war. The imagery of war and patriotism was a key feature of advertising during both the first and second world wars, and the lasting significance of the imagery of war is also evident in the content of advertisements through the interwar era. The makers of 'Army Club', 'Prince Charming' and 'Capstan' cigarettes and tobacco continued to draw on military imagery such as uniforms, rifles and ships. 'Army Club' repeatedly used the image of 'The Major' smoking a cigarette to reinforce the connection to war and military valour. ${ }^{110}$ An advertisement for 'Three Castles' from the 1930s made an even more direct connection - depicting a man dressed in a suit and hat, smoking a cigarette. A smaller image is inset showing a younger version of the man in military dress, also smoking a cigarette. The caption reads 'I still Roll-my-Own with Three Castles as I did in 1914' (figure 22). ${ }^{111}$

\footnotetext{
${ }^{107}$ A. L. Howie to Secretary of Otago Provincial Patriotic Society, 17 September 1919, Record book of tobacco issued to ex-servicemen in individual hospitals, 1916-1922, AG-113/182, Otago Provincial Patriotic Council records, ARC-0514, Hocken Library, Dunedin.

10821 June 1920, Waikari Hospital, Record book of tobacco issued to ex-servicemen in individual hospitals, 1916-1922, AG-113/182, Otago Provincial Patriotic Council records, ARC-0514, Hocken Library, Dunedin.

109 Allied Prisoners of War and Civilians in Enemy Territory, Parcels, Cigarettes and Tobacco For Personnel in Europe, 1941-1945, EA, 1, 662, 88/8/4, part 1, Archives New Zealand, Wellington. 110 Advertisement - Army Club, New Zealand Sporting and Dramatic Review, 1 April 1926, p.2. Early in 1918 the N.Z. Freelance published the 'Three Castles trench series', of advertisements, depicting both ablebodied and wounded soldiers enjoying 'Three Castles' cigarettes. See, for example, N.Z. Freelance, 18 January 1918, p.10; 25 January 1918, p.17; 15 February 1918, p.13.

111 Advertisement - Three Castles, New Zealand Herald, 3 April 1934, p.15.
} 


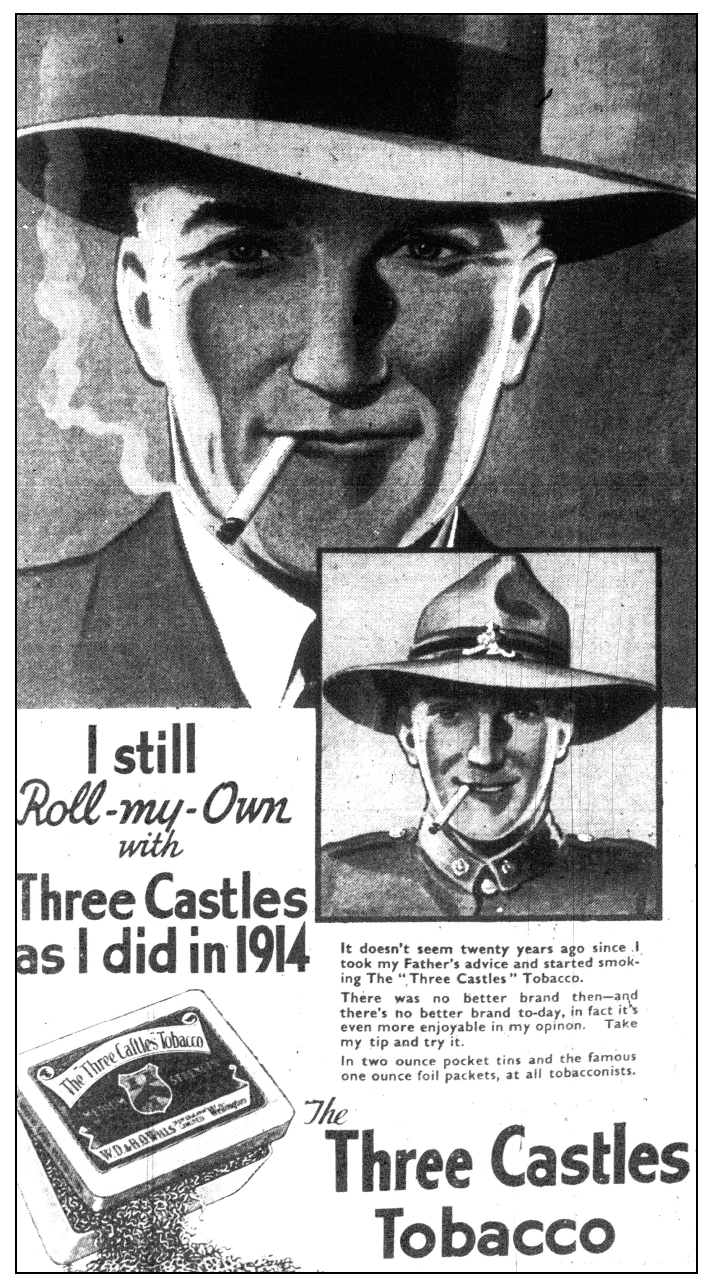

Figure 22

Advertising such as this 1934 'Three Castles' advertisement continued to draw on military symbols and messages through the 1920s and 1930s.

New Zealand Herald, 3 April 1934, p.15

During and after the second world war advertisers for all kinds of products continued to underline connections with patriotism and the war. In Britain during this period, even when a product was rationed or not available, 'major advertisers endeavoured to keep their names before the public. ${ }^{112}$ Analysis of the content and character of print advertisements in New Zealand over the war years, reveals that despite an overall decline in advertising, advertisers repeatedly drew on the imagery of war to promote brands such as 'Player's Navy Cut', 'Silver Fern', 'Major', 'First Lord', and 'Senior Service' - most using the image of smiling navy, army or airmen. 'Silver Fern' contended that their tobacco was smoked by 'worthy sons of New Zealand', picturing members of the army and air force happily smoking a cigarette together (figure

${ }^{112}$ Nevett, p.169. 
23). ${ }^{113}$ This advertisement is clearly directed toward friends and family on the home front who had the opportunity to choose which brand they wished to send to New Zealand servicemen via the Postal Tobacco Scheme. Other advertisements reinforced the idea of universality - one advertisement for 'De Reszke' omitted the smiling faces, simply placing two hats, a cigarette and hands offering a cigarette - 'for all service folk', suggesting that any one could imagine their face in that image (figure 24). ${ }^{114}$

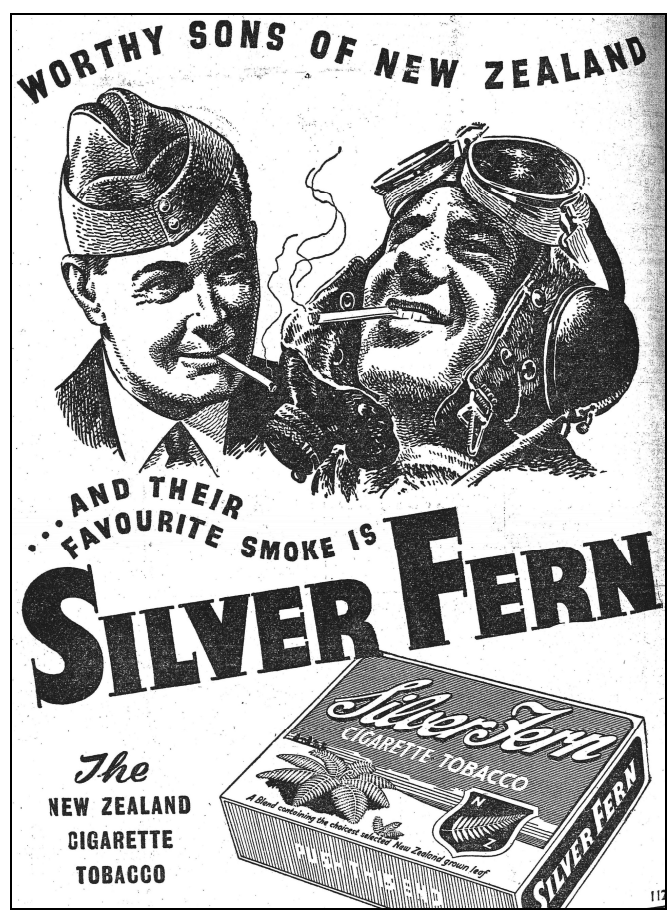

Figure 23

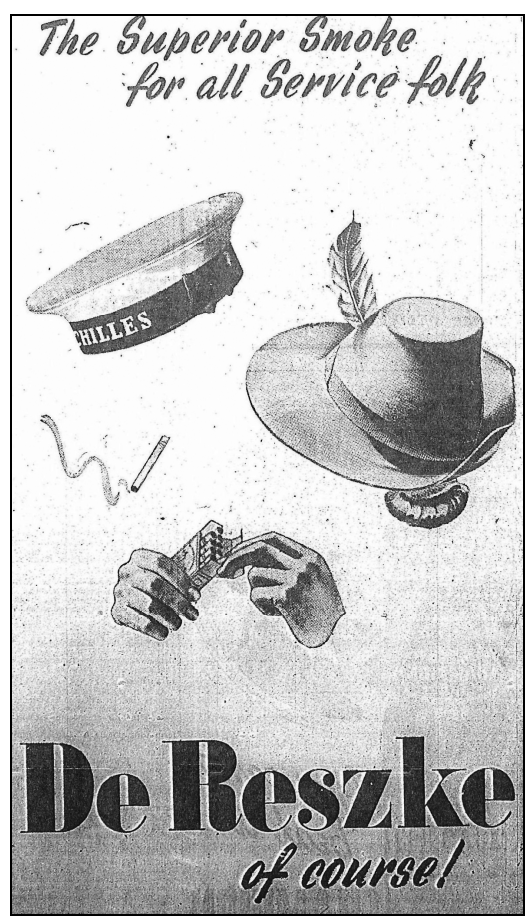

Figure 24

These advertisements from the second world war served as a reminder to family and friends to purchase tobacco via the postal tobacco scheme, through which both 'Silver Fern' and 'De Reszke' tobacco brands were available.

Beyond the tobacco industry's wider goal to ensure that its product was supplied and individual brands were reinforced to the New Zealand troops and the New Zealand public, it is also important to address the more specific claims or promises stressed by advertisers in wartime. How did this promotional context affect the spatial and gendered take-up and consumption of tobacco by men and women during the second world war? War was a key recruitment period for the tobacco industry and also provided a very different social and political climate - which served to shift and intensify the function of the cigarette. A key 'function' of smoking encouraged by

113 Advertisement - Silver Fern, Listener, 3 March 1944, p.40. See also, Advertisement - Silver Fern, Listener, 24 December 1943, p.40; Advertisement - Silver Fern, Listener, 7 January 1944, p.32.

114 Advertisement - De Reszke, The Press, 23 August 1940, p.9. 
advertisers during wartime was the role of smoking as a coping mechanism, serving to calm nerves, offering relaxation and refreshment. Smoking became a way of dealing with the increased physical and psychological pressures connected with war. In her history of the New Zealand home front during the second world war, Nancy Taylor asserts that the cigarette was 'widely accepted as a prop to wartime morale, soothing and companionable. ${ }^{115}$ The use of smoking as a coping mechanism was promoted as available to both men and women, military and civilian. The concept of entitlement, advanced in the discussion of smoking's connection to work, was intensified in wartime. 'War', therefore, as a special or unique circumstance, came at a crucial point in the rising trajectory of tobacco consumption in New Zealand. Within this rise, war served to consolidate and accentuate existing trends.

The construction of tobacco and cigarettes as a right or entitlement for New Zealand servicemen is most evidently seen in the massive and sustained supply of tobacco, ensured and supported by the tobacco industry, the government and the public. A series of images offer a more nuanced look at what smoking meant to military life beyond the grounds of entitlement. Firstly smoking was established as an integral part of leisure or time out for New Zealand soldiers - numerous photographs from the Department of Internal Affairs official war archive depict men relaxing and smoking such as the portrait of R. Dysart in the Western Desert in Northern Africa in 1942 (figure 25). ${ }^{116}$ The contemplative nature of the photograph is reminiscent of a card designed by William Frederick Bell during the first world war for soldiers to send home as a Christmas card to their families in 1917 (figure 26). ${ }^{117}$ The card depicts a soldier leaning on a milestone reading 'France to New Zealand 13,000 miles', while holding his pipe; the smoke from the pipe has formed a large smoke cloud in which appears an outline of New Zealand and the word 'Aotearoa', obscuring the destructed buildings behind him. ${ }^{118}$

\footnotetext{
${ }^{115}$ Nancy M. Taylor, The New Zealand people at war: the home front volume II, Wellington, 1986, p.768, available from http://nzetc.org/tm/scholarly/tei-WH2-2Hom.html, accessed 13 September 2008.

${ }_{116}$ New Zealand soldier R. Dysart, Western Desert, North Africa, c.6 November 1942, DA-02713-F, ATL, Wellington.

117 William Frederick Bell, Aotearoa, Greetings card, 1917, Eph-A-CARDS-Christmas-WWI-1917-01, ATL, Wellington.

118 Ibid.
} 


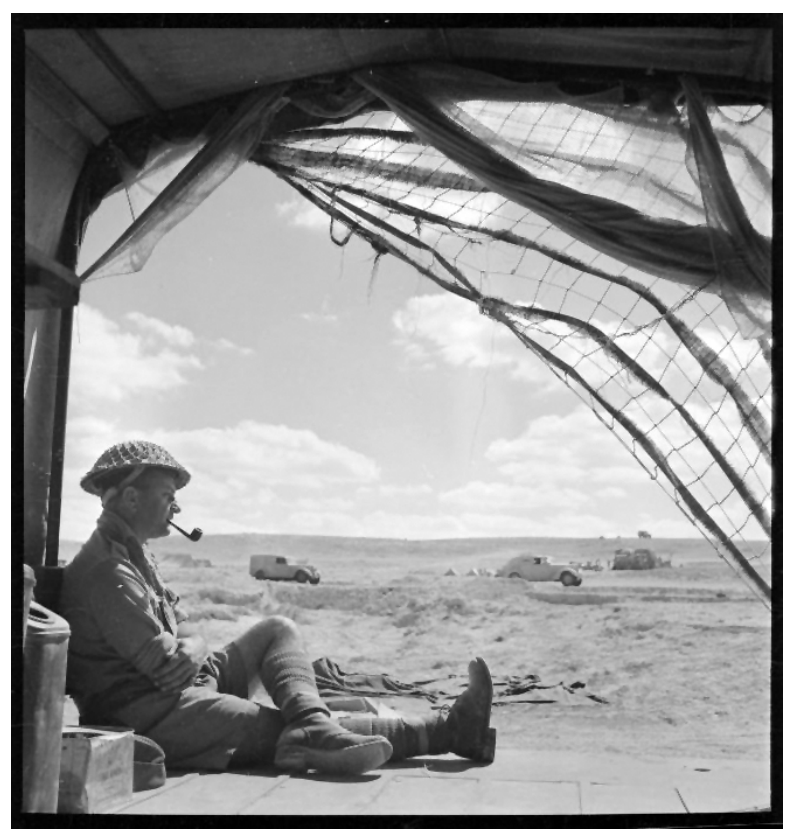

Figure 25

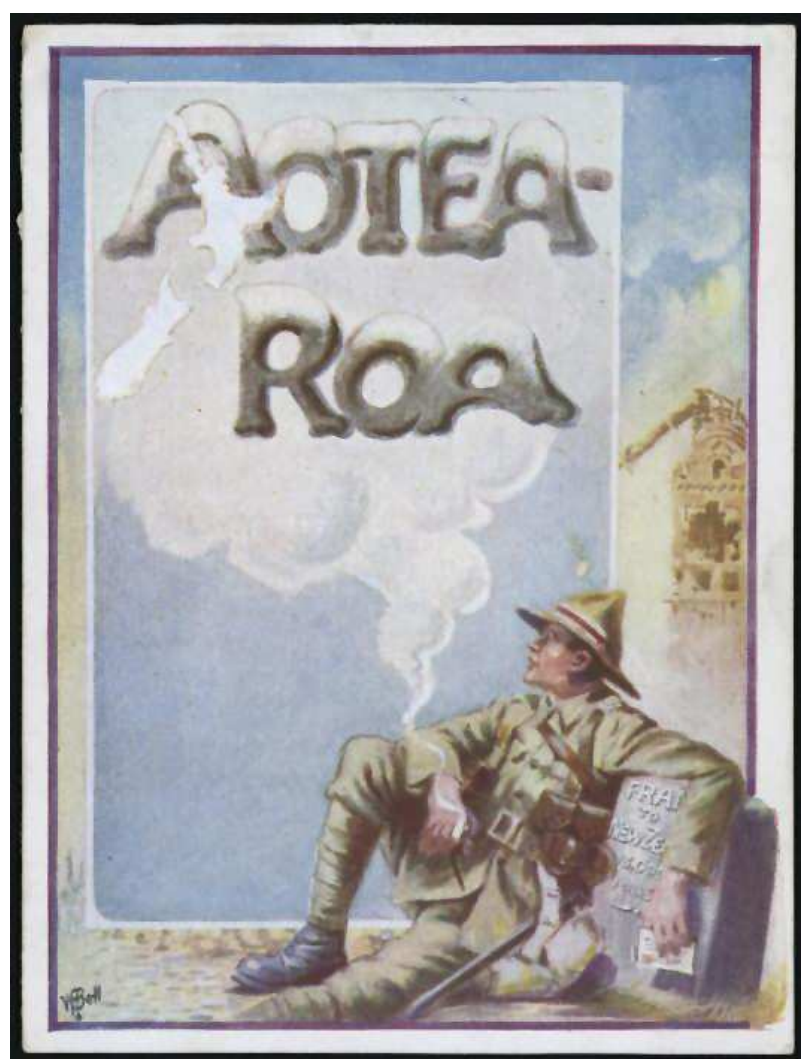

Figure 26

This 1942 image of New Zealand soldier R. Dysart in the Western Desert, North Africa during the second world war (figure 25) parallels an earlier postcard designed by William Frederick Bell during the first world war (figure 26). Both images evoke an contemplative state of mind connected with smoking during time out during wartime, with Bell's soldier imagining home, Aotearoa, floating in the cloud of smoke from his pipe. 
Smoking and cigarettes were also central to notions of 'mateship' and military masculinity. Two images powerfully remind us of the function that the sharing and offering of cigarettes held as a wartime ritual. The first is similar to Bell's postcard - a propagandist YMCA postcard from the second world war, depicting four soldiers (two New Zealanders and two Australians) sharing a smoke during their time out (figure 27). ${ }^{119}$ In the foreground two soldiers laugh, chat and smoke - behind them a New Zealand soldier lights his cigarette from an Australian soldier's cigarette, and in the background other soldiers are relaxing together around a table. If it were not for the uniform, you would not know that it is wartime; all are clean shaven, jovial and happily smoking. A 1943 photograph, again from the Department of Internal Affairs archive, of New Zealanders serving in the Pacific perhaps more accurately depicts the reality of war. In figure 28 the New Zealand soldiers look considerably rougher - unshaven, unbuttoned collars, and perched on the ground in the bush. ${ }^{120}$ One soldier draws on his cigarette, lighting it from his fellow soldier's cigarette. While these are essentially non-commercial examples, these four images do form part of our understanding of the promotional context of tobacco during wartime. These images were sanctioned and endorsed by wartime governments with the agenda to encourage and support wartime morale. The importance of relaxation and the relief of nerves was a key function of smoking for soldiers and these images served as a reminder for the public to support patriotic funds which distributed such comforts.

\footnotetext{
119 Young Men's Christian Association: Cobbers/Thompson - Post-card, Red Triangle Series, On active service, 1939-1945, Eph-A-WAR-WII-1940s-04, ATL, Wellington.

120 World War II Soldiers in the Pacific, c.1943, 1/2-041645-F, ATL, Wellington.
} 


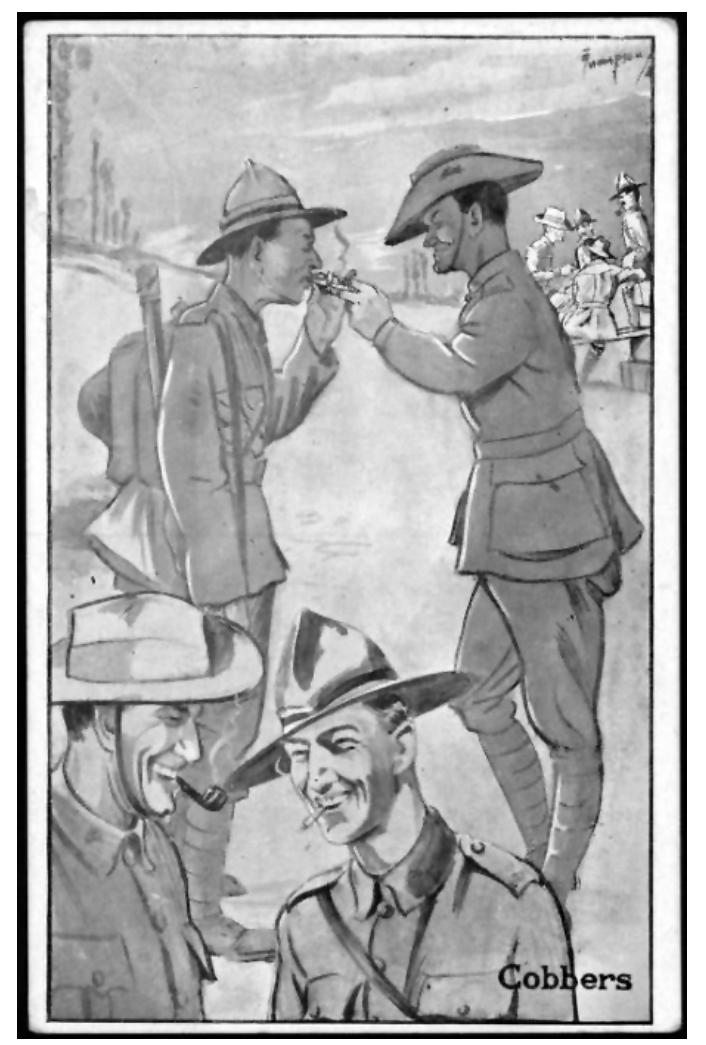

Figure 27

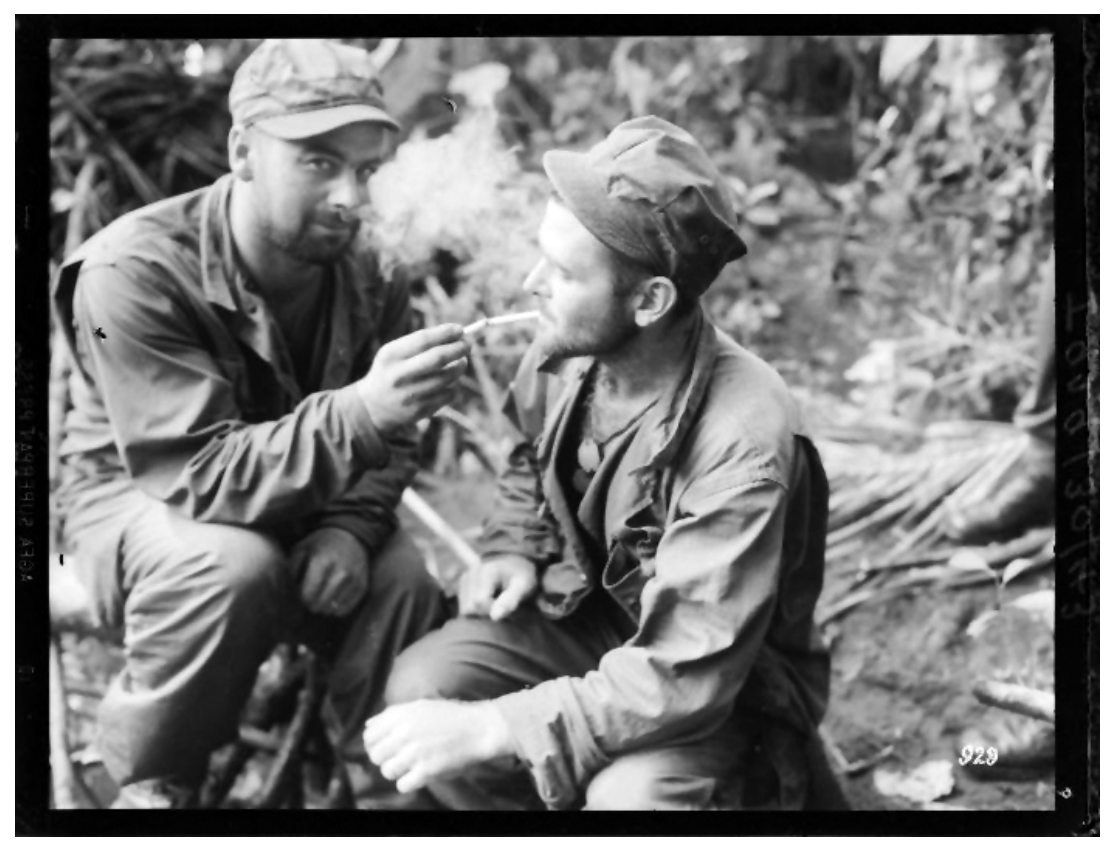

Figure 28

Figure 27 is a postcard from the YMCA's second world war Red Triangle Series. Figure 28 depicts two unknown New Zealand soldiers stationed in the Pacific in 1943. Both images underline the cigarette's role as something to be offered or shared among troops on active service.

Eph-A-WAR-WII-1940s-04, ATL; 1/2-041645-F, ATL 
For New Zealanders dealing with the stresses of war on the home front, smoking was also reinforced or amplified during wartime as a right or entitlement. During the second world war New Zealanders were working much harder as well as dealing with the absence of loved ones. Smoking was reassuring and a part of continuity and normalcy in a time of threat and insecurity. Smoking worked as an aid for relaxing and calming nerves. In Britain the 'establishment of tobacco consumption as a legitimate need for women as well as men' was a significant factor contributing to increases in women's smoking over the 1940s. ${ }^{121}$ Women too were encouraged to take up smoking for both 'social reasons' and to 'assist in coping.' ${ }^{22}$ A similar trend was evident in Australia where the tobacco industry specifically targeted everyday citizens dealing with the stresses of war in their own lives, emphasising the 'soothing qualities of tobacco.' 123

Female involvement on the home front is also central to our understandings of tobacco industry efforts at the recruitment of new smokers during the second world war. In New Zealand this notion of entitlement based on a physical and psychological need for smoking was intensified by greater female participation in paid work. Increased female participation in paid work during the 1920s and 1930s discussed earlier in this chapter acted as a precursor to the widespread use of women to fill employment vacancies during the second world war. From March 1942 New Zealand women found themselves conscripted, or 'manpowered' into essential industries (as discussed in connection to the tobacco industry in chapter one). However, as Deborah Montgomerie reminds us, the widespread use of women during the war was an emergency and temporary measure - women were only holding jobs for men while they were away at war. ${ }^{124}$ Yet these employment opportunities, coupled with the need to deal with the stresses of war, worked as a catalyst for women to assert greater agency over their consumption decisions. In the wartime climate tobacco was a legitimate and necessary item upon which to spend discretionary income, that is - if they could get access to a supply of tobacco.

In Australia the Commonwealth Director of Tobacco found that over the interwar and second world war period, women smokers were responsible more for changing the 'type and quality of tobacco' consumed 'than they were for raising the

\footnotetext{
121 Tinkler, Smoke signals, p.64.

122 Ibid., pp.63-4.

123 Tyrrell, Deadly enemies, p.40.

${ }^{124}$ Deborah Montgomerie, 'The limitations of wartime change: women war workers in New Zealand', New Zealand Journal of History, vol. 23, no. 1, 1989, p.72.
} 
overall consumption. ${ }^{125}$ This trend is also evident in New Zealand where the difference in consumption between tailor-made cigarettes and loose tobacco for roll-your-own and pipe smoking over the 1940s is a powerful indicator signalling that women's consumption increased. In 1940 the percentage of manufactured or tailor-made cigarettes accounted for just 30 per cent of total consumption, this level had been consistent from around the mid-1930s after recovering from a decline during the depression. During the war however, this figure rose to 39 per cent of total consumption by 1945, and continued to rise quickly in the post-war years to around 46 per cent by 1950 and 52 per cent by $1955 .{ }^{126}$ By the end of the war Terence McCombs declared in parliament that 'cigarette smoking, these days, was distinctly feminine. Smoking among women had become so common that it could fairly be said that it was no longer a manly thing to smoke. ${ }^{, 27}$

Tobacco manufacturers were particularly keen to promote female wartime workers as people who were legitimately entitled to smoke due to their participation in the war effort and need for refreshment and relaxation. Uniformed women, and especially nurses, were powerful symbols of the female connection to war. A 1941 advertisement for 'Capstan' is typical of such advertising - it depicts a young nurse in the foreground with a row of occupied hospital beds in the background. The nurse's hand holds a 'Capstan' cigarette at the ready - declaring 'A Job Well Done, And it's Time for a Capstan' (figure 29). ${ }^{128}$ This slogan echoes Alfred Cockayne's vision of an image of a female smoker such as a nurse who finds 'more than pleasure in a cigarette after a job of hard work. ${ }^{129}$ A more realistic depiction of Cockayne's vision for a female smoker 'not of the picture-star type', though still reflecting the central message of tobacco promotion through the war, is John Pascoe's photograph of 'land girl' Carol Sladden (figure 30). Taken in the Hawke's Bay in 1943 as part of Pascoe's collection as home front photographer, Sladden is shown perched on a fence, dressed in overalls and is lighting a cigarette in her cupped hands. Pascoe's image epitomises the essence of tobacco advertisers' construction of the female wartime worker as entitled to a rest, to a

\footnotetext{
125 Cited in Tyrrell, Deadly enemies, p.114.

${ }^{126}$ Laugesen, Tobacco statistics 1991, p.12.

127 Terence McCombs, NZPD, vol. 271, 14 November 1945, p.421.

128 Advertisement - Capstan, Listener, 20 June 1941, p.15. See also, Advertisement - Capstan, Listener, 16 May 1941, p.48.

${ }^{129} \mathrm{Mr}$ A. H. Cockayne (Director General of the Department of Agriculture) to Mr Wise (Secretary of the Tobacco Board), 1 September 1939, Exhibitions, Films and Displays (c), 1937-1959, TB, W2303, 3, 1/18, Archives New Zealand, Wellington.
} 
quiet pleasurable moment in which to enjoy a cigarette as a reward for her work which was directly connected to the war effort. ${ }^{130}$

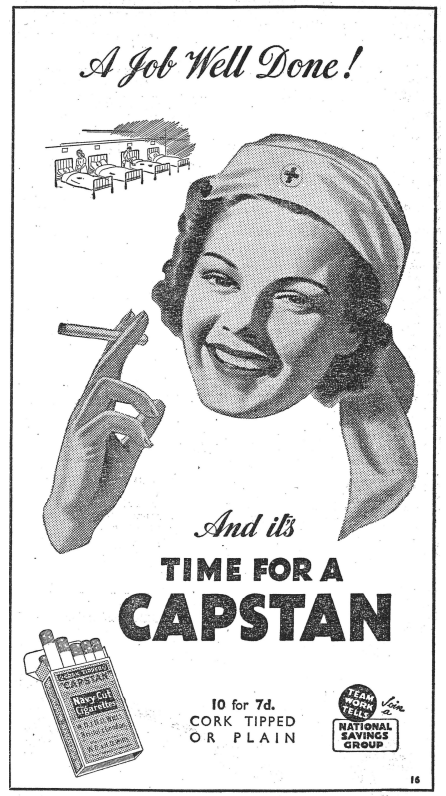

Figure 29

During the second world war tobacco advertisers frequently used the image of a nurse to characterise female smokers.

Listener, 20 June 1941, p.15

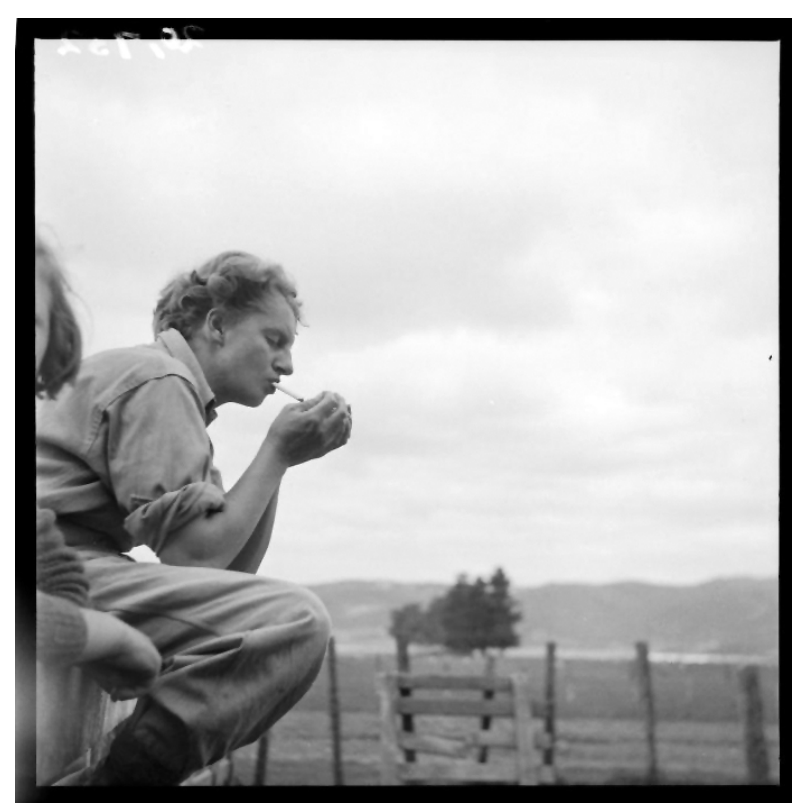

Figure 30

'Land girl' Carol Sladden enjoying a cigarette during a break from work on a farm in Mangaorapa, Hawke's Bay.

1/4-00732-F, John Pascoe Collection, ATL

${ }^{130}$ For a wider discussion of this image and the context of Sladden's work and leisure as a land girl, see Deborah Stowe, 'John Pascoe's photography of the New Zealand home front during the Second World War: an historical analysis', MA thesis in History, Victoria University of Wellington, 2006, pp.78-80. 
Alfred Cockayne's request for photographs for the Centennial Exhibition in 1939 showing tobacco consumption rather than manufacture epitomises the core messages of the tobacco industry through the period 1920-1962. Cockayne stressed 'appreciation' of tobacco and an almost universal entitlement to smoking, aligned alongside participation in paid employment. The gendered expansion of smoking is also a key feature of his request - Cockayne was keen to stress equal entitlement to tobacco by both men and women. Cockayne was an agent of a government which strongly backed the tobacco industry and given the revenue generating potential of the product, had a vested interest in the sustained and increased consumption of tobacco. This chapter has shown that the tobacco industry's promotional activities successfully propelled the spatial and gendered expansion of smoking in New Zealand through the period 1920-1962. Advertising through this period was widespread and pervasive, stressing a core message of universality - that smoking could and should be practised anywhere by anyone. Tobacco was a product which needed to be promoted and the aggregate rise in consumption through the mid-twentieth century confirms that the industry's promotional activities were highly effective in persuading a mass of consumers to become smokers. For the increasingly prosperous tobacco industry, the promotional opportunities presented by the second world war came at an crucial point in the rising trajectory of tobacco consumption in New Zealand. War provided a useful context in which to consolidate existing trends which constructed smoking as a legitimate need to relieve nerves and to relax, as an entitlement or recompense for work, and as a powerful symbol or display of patriotism. The work and economic opportunities presented by the second world war coupled with the promotional impetus of the tobacco industry also acted as a catalyst for increasing female consumption over the war years. Above all tobacco promotion established the habit as a central economic, social and cultural feature of twentiethcentury life. 


\section{Chapter Three}

\section{'As harmless as fresh air'? arguments and discourses around smoking c.1900-1962 ${ }^{1}$}

In May 1937 the Auckland Education Board imposed a ban on teachers smoking in the schools in its region. For six long months in the lives of the affected school teachers, they were not allowed to smoke in classrooms, in the playground or in their staff room. ${ }^{2}$ The regulation was imposed ostensibly as a precaution against the fire danger posed to the old wooden school buildings. Reaction to the ban was rapid and widespread. In the 1930s the Auckland Education Board's jurisdiction covered almost the entire top half of the North Island and both the Board and the Education Department received numerous complaints from individual teachers, school committees and teachers' organisations opposing the ban. ${ }^{3}$ When the Minister of Education, Peter Fraser, was interviewed by staff at Matamata District High School in September 1937, the staff asked for his help to resolve the smoking issue. Fraser appeared aware that the ban was initially imposed because of the fire danger, yet saw fit to pose other questions about the wisdom of teachers smoking on the job. He asked:

Had smoking now become a moral question? Was it a good thing for children to see teachers in the playground with cigarettes in their mouths? Did it give a feeling of efficiency and standing for the children to live up to? ${ }^{4}$

The moral influence of smoking on children appeared to be the primary concern, yet Fraser also acknowledged that the ban 'would be beneficial from a health point of view for those teachers who smoked too much. ${ }^{5}$ Fraser does not offer evidence to back up his moral or health musings, other than his own opinion. Official opposition to smoking was not clearly enunciated at this time and the ban was eventually rescinded in October 1937.

\footnotetext{
${ }^{1}$ Advertisement - Toasted Tobacco, The New Zealand Railways Magazine, vol. 9, issue 1, 2 April 1934, p.21, available from http://nzetc.org/tm/scholarly/tei-Gov09 01Rail-t1-body-d7-d6.html, accessed 11 April 2009.

2 Teachers. General. Smoking in Schools, 1937-1947, E2, 1947/53d, 24/1/130, Archives New Zealand, Wellington.

${ }^{3}$ Ibid.; Weekly News, 13 October 1937, p.21.

${ }^{4}$ Education Department Ministerial, 17 September 1937, Teachers. General. Smoking in Schools, $1937-$ 1947, E2, 1947/53d, 24/1/130, Archives New Zealand, Wellington.

${ }^{5}$ Ibid.
} 
As chapter two has shown, by the mid-1930s smoking was pervasive in all areas of New Zealand society, including workplaces, and was becoming increasingly common for women as well as men. This chapter seeks to understand the range and nature of debates and discourses around smoking from 1900 to 1962 - examining time periods when smoking was uncontroversial, and when it became something to be argued about. In particular the chapter asks: when did opposition to smoking occur? What was the scale of opposition and what reaction did it receive from smokers? Most importantly, who was opposed to smoking, what were the grounds for their opposition, and how did this opposition correspond with wider public discourses around smoking? The 1937 Auckland teachers ban highlighted a range of objections to smoking - chief among them were concerns with fire danger, along with the moral question of whether children should see their teachers smoking, and whether cutting back would benefit the health of the teachers. While this incident is indicative of the grounds on which smoking was opposed, it was highly anomalous for its time and was relatively small in magnitude; incidences of opposition were much more common at the very beginning and end of the period under investigation. Moral objections to smoking were more prominent in the early years of the twentieth century but largely disappeared during the first world war. Health discourses against smoking did not emerge until much later near the end of the 1950s and were crystallised in 1962 when the RCP released their report Smoking and bealth. Between these two periods, apart from isolated incidents such as the 1937 teachers ban, opposition to smoking was almost entirely absent. Through this middle period tobacco use was largely seen to be uncontroversial and normative, and discourses around smoking lacked a distinct anti-smoking rhetoric.

The earliest organised anti-smoking campaigns reached their height in New Zealand in the period from the turn of the twentieth century to the beginning of the first world war. The campaign against smoking was primarily propagated in this period by the Women's Christian Temperance Union (WCTU) and the Salvation Army. The WCTU operated in New Zealand through a national executive and local chapters. Alongside their central temperance reform activities, departments were responsible for the many and varied additional concerns of the Union such as 'temperance literature, juvenile work, prison work, social purity, Sunday school activity, dress reform, franchise and 
legislation.' The 'narcotics' department dealt with tobacco use. ${ }^{6}$ Annual reports by departmental superintendents in the White Ribbon - the official organ of the WCTU give some indication of the union's activities regarding tobacco use in New Zealand. In 1913 Annie Wright, superintendent of narcotics, reported that literature on smoking from the Salvation Army had been read at meetings around the country. ${ }^{7}$ This literature was frequently republished in the White Ribbon. By 1916 however, Wright regretted that she had 'very little to report' on her department's progress over the year - the only notable achievement being that the 40 member strong Ngaere chapter in the New Plymouth region had formed a 'Non-Smoking League' and had managed to 'secure pledges among men and boys. 8

The Salvation Army's anti-smoking activities were also concentrated in the years preceding the first world war. In 1910 New Zealand leaders of the Salvation Army followed their Australian counterparts by establishing an 'Anti-smoking and Gambling League." At its inauguration the League (which initially excluded women and girls), signed up about 'three dozen lads', who were required to sign a pledge stating that not only would they not smoke themselves, but also that they would do everything in their power to dissuade others from gambling and smoking. ${ }^{10}$ Throughout that year the Salvation Army distributed pledge cards and buttons to the League's members. Meetings were held throughout New Zealand in 1910 attempting to spread the antismoking and gambling message. At a Taumarunui meeting, where League numbers reached 31, for example, Dr Howard gave a presentation to boys on the 'evils' of the twin vices - smoking and gambling, showing 'very plainly the ill effects that smoking has upon the human system. ${ }^{11}$ At other meetings boys (and girls - who were eligible for membership from July 1910) submitted essays on the topic to essay competitions. ${ }^{12}$ In July 1910 the Salvation Army published a whole issue of $W$ ar Cry dedicated to the antismoking and anti-gambling message, reproducing national and international literature on smoking and gambling, testimony from reformed smokers, athletes and from Salvation Army members. ${ }^{13}$

\footnotetext{
${ }^{6}$ Raewyn Dalziel, 'New Zealand Women's Christian Temperance Union', Anne Else (ed.), Women together: a bistory of women's organisations in New Zealand: nga ropu wabine o te motu, Wellington, 1993, p.72.

7 White Ribbon, 18 March 1913, p.13.

8 Ibid., 18 April 1916, p.24.

${ }^{9} \mathrm{War} C r y, 26$ March 1910, p.6.

${ }^{10}$ Ibid., 26 March 1910, p.6.

${ }^{11}$ Ibid., 11 June, 1910, p.2.

12 Ibid., 23 March 1912, p.6.

13 Ibid., 16 July 1910.
} 
It is important to note the very small scale of the anti-smoking campaigns; reports of participation were restricted to small, isolated meetings where attendance rarely exceeded 50 people. Anti-smoking activities were also subsidiary to these organisations' main concern with temperance reform. Temperance reform was a far more prominent and publicly fought issue which achieved major success in regulation through this era with the passage of restrictive laws. ${ }^{14}$ Anti-gambling campaigners also achieved some success in this period, an amendment to the Gaming and Lotteries Act in 1910 saw that bookmakers were banned from $1911 .{ }^{15}$ Anti-smoking activities failed to gain the traction that the temperance campaigns did. One reason for this might be that tobacco was seen as much less of a threat to 'social arrangements' than alcohol; alcohol and drunkenness had a much greater capacity to provoke violence, desertion and social upheaval. ${ }^{16}$ The only real success of the pre-first world war anti-smoking campaigns was the passage of the Juvenile Smoking Suppression Act, 1903, which legislated against the sale of tobacco to young people. The initial fervour with which the anti-smoking campaigns began was already in decline by the first world war. Yet, however marginal, the presence of these early campaigns does provide a useful indication of the nature of the opposition to smoking at a time when New Zealand was on the cusp of a major rise in tobacco consumption.

What then were the grounds for the early lobbyists' objection to smoking? Primarily the campaigners argued that smoking was habit forming. Lieutenant Squire Nicholson of the Salvation Army likened the smoking habit to a form of 'modern slavery', citing James II's deathbed adage 'there is no slavery like sin. ${ }^{, 17}$ Tobacco was seen to have power or control over the body and a loss of self-control signified weakness of character. Nicholson argued that 'habits produce habits; they increase in number and power. ${ }^{18}$ The habitual nature of drinking, smoking and gambling were viewed as interlinked, once a person had fallen to smoking for example, they were more vulnerable to other temptations such as drinking. Campaigners objected to habit forming substances because they signified a loss of control over the mind, the body, and crucially, the will. The habit took hold and prevented a person from leading a pure and good life. Another key objection to smoking was the wasteful expenditure of money on a useless habit. While tobacco may not have been overly expensive in the early

\footnotetext{
${ }^{14}$ Christoffel, pp.32-44.

${ }_{15}$ David Grant, On a roll: a history of gambling and lotteries in New Zealand, Wellington, 1994, pp.89-90.

${ }^{16}$ Walker, p.42.

${ }^{17}$ War Cry, 16 July 1910, p.2.

18 Ibid.
} 
twentieth century, the argument was more about the fact that young men should spend their money more wisely. The $W$ ar Cry argued that 'no man, whether he be rich or poor can really be justified in wasteful and selfish expenditure. ${ }^{19}$ Spending money on 'vice' and sin such as drinking, smoking and gambling was seen to be a 'wilful and wicked squandering of money. ${ }^{20}$ Thrift was a virtue much more closely aligned to morality.

Campaigners also objected to smoking because it involved a substance entering and threatening the purity of the body. Tobacco was seen to be a 'poisonous mixture' which polluted the body. ${ }^{21}$ This idea paralleled a key temperance objection to alcohol that it was a 'source of pollution' which threatened the sanctity of the body as a temple of the Holy Spirit. ${ }^{22}$ The WCTU's quest for social purity also involved a campaign to ban alcoholic wine in church - social purity 'demanded the total prohibition' of alcohol and other drugs which polluted the body and the mind. ${ }^{23}$ This idea of 'polluting' by poisons was the key basis of medical opposition referenced by the WCTU and the Salvation Army. Health arguments were not backed by systematic medical research in this early period, yet medical doctors were still frequently called upon to present health risks associated with cigarette and pipe smoking. In Lawrence, Otago, in 1913 Dr

Sutherland gave this general argument against smoking:

It really however, injured a man physically, mentally and morally.

The extent of that injury is difficult to say; but in any form there was no good in it, in fact it was altogether harmful. ${ }^{24}$

Other doctors argued against existing positive health claims which might have been in circulation. For example doctors in 1910 disputed the idea that smoking worked as a treatment for tuberculosis, finding that germs survived on the end of a cigarette that a 'consumptive young man' had been smoking. ${ }^{25}$ Some doctors also argued that tobacco led to insanity and stunted growth. ${ }^{26}$ In comparison to the health discourse which emerged at the end of the study period in the 1950s, medical opinion was varied and more generalised in this earlier period. The $W$ ar $C r y$ was particularly concerned to repeat views such as Dr Sutherland's which supported their position on smoking.

\footnotetext{
${ }^{19}$ Ibid., p.11.

${ }^{20}$ Ibid., p.4.

${ }^{21}$ White Ribbon, 18 March 1913, p.13.

22 Phillida Bunkle, 'The origins of the women's movement in New Zealand: the Women's Christian Temperance Union 1885-1895', Phillida Bunkle and Beryl Hughes, (eds.), Women in New Zealand society, Auckland, 1980, p.68.

${ }^{23}$ Bunkle, pp.63, 70.

${ }^{24}$ War Cry, 5 July 1913, p.6.

${ }^{25}$ Ibid., 16 July 1910, p.3.

${ }^{26}$ Ibid., 18 March 1919, p. 2; 18 October 1912, p.7.
} 
With their core objection to the 'habitual' nature of smoking, anti-smoking campaigners focused their attention and activity on young men in order to catch them before they gave in to any of the vices and got caught up in the 'habit' spiral. This gendered focus occurred in part because of the nature of the wider work which the Salvation Army and the WCTU were engaged in. The Salvation Army in particular worked with people at the fringes of society: alcoholics, homeless people and derelicts. On a daily basis they witnessed the effect that alcohol and the squandering of money on gambling and tobacco wreaked on these people's lives. Tighter regulation of substances such as alcohol and tobacco and the habits associated with them would have a huge effect on the people they worked with. Stories were published in the $W$ ar Cry detailing the deleterious effects that loss of control and money had on men - leading to poverty, violence and dereliction. As Sarah Thomson argues in her study of the Juvenile Smoking Suppression Act, 1903, smoking was also seen to be a trigger or habit which led young men, in particular, to antisocial behaviour and juvenile delinquency. ${ }^{27}$ These objections were, however, not overly prominent in the early twentieth century. The first world war provided a massive impetus for increased smoking take-up, extinguishing any smouldering embers of anti-smoking rhetoric in these early years.

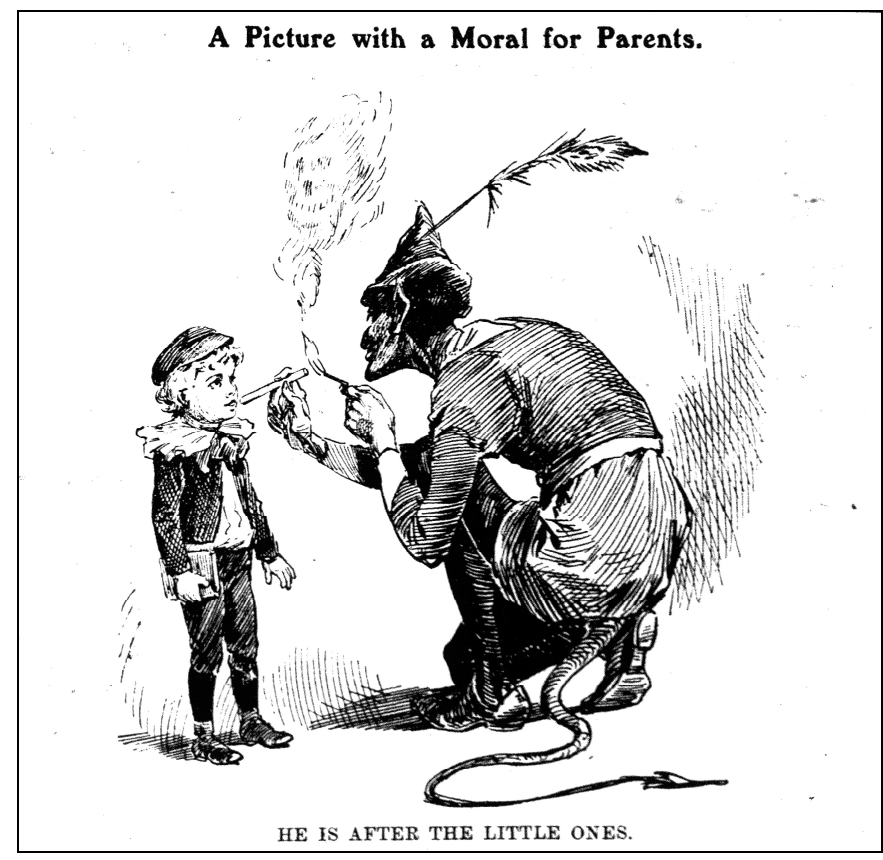

Figure 31

This cautionary image of the devil lighting a cigarette for a young boy appeared in the 'AntiSmoking and Gambling' edition of the War Cry in 1910.

$$
\text { War Cry, } 16 \text { July 1910, p.5 }
$$

${ }^{27}$ Thomson, 'Evils of the fragrant weed', pp.9-12. 
The chief reason that anti-smoking campaigners lost influence can be seen in wartime smoking practices and rhetoric which connected smoking with notions of patriotism and military masculinity. In a sense, the first world war served to flip the anti-smoking message on its head; the initial argument had been that smoking resulted in stunted growth, and moral and mental degeneracy, yet during the war years smoking was heralded as a nerve relaxant central to wartime service. The organisations which had been so adamantly opposed to smoking before the war had to (like many other New Zealanders) align their work more closely with the war effort. In 1910 the Salvation Army published articles, letters and testimonials against smoking, yet in the first world war was actively involved in promoting and distributing tobacco to troops. Bert Hughes, a New Zealander who joined the army towards the end of war, arrived in France early in 1918. Hughes recalled a particular Salvation Army officer, Brigadier Walls, who used to come along the parapet of the trenches in the afternoons, distributing 'cigarettes, chocolate, and everything. ${ }^{, 28}$ Hughes appreciated the attitude of the Salvation Army who 'treated you like a gentleman', because they were aware of the importance of the role that New Zealand troops were playing in the war. ${ }^{29}$ Such actions directly contradicted the strong rhetoric of the organisation just eight years earlier. In Canada and Britain historians have noted that the first world war silenced early antismoking campaigns. New Zealand followed a similar pattern. Anti-smoking lobbyists were in a much weaker position to resume their campaigns after the war. The campaigns were not as pronounced in New Zealand and thus their demise was less noticeable.

The significance of smoking as a 'prop' to wartime morale and as a relaxant both on the battlefield and the home front for New Zealanders has been discussed in the previous two chapters. The Australian Medical Services found that in the first world war tobacco and alcohol were perceived to be ways of relieving stress 'and as such the medical authorities sanctioned them as a preventive of neurosis. ${ }^{30}$ Accordingly, smoking was permitted for returned servicemen in New Zealand hospitals and these men continued to be the focus of the patriotic provision of tobacco and cigarettes both during and following the first and second world wars. ${ }^{31}$ Before the first world war the

\footnotetext{
28 30.00", Interview with Herbert Thomas Hughes.

${ }^{29} 28.00$ ", ibid.

${ }^{30}$ A.G. Butler, Official history of the Australian Army Medical Services in the war of 1914-1918, Canberra, 1943, p.138, cited in Walker, p.55.

31 See for example, 'Record book of tobacco issued to ex-servicemen in individual hospitals', 1916-1922, AG-113/182, Otago Provincial Patriotic Council records, ARC-0514, Hocken Library, Dunedin.
} 
New Zealand Army's medical examinations on men enlisting for service make no mention of smoking or its effect on physical fitness. ${ }^{32}$ During the war the military medical services began to express some concern at the rate of tobacco consumption by New Zealand servicemen. While smoking was perceived to be a relaxant for nerves, some doctors in New Zealand hospitals found that soldiers' nerves could in fact have been exacerbated by smoking. As early as 1915 the Medical Superintendent of Christchurch hospital, Dr Fox, argued that the 'general public make a practice of showering gifts of cigarettes upon the sick and wounded men', but that the result is that 'some of the soldiers are absolute cigarettes fiends and it has really become quite a serious matter. ${ }^{33}$ About a month later James Allan, Minister of Defence received a letter from C.E. Statham, MP for Dunedin Central, passing on the concerns of Reverend Vincent Bryan King who wanted the minister to know that many returned servicemen were 'most emphatic about the harmful effects of the continuous cigarette smoking."34 While King might be overstating the degree of concern among returned servicemen, particularly among those in hospitals who received a steady supply of donated cigarettes, the Minister agreed that smoking was 'overdone' but that there was little that could be done about it. In 1921 Donald McGavin, military director general of the New Zealand Medical Services, commented publicly that he thought men in military hospitals should stop being issued with cigarettes and tobacco. ${ }^{35} \mathrm{McG}$ avin recognised that smoking was more dangerous for some patients than others and wanted a blanket ban on smoking across all military hospitals. He noticed that some patients' conditions (such as those with respiratory diseases like tuberculosis) were worsened or aggravated by smoking. McGavin reasoned that 'handing cigarettes to tuberculosis and functional disease cases would be the same as that doctor offering his patient a whisky and soda, or the hypodermic needle', though many doctors were still recommending alcohol at this time. $^{36}$

As with the anti-smoking campaigns prior to the first world war, these medical concerns were a minority view within wider public and military attitudes toward

\footnotetext{
${ }^{32}$ Lynnette Callon, 'Fighting fit? a study of the army's medical examinations 1916-1918', BA(Hons) research essay, University of Otago, 1980.

${ }^{3}$ Notes of an interview with the Chairman of the Hospital Board and Medical Superintendent Dr Fox of Christchurch Hospital, 29 December 1915, Miscellaneous - cigarettes smoking among soldiers, 1916, AD, 1, box 1141, 46/421, Archives New Zealand, Wellington.

${ }^{34}$ C. E. Statham, MP to Minister of Defence, 20 January 1916, Miscellaneous - cigarettes smoking among soldiers, 1916, AD, 1, box 1141, 46/421, Archives New Zealand, Wellington.

35 The Press, 24 September 1921, p.15; Ross D. Blair, 'McGavin, Donald Johnstone 1876 - 1960', Dictionary of New Zealand Biography, updated 22 June 2007, available from http://www.dnzb.govt.nz, accessed 11 April 2009.

36 The Press, 24 September 1921, p.15.
} 
smoking. Servicemen were well supported in their habit by patriotic donations and a developing culture of normative and popular smoking in New Zealand. Medical professionals were not as active as the anti-smoking lobbyists in the pre-first world war era and despite alarm expressed by a handful of doctors during and after the war, health concerns were not a strong base for anti-smoking views or agitation in the early twentieth century. Some doctors may have noticed the ill effects of smoking, however others saw smoking as potentially beneficial, and were confronted with a public which equated smoking with wartime patriotism, and were on the cusp of a major, sustained increase in national consumption.

The first world war effectively muted the early twentieth-century anti-smoking lobbyists. What followed was a prolonged period through the 1920s to the 1950s in which opposition to smoking was largely absent. Smoking was uncontroversial and as discussed in chapters one and two, this period saw a substantial and sustained upward trend in tobacco consumption. Two themes will be explored through this normative phase. Firstly this discussion will examine the nature of a pro-smoking discourse, building from the concept of liberalism advanced in the existing international historiography on smoking. Secondly the discussion will turn to address public rhetoric around health and smoking in the period 1920-1950, before either the medical profession or the government recognised and publicised a conclusive link between smoking and negative health effects.

When the Auckland Education Board imposed their short-lived ban on teachers smoking in 1937, they were met with resistance from around the district. Seven teachers' organisations and 43 school committees wrote letters of complaint. ${ }^{37}$ Others found the ban so offensive that they took the matter higher, writing directly to the Minister of Education. Some teachers were particularly affronted that at a September meeting, the Auckland Education Board's discussion 'centred round the moral influence on pupils of teachers smoking in their presence, while the question of fire risk to school buildings,

${ }^{37}$ New Zealand Herald, 7 October 1937, p.12. 
the justification for the original resolution, was ignored. ${ }^{38}$ Even more, the teachers objected to the fact that the ban was restricting their right or entitlement to smoke, and affecting the equality of their rights with those of their colleagues in other parts of the country. Identical letters penned by four staff from Helensville District High School were written to the Minister in September 1937 asking for his help to resolve the smoking matter which they believed to be 'inequitable. ${ }^{39}$ B.S Barnes, secretary of the Auckland branch of the Men Teachers' Guild, wrote to Fraser in December 1937, after the ban had been rescinded, complaining of the overall manner in which teachers had been treated by the Board. He argued that the Board's attitude and action was seen by the teachers as 'an infringement of their personal liberty' and that the ban amounted to a 'restriction of personal freedom of members of the teaching staff., 40

The ideas and language of equality, liberty and freedom serve to highlight the nature of a pro-smoking discourse which encouraged debates elevating equality with other teachers and other workers, and emphasising an egalitarian 'right' to smoke. The language used by the teachers in this instance is a variation of the strong connection between smoking and the notion of liberalism which Matthew Hilton and Jarrett Rudy ascribe to smoking practices in their studies of nineteenth-century Britain and Montreal. ${ }^{41}$ Hilton and Rudy credit upper-class men in the nineteenth century with establishing a smoking culture and discourse in which liberal ideas of independence and individuality were advanced. Hilton and Rudy's arguments are grounded in the idea of a 'culture of individuality' governing smoking choices and practices, rather than an adherence to a liberal political ideology, institutions or government by liberal party views, though these facets of liberalism are all closely related. ${ }^{42}$ Although Hilton and Rudy both begin their discussions of smoking in the nineteenth century, neither make explicit connections with late nineteenth-century liberal politics as such, but rather with the ideas upon which classical or nineteenth-century liberalism was based: of freedom, independence and individual rational choice.

Rudy's reading of Ian McKay's much broader definition of liberalism is useful for understanding how debates such as those around the 'right to smoke', were framed.

\footnotetext{
38 B.S. Barnes to Minister of Education, 4 December 1937, Teachers. General. Smoking in Schools, $1937-$ 1947, E2, 1947/53d, 24/1/130, Wellington, Archives New Zealand.

${ }^{39}$ Teachers. General. Smoking in Schools, 1937-1947, E2, 1947/53d, 24/1/130, Wellington, Archives New Zealand.

${ }^{40}$ B.S. Barnes to Minister of Education, 4 December 1937, Teachers. General. Smoking in Schools, $1937-$ 1947, E2, 1947/53d, 24/1/130, Wellington, Archives New Zealand.

${ }^{41}$ Hilton, Smoking in British popular culture; Rudy, The freedom to smoke.

${ }^{42}$ Hilton, p. 3.
} 
McKay defines liberalism as 'something akin to a secular religion or a totalizing philosophy... [rather than] an easily manipulated set of political ideas. ${ }^{43}$ These historians argue that a nineteenth-century culture of bourgeois-liberal men defined smoking practices based on a hierarchy of tobacco tastes. While all men might have had the economic capability to purchase tobacco, the particular brand and design choices that men made defined them as 'self-possessed' or 'rational', and placed the individual at the centre of the tobacco process. ${ }^{44}$ Their smoking patterns were constructed in opposition to more basic or rudimentary working class smoking habits. With the twentieth century came the advent of cheaply produced cigarettes (among many other consumer products), and prompted a redefinition of the bourgeois-liberal smoker within the emerging mass-consumer market. In this new market manufacturers and governments now played a much larger role in deciding and defining what rational economic decisions would benefit the state and its citizens. ${ }^{45}$ Hilton and Rudy argue that such liberal values endured through the first half of the twentieth century, yet were recast within a developing economic climate of mass consumer culture. The definition of the liberal individual widened - significantly - including women.

The late nineteenth and early twentieth century saw a shift from classical liberal notions of self help, freedom and individualism, to 'new' or social liberalism, favouring greater state intervention in the lives of citizens whose personal freedom was limited by their social or economic situation. So while the liberal smoking culture that Rudy and Hilton discuss was not separate from political developments, it is the notion of freedom and individual independence that governed smoking practices. As Hilton points out, through the twentieth century

only rarely had governments attempted to direct individuals' consumption decisions, which surviving liberal principles held as being independent of, or existing beyond, the authority of the state. ${ }^{46}$

What then was the shape and character of a smoking discourse in New Zealand through the period 1920-1950 and how was it a variation of the dominant liberal themes in the British and Canadian case studies?

Given the marked absence of discussion around smoking through this normative, uncontroversial phase, there is some difficulty in assessing the extent and

\footnotetext{
${ }^{43}$ Ian McKay, 'The liberal order framework: a prospectus for a reconnaissance of Canadian history', Canadian Historical Review, vol. 81, 2000, pp.617-45, cited in Rudy, p.4.

44 See Hilton, pp.1-16; Rudy, pp.3-12.

${ }^{45}$ Hilton, p.6.

46 Ibid.
} 
character of discourses around smoking. However the anomalous nature of the 1937 teachers ban, as an unusual and contained moment in which arguments around smoking came to the fore, offers some insight into how discourses around smoking had shifted by that time. In the early twentieth century, as we have seen, objection to smoking was grounded in the idea that tobacco use led to a lack of self control, that it was a habit forming behaviour which took over the body and mind and led to other antisocial behaviours such drinking and gambling. These earlier arguments stressed the need for regulation of tobacco to remove temptation. In 1937 the Board of Education made an unclear and confused case against smoking, masked by fire danger but incorporating some of the moral elements of the earlier campaigns. The teachers were arguing that smoking was an expression of their freedom as adults to choose how they behaved and what they consumed. The teachers saw their treatment as 'inequitable' and unfair, positioning this assertion within what was the status quo in other school districts.

Indeed the nature of shifting discourses around smoking through this period are inextricably linked to key themes in chapter two's discussion. The tobacco industry's sustained, frequent and highly visual appeal for universal enjoyment of and entitlement to smoking propelled attitudes which elevated the 'right to smoke' discourse. Noncommercial influences were also a key feature of this rising prevalence of a pro-smoking discourse. In particular the state's interest in smoking practices and the tobacco industry was complex and multifaceted. From around the end of the first world war, tobacco crop growth and imports proved to be a valuable form of excise and customs tax revenue. The tobacco industry created jobs, and cigarette smoking, which established itself as central to wartime experiences and morale in the first world war, gained support as an 'essential' industry in the second world war. Aside from unusual incidents such as the 1937 teachers ban, the government supported tobacco consumption and made few interventions to suppress or control the smoking decisions of New Zealanders. Compared to regulations around alcohol which restricted both the space and time in which adults could drink, limits or controls on where and when adults could smoke were not a feature of this period. ${ }^{47}$ The language employed by New Zealanders to talk about smoking through this period reflected both commercial and non-commercial influences which promoted the idea of a fair and egalitarian access to smoking across time and space.

\footnotetext{
${ }^{47}$ For example six o'clock closing, introduced during the first world war and the creation of 'dry' districts imposed significant restrictions on where and when alcohol could be consumed. See Belich, pp.170-1.
} 
However, it is not merely a lack of government regulation which suggests a variation of a liberal approach to smoking practices in New Zealand. Ideas and rhetoric of individual liberal choice also propelled a pro-smoking discourse. While the 1937 teachers ban might seem to go against the dominant trend of limited state intervention in the behaviours and consumption choices of its citizens, government and regulatory involvement was more complex. The Auckland Education Board imposed the ban yet the Minister of Education Peter Fraser, who agreed on moral grounds that smoking in front of children was not a good idea, also expressed his discomfort with the principle of the ban: 'what he did not like was the repression side of it.' Fraser considered 'the fewer bylaws the better. ${ }^{48}$ Fraser's attitude here shows consistency with government's limited regulation of smoking consumption choices of New Zealanders.

Apart from exceptions like the 1937 schools incident, anti-smoking discourse through this middle period was largely silent. However, changing behavioural norms by this time were grounded in the spatial and gendered expansion of smoking as explored in chapter two in connection to sociability, pleasure, and entitlement and had a considerable effect on behaviour and discourses around smoking. Smoking was normal and acceptable, encouraging the affected teachers in 1937 to clearly enunciate their views through a dominant pro-smoking discourse which elevated an equal right and freedom to choose where and when they smoked. This pro-smoking culture is one aspect or reason contributing to a much more complex and multifaceted way that smoking was understood in New Zealand before the 1962 reports resulted in the return of an anti-smoking rhetoric.

Another key feature central to our understanding of the rhetoric around smoking is the nature of the health context through the normative period of tobacco consumption. Smoking was not recognised as a serious health issue by medical professionals or government officials through the period 1920-1950. In large part the negative health consequences of smoking were not recognised because of the considerable lag which occurred between the increased take-up of smoking in New Zealand from the 1920s, and the sustained emergence of an upward trend in lung cancer mortality rates from the 1940s. ${ }^{49}$ Over the period $1940-1960$ the rate of lung cancer mortality, represented in

\footnotetext{
48 Education Department Ministerial, 17 September 1937, Teachers. General. Smoking in Schools, $1937-$ 1947, E2, 1947/53d, 24/1/130, Wellington, Archives New Zealand.

${ }^{49}$ See Laugesen, Tobacco statistics 1991, p.23.
} 
figure 32, among males aged from 35-64 rose from 10.8 per 100,000 to 40.7 per 100,000 in $1960 .^{50}$ The emergence of a disease trend occurred two decades after the widespread rise in tobacco consumption from the 1920s, and as such the link between the two trends was not recognised until the 1950s, nor the massive and lasting health consequences fully realised until the early 1960s.

\section{Figure 32}

Lung Cancer Mortality Rate, 1940-1988

(per 100,000 persons aged 35-64, age standardised, by sex)

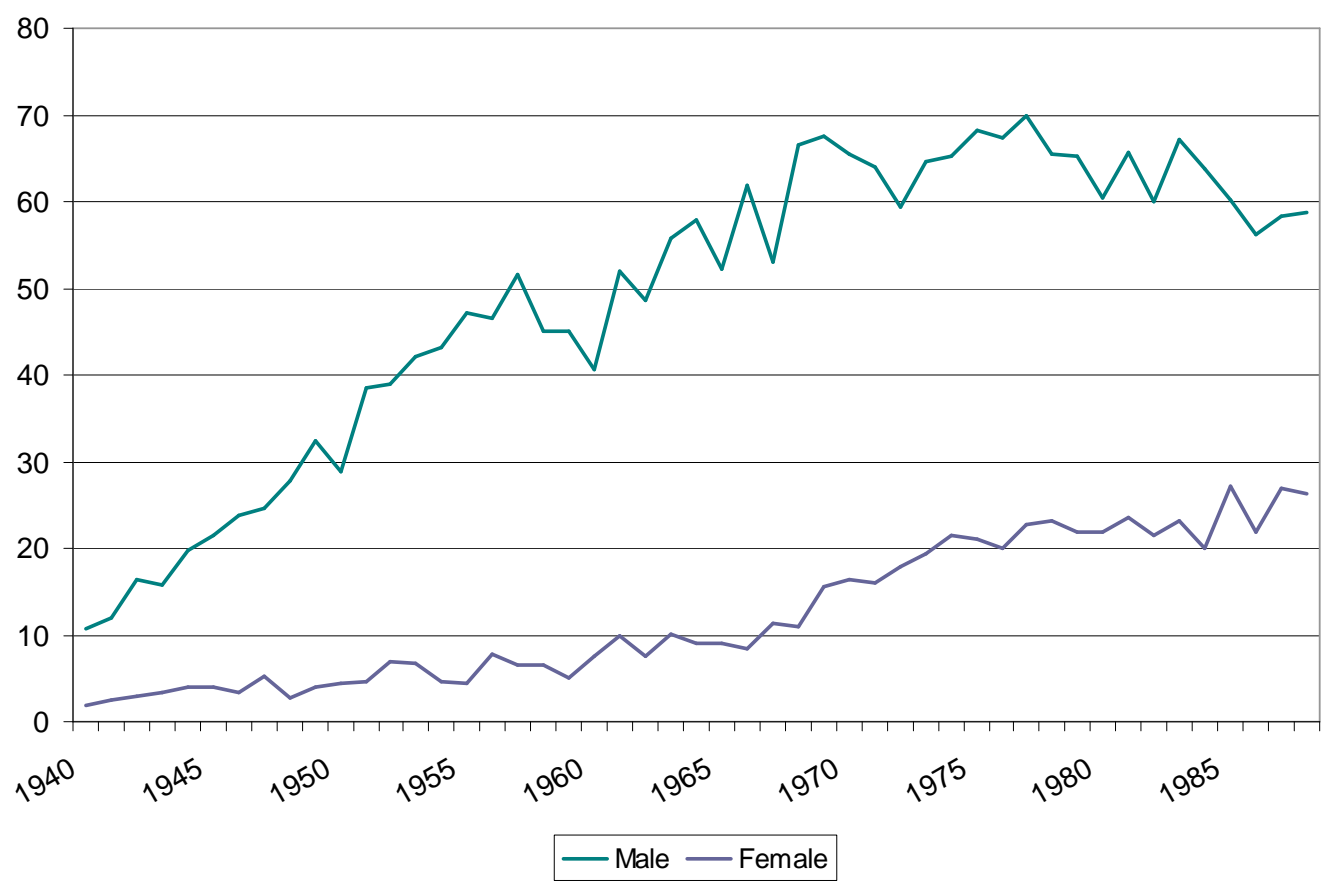

Source: Laugesen, Tobacco statistics 1991, p.22.

Through the period 1920-1950 other health issues proved to be higher on the medical agenda than the search for new health problems such as the rising incidence of lung cancer. The period following the first world war was one marked by a substantial expansion in wider government investment and responsibility in the public health system under the Public Health Act 1920. ${ }^{51}$ In 1938 the Social Security Act significantly bolstered what the Department had started in 1920, widening government responsibility to provide free and accessible health care in the form of free general practitioner and

${ }^{50} \mathrm{Ibid}$. Note that female rates of lung cancer were much smaller and increased slowly from around the mid-1950s, this rise was more rapid from the mid-1960s.

51 See Dow, pp.92-3. The Public Health Act restructured the public health system, had a greater focus on infant and maternal health, and introduced greater health and education facilities run through schools such as the schools dental service, toothbrush drills, the Health Camp movement, and the promotion of immunization. 
hospital visits, prescriptions and maternity care. ${ }^{52}$ Alongside this reorganisation and widening responsibility for the provision of health care, the first half of the twentieth century also represented an era of massive and widespread identification and control of infectious diseases. Over this period, extending into the 1940s and 1950s, the Department of Health oversaw the highly successful and effective control through the development of vaccinations and antibiotics for a large number of major diseases such as tuberculosis, diphtheria, poliomyelitis, measles, tetanus, mumps and rubella. ${ }^{53}$ These measures massively enhanced the health of New Zealanders and were major achievements for medical researchers and authorities. It is evident that the focus over this period was on the control of existing diseases, which were a major threat to New Zealanders' health, rather than the search for new diseases such as lung cancer which took time to show a pattern of disease and did not show a marked increase in prevalence until the late 1940s. Even as late as 1964 (two years after the RCP report) when Francis Maclean wrote the first history of public health in New Zealand, smoking did not warrant a mention as a major health problem. Rather, Maclean focused on the major accomplishments in the control of communicable and other diseases achieved by the Department of Health by the 1960 s. $^{54}$

Beyond an understanding of what was occurring in the government and medical sphere through the period in which smoking was not recognised as a health issue, this discussion now turns to assess the nature of a 'health' discourse in the public sphere through the period 1920-1950. Three key factors are central to our understanding of public rhetoric surrounding health and smoking in this era. Firstly, beyond the noncommittal attitude of medical authorities and government officials, another level of contradictory and unqualified medical understanding existed about the relationship, if any, between smoking and disease. Secondly, the circulation of ideas about what levels of 'healthy' smoking might look like - including the moderation thesis and 'safe' smoking - which were particularly propagated through advertising. The final factor which affected the shape of public rhetoric was the distribution and pervasive nature of smoking by mid-century. Not only did smoking become more acceptable in more and more spaces from the first world war, but it also became extremely normative and unquestioned by a large proportion of the population - smokers and non-smokers alike.

\footnotetext{
52 Ibid., p.122.

53 Ibid., p.12.

${ }^{54}$ F. S. Maclean, Challenge for health: a history of public health in New Zealand, Wellington, 1964.
} 
Links between health and smoking drew little media attention prior to the 1960s and it is therefore difficult to gauge the level of public knowledge or concern on a large scale. It is recognised that on any issue 'public opinion' is difficult to determine with certainty, but rather the aim is to understand the external factors which shaped levels of popular understanding, knowledge and belief.

The link between poor health, disease and smoking was most often presented to New Zealanders in the form of unsupported or contradictory medical advice. We do not know the nature of advice that was given to individual patients by doctors and surgeons, however some common notions existed as to the positive effects smoking had on the body. In his study of the 1918 influenza epidemic, Geoffrey Rice noted that smoking was one of many personal preventives offered (along with garlic and onions, camphor bags and whisky or brandy) to avoid contracting influenza. Many non-smokers took up smoking for a period during the epidemic. ${ }^{55}$ Smoking was also probably recommended by doctors for other ailments such as nervous conditions. Indeed even the Juvenile Smoking Suppression Act contained a clause which allowed children and young people to smoke if they obtained a medical certificate from a doctor which stated that smoking was beneficial to their health. ${ }^{, 56}$

Another health benefit, particularly aimed at women, was the notion that smoking assisted with weight loss. In America the promoters of Lucky Strike cigarettes came up with a famous campaign slogan in 1928, 'Reach for a Lucky instead of a sweet', which attracted widespread condemnation from the confectionery industry. ${ }^{57}$ This campaign was not promoted in New Zealand, however the effect of smoking as a slimming agent was (and remains) a widely held notion around the developed world, with Hollywood stars playing a major role in its dissemination. In 1962 following the release of the RCP report, the Listener interviewed some New Zealanders about what should be done about New Zealanders' smoking habits. Three of the women surveyed made specific reference to weight-gain being the alternative to smoking, which they were loathe to give up. ${ }^{58}$

From 1946 the Department of Health opened a file to collect the numerous complaints it received concerning the lack of regulation around smoking in places where

\footnotetext{
${ }^{55}$ Rice, p.152.

${ }^{56}$ NZPD, vol. 124, 30 July 1903, p.129, cited in Thomson, 'Evils of the fragrant weed', pp.32-3. This clause was retained in 1908 when the conditions of the Juvenile Smoking Suppression Act were transferred to the Police Offences Act. The clause remained in the Police Offences Act through to 1988. 57 Sharon Anne Cook, "Liberation sticks" or "coffin nails"? Representations of the working woman and cigarette smoking in Canada, 1919-1939', Canadian Bulletin of Medical History, vol. 24, no. 2, 2007, p.380. 58 'The trouble with smoking', Listener, 4 May 1962, pp.6-7.
} 
food was bought or consumed. By this time, as a basic hygiene measure workers who made or served food were not permitted to smoke while they were working, but there was no regulation against smoking in restaurants or eating houses. One complaint addressed the fact that eatery workers were still frequently found smoking on the job, arguing that 'ladies should not be allowed to sell food while smoking, or to smoke in shops where food is on display. ${ }^{59}$ Patrons' complaints to the Department of Health predominantly centred on both hygiene and what was seen to be good manners. Some addressed the 'unhealthy' habit of smoking after a meal, while others bemoaned the conduct of 'mainly ladies (so-called) inhaling smoke and then blowing it in one's face and over the food. ${ }^{60}$ In a reply to a disgruntled patron in 1949 Mabel Howard, Minister of Health, stated that such complaints were not really the domain of the Department of Health. The complaints were not couched in the dominant health themes in this period of controlling the spread of communicable disease. Howard argued that it 'cannot be shown that because a person smokes there are necessarily any more germs in his breath than if he did not. ${ }^{61}$ The significance of Howard's reply is that she was more concerned with the smoke rather than the smoker. For 'health' to be jeopardised, it would have to be proved that smoke spread infection, rather than being simply unhygienic or 'unhealthy'.

A second theme in the nature of public knowledge and understanding of the health thesis is that, beyond the contradictory understandings of the consequence or benefits of smoking, an implicit pro-smoking discourse developed around ideas about levels of 'healthy' smoking. The central notion was that smoking in 'moderation' was healthy. This discourse was particularly propagated by commercial influences such as advertising and the Tobacconists' Review. In 1937 the Tobacconists' Review recommended:

when customers tell you that they have been advised to curtail their smoking or to stop it all together because they are suffering from some physical ailment, it is time to exercise a goodly amount of diplomacy in your efforts to convince them that they can, through careful selection, continue to smoke without running any risk of injuring themselves. ${ }^{6}$

\footnotetext{
${ }^{59}$ G. W. Mills to Minister of Health, 15 September 1950, Food Hygiene - Smoking in Food Premises, 1946-1983, ABQU, 632, W4452, 906, 143/4/2, Archives New Zealand, Wellington.

${ }^{60}$ W.H. Gillingham to Minister of Health, 27 July 1949, Food Hygiene - Smoking in Food Premises, 1946-1983, ABQU, 632, W4452, 906, 143/4/2, Archives New Zealand, Wellington.

${ }_{61}$ M. B. Howard to E. H. Wright, 26 May 1949, in Food Hygiene - Smoking in Food Premises, 19461983, ABQU, 632, W4452, 906, 143/4/2, Archives New Zealand, Wellington.

62 Tobacconists' Review, 15 September 1937, p.16.
} 
The Tobacconists' Review argued that 'tobacco, used judiciously, is not harmful, and that it has a beneficial effect on men suffering from overwrought nerves. ${ }^{63}$ Not only were doctors or 'health cranks' threatening their business but so too were customers' friends who were equally likely to convince them that their health would benefit from giving up smoking. The moderation argument was prominent right through the time period under investigation and continued to persist in the public mindset to a large extent right through the second half of the twentieth century. Through this later period the idea persisted in public (and some medical) rhetoric, stressing that it was the level of smoking, rather than smoking itself which was the key link to negative health outcomes.

Moderation was a major part of the pro-smoking discourse through the normative, health-neutral phase of tobacco consumption c.1920-1950. Moderation promoted levels of 'healthy' smoking, and worked to dispel some of the myths disseminated by participants in the pre-first world war anti-smoking campaigns. A 1938 Truth article attributed the rise in smoking since the depression to a 'change in ideas' about smoking, stating that 'footballers and sportsmen generally have found that the old dire warnings about the dangers of smoking to physical fitness have been grossly exaggerated, and that even in training, a cigarette in moderation does no harm. ${ }^{64}$ There does not, however, appear to be any clear definition of what constituted moderate smoking. It is likely that as smoking became more pervasive and consumption increased these categories broadened. Women, for example, might have smoked 'in moderation', but would have been considered light smokers, whereas a moderate male smoker might have smoked more than twice as many cigarettes as a female smoker. In O. B. Cook's 1962 study a 42 year old female patient reported having regularly smoked eight to ten tailor-made cigarettes a day since she was eighteen, which she regarded as 'one of the few pleasures remaining in her life', yet she did not think herself to be a habitual smoker. In her view, habitual smokers were people who smoked 30 or 40 cigarettes a day. ${ }^{65}$ Such evidence suggests that notions of light, moderate and heavy smoking were subjective and relative through time, changing with increasing consumption and views of heath consequences or benefits.

\footnotetext{
${ }^{63}$ Ibid.

${ }^{64}$ New Zealand Truth, 9 November 1938, Miscellaneous Press Cuttings, 1936-1941, TB, W2303, 2, 1/9, part 1, Archives New Zealand, Wellington.

65 'Case 2' in O. B. Cook, 'Smoking and lung pathology', preventive medicine dissertation, Otago Medical School, University of Otago, 1962, p.20.
} 


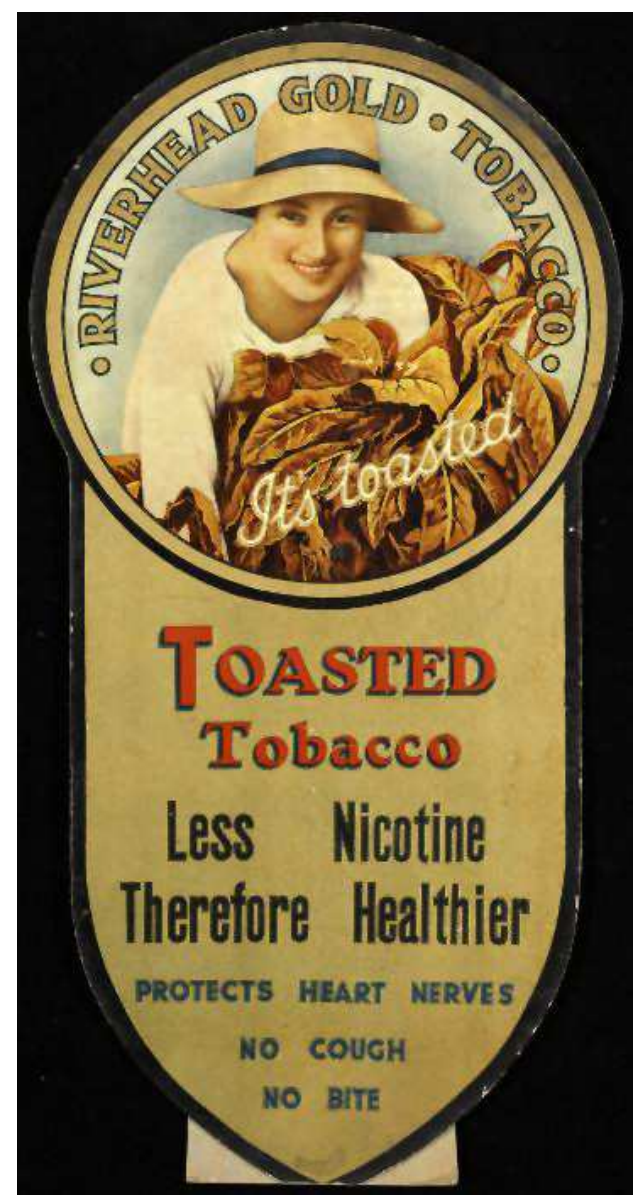

Figure 33

Riverhead gold was one of five brands of tobacco produced by the National Tobacco Company in Napier which claimed that the toasting process reduced the nicotine content of the tobacco.

Eph-C-Tobacco-NTC-1920s-02, ATL

Beyond interpretations of what moderate smoking might represent, and the significance of the quantity of tobacco smoked, the debates also focused on how people smoked. Many devices and techniques circulated which promoted ideas that there were 'more' healthful ways of smoking. The National Tobacco Company manufactured pipe and roll-your-own tobacco at its Napier factory. National's signature catchphrase 'It's Toasted' advertised that their tobacco contained 'next to no nicotine. ${ }^{66}$ Aside from being recommended by doctors as the 'safest and purest smoke!' this toasting process also promised an assortment of other health claims, among them protection from smoker's heart, shattered nerves, cough, sore throat, and impaired vision! ${ }^{67}$ The National Tobacco Company used predominantly New Zealand leaf, and also used

66 Advertisement - Toasted Tobacco, The New Zealand Railways Magazine, vol. 11, issue 5, 1 August 1936, p.61, available from http://nzetc.org/tm/scholarly/tei-Gov11 05Rail-t1-body-d21-d4.html, accessed 11 April 2009.

${ }^{67}$ Advertisement - Toasted Tobacco, The Tobacconist and Hairdresser, 21 March 1932, p.5. 
distinctly New Zealand images and characters in their advertising for the five brands of 'toasted' tobacco. These advertisements were presented in the text of journals and magazines in the 1930s as short articles about ordinary New Zealanders discussing the benefits of smoking nicotine-free tobacco, for example one advertisement stressed that 'excessive smoking, by the way, is not always wise, but it needn't worry Maorilanders because "toasted" is always at their service. ${ }^{68}$ The extent to which this toasting process actually decreased or eliminated the presence of nicotine is not known. However The National Tobacco Company was happy to deceive their customers and have them believe toasted tobacco was a form of healthful smoking, arguing throughout that 'tobacco can be as harmless as fresh air, provided it's good. ${ }^{\text {,9 }}$

From the 1930s filter-tipped cigarettes were popularised as another method of ensuring 'healthier' smoking. As consumption resumed its rising trajectory following the brief stagnation of the depression in the early 1930s, filters were seen to be a key factor in the increase, convincing 'non-smokers' that smoking 'need not be a dangerous habit. ${ }^{70}$ Like other products promoted in this era, the health benefits of filters were promoted by advertisers as based on scientific or medical research. 'Magic' Millecel filters in Matinée cigarettes in the 1950s, for example, boasted more than 20,000 microscopic filter cells. ${ }^{71}$ Filters grew in popularity particularly from the late 1930 s and 1940s when women began to light up in greater numbers, and increased further still when the findings of the RCP report in 1962 were published. Filters were favoured by women because they left 'no shreds in the mouth', they were 'milder in taste', and 'more feminine. ${ }^{72}$ Filters became more popular because of both their perceived ability to protect the smoker from harmful aspects of smoking, but also because of a wider trend in female smoking patterns which favoured the taste and look of tailor-made filter cigarettes.

Despite such claims of the purity of some tobaccos, whether or not to inhale was another common myth which suggested that 'healthier' forms of smoking were beneficial. In 1937 the Dental Journal of Australia offered some advice on how best to smoke in order to avoid damage to the mouth and teeth. Alongside using cigarette

\footnotetext{
68 Advertisement - Toasted Tobacco, Tobacconists' Review, 15 January 1938, p.4; Advertisement - Toasted Tobacco, Tobacconists' Review, 15 December 1936, p.4.

${ }^{69}$ Advertisement - Toasted Tobacco, The New Zealand Railways Magazine, vol. 9, issue 1, 2 April 1934, p.21, available from http://nzetc.org/tm/scholarly/tei-Gov09 01Rail-t1-body-d7-d6.html, accessed 11 April 2009.

70 Tobacconists' Review, 15 August 1936, p.12.

${ }^{71}$ Advertisement - Matinée, New Zealand Woman's Weekly, 3 December 1956, p.36. See also, Advertisement - du Maurier Filter Tip, New Zealand Herald, 5 October 1956, p.8.

${ }^{72}$ Hobson, p.8; Advertisement - Four Square Filters, Listener, 7 December 1956, p.21.
} 
holders or pipe stems and smoking in the open air, the article advised that smoke should be blown out 'as quickly as possible, and do not inhale. ${ }^{73}$ While some tobacco advertisers drew on medical and technical research and information to promote notions of healthier smoking, others went for a much more direct approach, such as State Express's 555 slogan 'Smoke 555 - They're Good For You' (figure 34). ${ }^{74}$ Ardath cigarettes 'protects your health' and 'Craven "A" cigarettes did not 'affect the throat', (figures 35 and 37). Other products such as Kolynos dental cream and Wrigley's chewing gum were advertised as aids to ensuring healthy smoking by keeping teeth and the mouth clean. Listerine toothpaste was especially targeted at smokers with the promise that it 'gets those stains. ${ }^{75}$

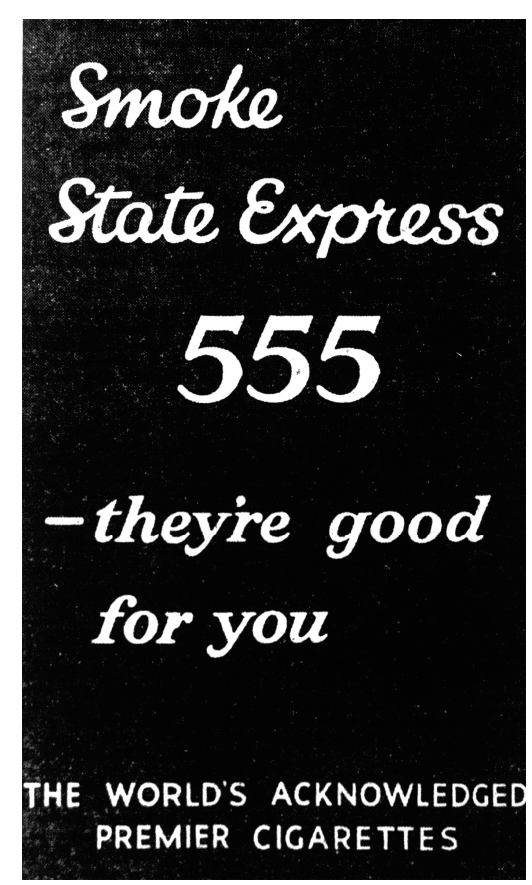

Figure 34

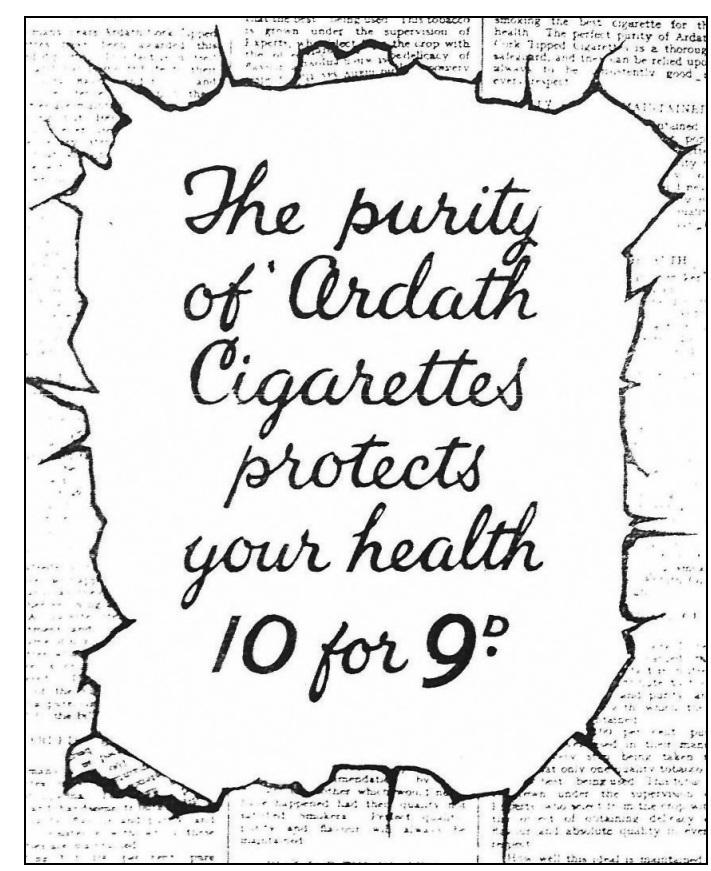

Figure 35

While advertisements for some brands promised that cigarettes would not harm the smoker, 'State Express 555' and Ardath confidently stated in the 1930s that their cigarettes were beneficial and protected the health of the smoker.

Weekly News, 26 September 1934, p.13;

New Zealand Herald, 2 April 1934, p.15

\footnotetext{
${ }^{73}$ Cited in the Tobacconists' Review, 15 July 1937, p.6.

${ }^{74}$ Advertisement - State Express 555, Weekly News, 26 September 1934, p.13. See also Advertisement State Express 555, The Press, 8 May 1933, p.16.

75 Advertisement - Kolynos Dental Cream, The Press, 8 April 1926, p.7; Advertisement - Wrigley's Chewing Gum, Weekly News, 31 August 1932, p.83 ; Advertisement - Listerine toothpaste, New Zealand Herald, 11 July 1935, p.6.
} 
Ian Tyrrell has argued that it is precisely the nature of the health discourse in advertising which illustrates the lingering scepticism in the public mind as to the possible dangers of smoking. ${ }^{76}$ Tyrrell argues that the use of a health discourse in advertising is seen as an attempt by the tobacco companies to 'counter arguments that cigarettes were unhealthy. ${ }^{, 77}$ Tyrrell however notes that the use of the 'health' theme in Australia is more prominent than in other countries in the interwar era and therefore Australians had a heightened awareness of health issues. ${ }^{78}$ While this thesis does not refute the basic premise of Tyrrell's argument - to some extent tobacco companies were countering health concerns - it is important to look also to a much wider reading of advertising and the nature of consumer culture over the period 1920-1950s.

Tyrrell bases his argument on a reading of advertisements in New South Wales newspapers between 1927 and 1937, arguing that because around 35 per cent of promoters mentioned some strand of the health discourse in advertisements that health was a common concern among consumers. He builds on the work of W. K. Viscusi who argued that the 'willingness to mention health risks in an ad [sic] is an implicit recognition that the safety of the product was a salient consumer concern. ${ }^{, 79}$ As has been identified in the selection of advertisements in the current discussion, it is evident that New Zealand advertisers too, engaged in this 'health' discourse. ${ }^{80}$ Rather than making the direct link to public concern with the dangers of smoking, this thesis argues that the health discourse in advertising can also be viewed within the context of a wider analysis of advertising patterns for commodities and consumer products through the 1920 s to the 1940s. Through this period there was a much wider theme in advertising which underlined the promise of health benefits of products designed for the body, such as soap and toiletries and other tonics or remedies.

The 'health' focus could also be explained within an understanding of the 'therapeutic ethos' which T. J. Jackson Lears identifies as a major influence in the culture of advertising from the 1880s through to the 1930s in the United States. ${ }^{81}$ Lears argues that in this period 'the quest for health was becoming an entirely secular and self-

76 Tyrrell, Deadly enemies, pp.130-3.

77 Tyrrell, 'The limits of persuasion', p.32.

${ }^{78}$ United States studies indicate around eighteen per cent of advertisements used a health theme, whereas Tyrrell's figure for Australia is proportionally much higher at 35 per cent. See Tyrrell, Deadly enemies, p.130. 79 W. Kip Viscusi, Smoking: making the risky decision, New York, 1992, p.39, cited in Tyrrell, Deadly enemies, p.131.

80 Acknowledging that both New Zealand and Australian tobacco companies imported not only tobacco leaf and product from the United States and Britain, but also advertising campaigns, images and ideas. 81 See T. J. Jackson Lears, 'From salvation to self-realization: advertising and the therapeutic roots of the consumer culture, 1880-1930', Richard Wightman Fox, T. J. Jackson Lears, (eds.), The culture of consumption: critical essays in American history, 1880-1980, New York, 1983, pp.3-38. 
referential project.' He suggests that the 'coming of the therapeutic ethos was a modern historical development, shaped by the turmoil of the turn of the century. ${ }^{, 82}$ Advertising played a key role in the fulfilment of this therapeutic ethos. Lears argues that advertisers drew on and popularised a 'pseudo-religion' of health, which gained traction among a population which was anxious and increasingly aware of individual health. ${ }^{83}$

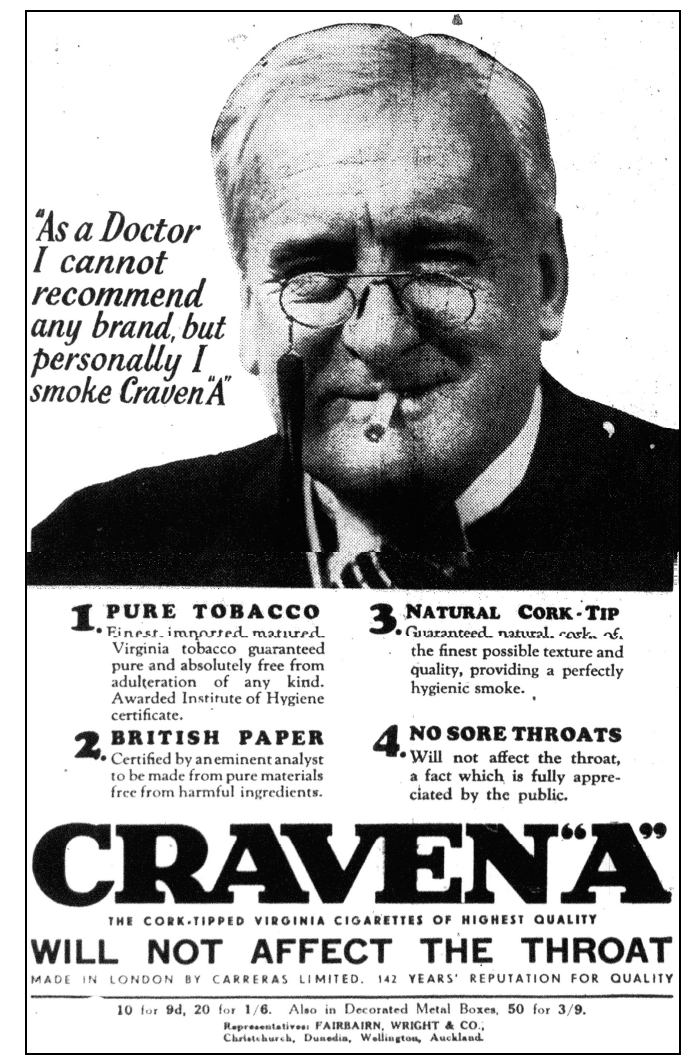

Figure 36

As with 'Doctor's Whiskey', medical practitioners were also portrayed endorsing particular tobacco brands such as this 1930 advertisement for 'Craven "A"'.

Otago Daily Times, 3 September 1930, p.13

Based on a selective analysis of New Zealand advertising from 1920 through to the 1950s, it is evident that, to a large degree, the elements central to the therapeutic ethos were present in New Zealand advertising rhetoric. Smoking might have been heralded as healthful, safe, preventive and hygienic, but so too were a wide assortment of other products which also boasted healthful qualities and medical testimony. Even alcohol, an item of arguably greater vice than tobacco, managed to tap into this culture of therapeutic and health benefits. In advertising numerous brands promoted the health

\footnotetext{
82 Ibid., p.4.

83 Ibid., p. 17.
} 
benefits of alcohol such as Wolfe's schnapps - 'One Wolfe's schnapps a day for your health's sake' - and even more explicitly, 'What the Doctor ordered - 'Doctor's special Whiskey. ${ }^{84}$ The influence of this therapeutic ethos on consumer advertising, and tobacco advertising in particular, takes the understanding of 'healthy' smoking into a much wider context and offers another angle from which to assess knowledge and understanding among the public in the health-neutral era.

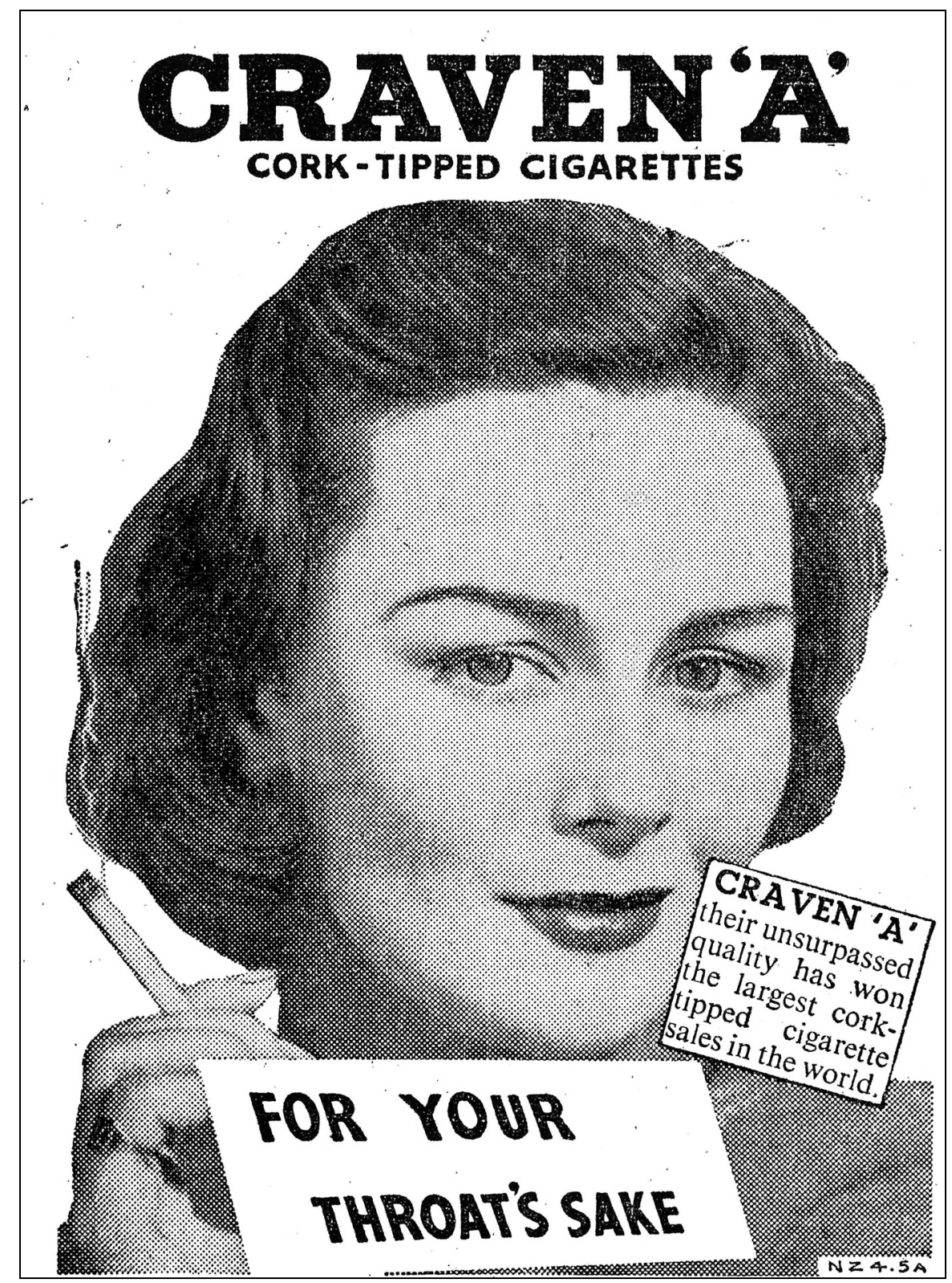

Figure 37

From the 1930s Craven "A" sold millions of cigarettes to both men and women based on their core marketing message that their cigarettes were so smooth that they did not affect the throat.

84 Advertisement - Wolfe's Schnapps, New Zealand Sporting and Dramatic Review, 15 April 1926, p.29; Advertisement - Doctor's Whiskey, New Zealand Sporting and Dramatic Review, 27 March 1924, p.31. See also, Advertisement - Coates' Plymouth Gin, Otago Daily Times, 2 September 1930, p.3. 
The final factor which affected the shape of public rhetoric was the distribution and pervasive nature of smoking by mid-century. Ideas about the health effects and benefits of smoking in the public arena were contradictory and complex. These ideas encompassed diverse notions of what constituted 'healthful' smoking, within a 'moderation' framework which in itself was full of ambiguities that were fluid in meaning over time. However, this thesis contends that the biggest factor which inhibited public and medical professionals from questioning smoking or recognising smoking as a health issue earlier, was the normal and pervasive nature of smoking as consumption continued to increase on a rising trajectory over this era. George Thomson and Nicholas Wilson, New Zealand health researchers prominent in the tobacco control field, argue that the 'normalisation' of tobacco was the 'most influential' reason for the lack of tobacco control in New Zealand over the period 1945 to $1961 .^{85}$ Normalisation was such a great hurdle because it would take so much to change societal attitudes, behaviours and thinking, and before conclusive medical knowledge was established such action was too huge and difficult for health authorities to conceive. ${ }^{86}$

The weight of public opinion (even for non-smokers) overwhelmingly favoured acceptance, and the usual, normative place of tobacco in everyday New Zealand life. By the 1940s most of tobacco's opponents, though sometimes vocal, were anomalous. When Minister of Health Mabel Howard responded to a complaint about smoking in eating houses and restaurants she argued that restaurateurs were welcome to impose smoking bans, but that it was at the risk of losing patronage from the majority who liked to indulge in a quiet cigarette after a meal. Indeed for many the restaurant was a leisure space where smoking (with eating and drinking) became an important place of mixed socialisation. Howard stated that she had 'come to the conclusion that whether or not the practice is to be restrained depends on public opinion rather than on reasons concerned with public health. ${ }^{87}$ Similarly National MP Jack Watts who succeeded Howard as Minister of Health, agreed, in his response to a similar complaint, that smoking in restaurants was 'a matter which is greatly influenced by the weight of public opinion and that whether the 'eating house proprietor' imposes a ban on smoking 'depends on the attitude of the public. ${ }^{88}$

85 Thomson and Wilson, 'Tobacco control in New Zealand', pp.101-3.

${ }^{86}$ Ibid., p.103.

${ }^{87}$ M.B. Howard (Minister of Health) to Ernest H. Wright, 26 May 1949, Food Hygiene - Smoking in Food Premises, 1946-1983, ABQU, 632, W4452, 906, 143/4/2, Archives New Zealand, Wellington. ${ }^{88}$ Jack T. Watts to G. W. Mills (RSA), 14 September 1950, Food Hygiene - Smoking in Food Premises, 1946-1983, ABQU, 632, W4452, 906, 143/4/2, Archives New Zealand, Wellington. 
On top of this normalisation argument lies a dominant pro-smoking culture which was, in large part, an outcome of limited scientific and medical knowledge, and limited government interference which resulted in a narrowing of anti-smoking sentiment over the same period in which consumption widened. It is this climate of contradictory medical and public opinion and limited government interest or intervention which provided the backdrop for increased medical and scientific knowledge emerging in the 1950s, and the reaction to the conclusive reports of the 1960 s.

From around 1950 medical debates around smoking began to emerge more vocally, signalling an end to the prolonged period of smoking in which the habit was largely uncontroversial. This section will look at how the basis for anti-smoking discourse at this end of the study period had a very different centre than the pre-first world war debates. These debates were strengthened by the international development of research into the link between smoking and lung cancer through the 1950s, culminating in the publication of the 1962 Royal College of Physicians' Report in Britain and later the 1964 Surgeon General's report in the United States. The final section of this chapter will look at the emergence of health discourses and debates over the period 1950-1962 in both an international and a local context. While the 1950s may have seen a shift in medical discourse, 1962 was the first time in which these results were powerfully put to the public both in New Zealand and around the world. This discussion therefore uses reaction to the report in 1962 as a lens through which to view the nature of public discourse and belief around smoking and particularly the smoking-lung cancer link at this point.

Medical scientists in the United States and Britain first began to investigate the link between smoking and lung cancer in the late 1940s. ${ }^{89}$ The British Medical Research Council (BMRC) first discussed the link between smoking and lung cancer at a

\footnotetext{
${ }^{89} \mathrm{It}$ is important to note that in the early 1940s research studies funded by the Hitler regime saw German scientists establish conclusive epidemiological evidence that smoking was both addictive and a cause of lung cancer. New Zealand medical professionals were much more closely aligned to their British and American colleagues. See Robert N. Proctor, 'The Nazi war on tobacco: ideology, evidence, and possible cancer consequences', Bulletin of the History of Medicine, vol. 71, no. 3, 1997, pp.435-488.
} 
conference held in 1947..$^{90}$ Between April 1948 and October 1949 BMRC members Richard Doll and Austin Bradford Hill led a research team which conducted a large scale survey of patients presenting at twenty London hospitals with cases of carcinoma of the lung. ${ }^{91}$ An equal number of non-cancer control patients were also included in the survey. The aim was to determine whether patients with carcinoma of the lung differed materially from other persons in respect of their smoking habits or in some other way which might be related to the atmospheric pollution theory. ${ }^{92}$ In assessing the patients they took into account their changing smoking habits by taking a longer history than that which was normally taken by the hospital, thus taking into account incidence where a 'moderate smoker' may have cut down from being a 'heavy' smoker or vice versa. ${ }^{93}$

Doll and Hill found that there was a 'real association' between smoking and lung cancer. The rate of lung cancer in Britain largely mirrored the increase in other countries around the same time. ${ }^{94}$ They found that the risk of developing lung cancer was the same for both men and women, but that incidences of lung cancer were much higher in men, attributable to the higher percentage of men who smoked. Doll identifies 1950 as a 'watershed' year for smoking/lung cancer research, with his and Hill's study being published alongside four other studies in the United States. ${ }^{95}$ Through the 1950s Doll and Hill expanded on their work by conducting a survey of over 34,000 male physicians in the United Kingdom. The results of this study, published in 1954, showed that 'the mortality from lung cancer was proportional to the amount smoked' and also made a link between smoking and coronary thrombosis. ${ }^{96}$ In the same year a large study emerged from the United States with similar findings. ${ }^{97}$ The 1950 s produced seven other

\footnotetext{
${ }^{90}$ Medical Research Council, 'Stories of Discovery: Smoking', available from http://www.mrc.ac.uk/OurResearch/Impact/Cancer/Smoking/MRC003518, accessed 8 July 2008.

${ }^{91}$ Doll and Hill also looked at aetiological factors which might lead to other forms of cancer. Richard Doll and Austin Bradford Hill, 'Smoking and carcinoma of the lung: preliminary report', British Medical Journal, no. 4682, 1950, p.740.

92 A smoker was defined as someone who had smoked at least one cigarette a day for at least a year, see Doll and Hill, 'Smoking and carcinoma of the lung', p.740.

${ }^{93}$ In all, 709 lung cancer patients were included in the survey. See Doll and Hill, 'Smoking and carcinoma of the lung', p.741.

94 Ibid., p.746.

${ }^{95}$ Levin et al., 1950, Mills et al., 1950, Schrek et al., 1950, Wynder and Graham 1950. Cited in Richard Doll, 'Evolution of knowledge of the smoking epidemic', in Boyle et al., (eds.), Tobacco: science, policy and public health, Oxford, 2004, p.6.

${ }^{96}$ Richard Doll and Austin Bradford Hill, 'The mortality of doctors in relation to their smoking habits. A preliminary report', British Medical Journal, 1, 1451-5, 1954, cited in Doll, 'Evolution of knowledge of the smoking epidemic', p.7. The Department of Health in New Zealand also conducted a different survey of the smoking habits of over 2,600 New Zealand doctors in 1963 with the results published in a report in 1964. See C. E. Gardiner and C. N. D. Taylor, Smoking habits of New Zealand doctors: a survey of the smoking habits of medical practitioners in New Zealand, Wellington, 1964.

${ }^{97}$ Hammond and Horn, 1954, cited in Doll, 'Evolution of knowledge of the smoking epidemic', p.7.
} 
substantial pieces of research into the lung cancer link in Europe, Britain and the United States, all determining the link between smoking and lung cancer. ${ }^{98}$

When the Royal College of Physicians in London released their first report on smoking in 1962, they based their findings on 23 studies in nine different countries similar to Doll and Hill's groundbreaking study. All the studies compared the retrospective smoking histories of patients presenting with lung cancer, against the smoking history of control patients without cancer. ${ }^{99}$ The College was able to assert for the first time a conclusive link between smoking and lung cancer, as well as a relationship with other diseases such as chronic bronchitis, tuberculosis, coronary heart disease, and cancers of the mouth and throat. The research showed that heavy cigarette smokers had up to 30 times the death rate of non-smokers. Building on earlier studies, the report addressed the much higher incidence of lung cancer in men than women, arguing that other aetiological factors did not account for such a divergence; smoking was the primary cause of lung cancer. The College estimated that around 75 per cent of adult men and 50 per cent of adult women were smokers in Britain at the time of their 1962 report. ${ }^{100}$

Despite the early works by Doll and Hill, the smoking 'issue' was not substantially recognised by New Zealand medical professionals until the late 1950s and the early 1960s. Thomson and Wilson argue that this was a symptom of a 'strong orientation of health services to treatment rather than prevention', and a lack of focus in New Zealand on 'continuing medical education. ${ }^{, 101}$ Through the 1950s some references to smoking and lung cancer began to appear in the New Zealand Medical Journal but there were no major studies conducted within New Zealand at this time. Studies became more frequent and gained greater prominence in the 1960s. Sir David Hay, a noted surgeon and pioneer of the tobacco control movement in New Zealand, recalled that both the Royal College of Physicians report and the United States Surgeon General's report of 1964 had a major influence on New Zealand doctors and policy makers. ${ }^{102}$ Hay was more aware of the smoking/health links in the 1950s because of his time spent at Brompton hospital in London which specialised in cardiac medicine. ${ }^{103}$ Hay recalled that

\footnotetext{
${ }^{98}$ Lang, paragraph 85.

${ }^{99}$ Royal College of Physicians, pp.12-6.

100 Ibid., p.4.

101 Thomson and Wilson, 'Tobacco control in New Zealand', p.103.

102 Sir David Hay, Heart sounds: a life at the forefront of health care, Wellington, 2005, p.122.

103 Thomson and Wilson, 'Tobacco control in New Zealand', p.101.
} 
'there was no doubt that the medical people there were totally convinced of the relationship between smoking and lung cancer. ${ }^{, 104}$ However in New Zealand the link between smoking and ill health was not a feature of medical training and was not widely discussed in medical circles. Dr Murray Laugesen remembered hearing about the smoking/health issue first in 1956 when a visiting British doctor talked to medical students. Professor George Salmond, who trained as a doctor in the late 1950s, remembered smoking being 'mentioned' but that it 'wasn't a great issue' at that point. ${ }^{105}$

Medical authorities in the Department of Health were aware of the shifting nature of the international health discourse surrounding smoking in the 1950s, yet, as Thomson and Wilson argue, 'this information does not appear to have produced a government response in any way relative to the problem. ${ }^{106}$ Initial attempts at tobacco control were primarily aimed at educating children and young people against starting to smoke. In 1959 Harold Turbott, head of the Department of Health, wrote to his British counterpart describing the tobacco control actions of his department to date. This record was limited to six mentions of the 'danger of lung cancer' by Turbott in his role as 'radio doctor' over the period 1950-1958, and a few articles about the 'dangers of smoking' in the Department's magazine Health since $1957 .{ }^{107}$ The department also made strong statements against smoking in its health focused advertising campaigns in the national press. One such example appeared in the Listener in 1958 stating that 'those who smoke heavily are more prone to lung cancer. ${ }^{, 108}$ Toward the end of the 1950s the Department of Health also underlined efforts to dissuade children and young people from smoking. The primary way the department sought to understand smoking patterns among young people was through a national survey of over 4,000 children, published in May $1961 .^{109}$

\footnotetext{
${ }^{104}$ Interview with Sir David Hay, 1999, cited in Thomson and Wilson, 'Tobacco control in New Zealand', p.101.

${ }_{105}$ Interviews with Dr Murray Laugesen (1996) and Professor George Salmond (1997) cited in Thomson and Wilson, 'Tobacco control in New Zealand', p.101.

106 Thomson and Wilson, 'Tobacco control in New Zealand', p.102.

${ }^{107}$ Harold Turbott to Sir John Charles, Ministry of Health, Britain, 23 January 1959, Health Education and Publicity - Campaign against cigarette smoking, 1957-1961, H1, 1777, 34/74, Archives New Zealand, Wellington.

108 New Zealand Department of Health, Cancer Poster, Listener, 10 October 1958, p.20.

${ }^{109}$ See C. E. Gardiner, C. N. D. Taylor, and L. D. Roberts, Smoking habits of school children: a survey of the smoking habits of New Zealand school children, Wellington, 1961.
} 
As in Britain and Australia, moves toward tobacco control were slow and limited through this period. ${ }^{110}$ In part this was a result of a different medical focus which continued from the first half of the twentieth century, as discussed earlier in this chapter; medical administrators still had a much greater focus on the control of recognised diseases. Frances Steel's study of the emergence of Chronic Heart Disease (CHD) as a rising health problem over the period from the 1930s offers a useful parallel to this study. Like lung cancer, medical scientists did not fully begin to unravel the causes of heart disease until the early 1960s. ${ }^{111}$ As CHD rates increased, medical researchers began to make links with New Zealand's comparatively high butter diet. Both the emergence of $\mathrm{CHD}$ and lung cancer as serious health problems were overshadowed by the Department's predominant and highly successful focus on the control of communicable diseases. Over the 1950s the medical profession and the Department of Health made initial steps toward recognition of their responsibility to warn New Zealanders against smoking based on emerging health research. However these steps were small, and often conflicting. As late as 1955 Dr Harold Turbott, in his role as 'radio doctor' recommended smoking as a tip for those suffering 'Housewife fatigue.' Turbott invited housewives to

Deliberately shut out worry about time and tasks, slump easily in a chair, have a cup of tea or a cigarette, or look at a picture magazine-five minutes really off duty! Don't overdo the cigarettes; chain smoking is a sure way to chronic tiredness. ${ }^{112}$

For adults moderation rather than complete cessation of smoking appears to have been the key message disseminated by the Department through this period.

1962 marks the point at which conclusive medical knowledge condemning smoking was presented to governments and publics around the world, unequivocally ending the period in which smoking could be seen as an uncontroversial habit. The 1962 and 1964 international medical reports effectively provided the impetus for the New Zealand

\footnotetext{
${ }^{110}$ Initial tobacco control attempts by the government in Britain were 'piecemeal', but 'centralised' following the publication of the RCP report in 1961. See Hilton, p.181. Tyrrell also reiterates the continued and complex interest of the Australian government in the tobacco industry through this period. Tobacco consumption was historically high in the early 1960s and remained a major source of revenue. See Tyrrell, Deadly enemies, p.162. Note that Rudy's study of smoking in Montreal does not cover the reception of the RCP report in Canada.

${ }^{111}$ Frances Steel, 'A source of our wealth, yet adverse to our health? Butter and the diet-heart link in New Zealand to c.1990', Social History of Medicine, vol. 18, no. 3, 2005, pp.475-493.

112 Harold Turbott, 'Housewife Fatigue', Listener, 18 February 1955, cited in Dow, p.192.
} 
medical profession and the Department of Health to act on a health issue which they had begun to suspect from the 1950s. The final section of this chapter turns to assess New Zealanders' views at this crucial knowledge turning point and in turn identifies the nature of the gaps in information and how this was accepted or used within public discourses around smoking at this time. The RCP's report was conclusive and its findings highly damning of smoking, yet smoking was extremely widespread and popular. As such, public reaction and resistance to the report was much more complex, revealing the strength of the normative place of smoking and the difficulties presented in unravelling a social norm. In New Zealand, as in Britain, there was 'incredible diversity' in how the findings of the report were disseminated in the press, and the degree to which the reports were amplified by media and medical professionals. ${ }^{113}$

Given that there were relatively few medical studies in New Zealand addressing the link between smoking and health in the 1950s and early 1960s, a handful of preventive medicine dissertations from the Otago Medical School focussing on the issue in the early 1960s have proven to be a valuable and untapped resource for this study. The dissertations are the work of fifth year medical students between the 1930s and the late 1970s who were required to conduct research on some aspect of public health or preventive medicine as part of their medical studies. ${ }^{114}$ Apart from one study which suggests smoking as one possible cause for lung cancer in 1951, there are no dissertations which address smoking as a health issue before the $1960 \mathrm{~s} .{ }^{115}$ The studies which emerged in the early 1960s, largely as a result of smoking gaining greater coverage in medical, media and public spheres, were some of the earliest to appear on the topic in New Zealand. While focused on potential tobacco control activities, these dissertations also provide an insight into the attitudes of both the authors and subjects of these studies, and reveal dominant themes in the language surrounding smoking by this time. $^{116}$

\footnotetext{
113 See Hilton, p.219.

114 The dissertations were originally part of Sir Charles Hercus' public health teaching programme in the Department of Bacteriology and Public Health from the 1930s. The theses typically concentrated on aspects of infectious and communicable diseases, and public health issues. From 1952 the Department became known as the Department of Preventive and Social Medicine. The students who wrote the dissertations discussed in this thesis would have worked under Professor Cyril Dixon who became Department Head in 1959. See J. M. Elwood, 'Preventive and social medicine', Edwin R. Nye, (ed.), Medical research in Otago, 1922-1997: as portrayed by 75 years of the Proceedings of the University of Otago Medical School, Dunedin, 1998, pp. 121-3; and Sir Charles Hercus and Sir Gordon Bell, The Otago Medical School under the first three deans, Edinburgh and London, 1964, pp.257-61.

115 Mary L. D. Skinner, 'Cancer of the lung', preventive medicine dissertation, Otago Medical School, University of Otago, 1951.

116 The preventive medicine studies typically involved a survey of a small but specific population group.
} 
Researchers found that from 1962 participants in their studies were, overall, aware that there was a debate over the health-smoking connection which had become particularly fervent in the media since the release of the RCP's report in March 1962. Many had read of the findings in daily newspapers such as the Otago Daily Times and one recalled reading of the report in Time magazine. ${ }^{117}$ The press and the radio were cited as the chief mediums through which people had heard about the report; Donald Gray found that despite Department of Health posters being in the public domain, 'not one person mentioned seeing them. ${ }^{, 118}$ Other participants stated that they had seen films on lung cancer and smoking, some commenting that such material had an immediate effect on their friends but that they quickly resumed smoking a day or so later. ${ }^{119}$ Many participants knew of the link with lung cancer but few had heard of the relationship between smoking and heart disorders. Evidence from the surveys suggest that the perceived risks of smoking were 'often discussed' among friends, but it appears that their confidence in the report's findings was contested ground, even when they had a friend or family member who had experienced lung cancer. ${ }^{120}$

While there may have been some consensus on the prominence and quantity of material in the public sphere and the media, public attitudes towards and acceptance of this material were much more divergent. This finding parallels British studies which similarly revealed

the ability of smokers to be aware of the publicised dangers of smoking, yet also an ability to refute this evidence by either their continued consumption and disbelief that it would not happen to themselves. ${ }^{121}$

A dominant theme in the reaction amongst the patients and members of the public participating in the surveys for the Preventive Medicine studies was that the lung cancer-smoking link was still unproven and the public remained sceptical of medical appeals for people to give up smoking. Such attitudes are evident from the language used by participants to describe the health-smoking link such as 'rumoured', 'suspicion', 'cancer scare' and 'possibility'; suggesting that the public might have been wary of the RCP's findings, as rumours of the link had been around since the early 1950s, though had never before been presented in such conclusive and compelling form. It was

\footnotetext{
117 'Case 2' in McKinnon, p.12.

118 Donald Harley Gray, 'Giving up smoking', preventive medicine dissertation, Otago Medical School, University of Otago, 1963, p.17.

119 'Case 5' and 'Case 6' in Cook, 'Smoking and lung pathology', pp.25, 28.

120 'Case 4' in Cook, 'Smoking and lung pathology', p.20.

${ }^{121}$ Hilton, p.225.
} 
acknowledged that the report was authoritative however many believed that the premise of it was unproven and others found the facts confusing. All of Edison Hobson's twenty female participants, aged between 18-24, had heard of the research (though 'accurate knowledge was lacking'), yet only two believed that there was a proven link between smoking and lung cancer. ${ }^{122}$

It is not surprising, given the prevalence and normative nature of smoking among New Zealanders, that one strand of the counter-argument circulating in the public sphere was that incidence of lung cancer (and other cancers) had more to do with chance or fortune than with epidemiological facts. One participant in McKinnon's study, a 26 year old freezing worker, 'had read the press accounts of the Report and had considered that a smoking-cancer link was possible. However, as he said, he liked his cigarettes and he was not going to give them up just because he might get lung cancer. ${ }^{123}$ Of Hobson's participants only one was considering giving up smoking in light of the medical findings, while the other women thought that their 'chances' of developing lung cancer from smoking were 'statistically' remote. ${ }^{124}$ Another 61 year old participant who had recently undergone removal of part of his lung affected by lung cancer, said that many of his friends considered him 'unlucky to have developed lung cancer' and none of his friends had made efforts to stop smoking. ${ }^{125}$ Given the high prevalence of smoking in New Zealand by this time, the 'bad luck' argument gained support among a public that was very reluctant to give up what had become an established pleasure and habit in their daily lives, many claiming that they 'had to die sometime. ${ }^{, 126}$ Smoking was just one of many behaviours which could lead to ill health or death.

What bearing then did these sceptical attitudes to the RCP report and its dissemination through the media have on the smoking behaviour of New Zealanders surveyed around the time of the report's release? While some attempted to quit - with mixed results - the majority of participants limited their actions to changing to what the report identified as safer forms of smoking such as switching to pipes, filters and only smoking the top half of the cigarette (the smoke from the bottom half of the cigarette was seen to contain higher concentrations of toxic substances if it has acted as a filter for the top half of the cigarette). The authors of the RCP report had identified such

\footnotetext{
${ }^{122}$ Hobson, p.17.

123 'Case 14' in McKinnon, p.24. (Emphasis in original)

${ }^{124}$ Hobson, pp.17-8.

125 'Case 2' in Cook, 'Smoking and lung pathology', pp.12-3.

126 'Case 7', in McKinnon, p.17.
} 
actions as a last resort if the smoker was unable to quit altogether. ${ }^{127}$ McKinnon interviewed a 31 year old banker who regularly smoked twenty cigarettes a day. Upon reading of the smoking-lung cancer link he attempted to give up smoking but quickly relapsed, however he 'had read that cigarette holders made smoking safer' so started using these, and 'although he was smoking much the same number as before felt that at least had had achieved something. ${ }^{, 28}$ Similarly Hobson found that 80 per cent of his female participants used filter-tipped cigarettes, and one reason given was that there was perceived to be less danger to health, 'just in case there is something in this smoking and lung cancer business. ${ }^{, 129}$

A final theme evident in the rhetoric surrounding the release of the 1962 report was that, by and large, whether to smoke or not was a matter of individual choice. The language used by participants shows that the 'right to smoke' discourse evident in the teachers' reactions to the 1937 ban discussed earlier, was entrenched by this period and was to remain a prominent feature of pro-smoking discourse for years to come.

Smoking was still very much seen as a personal choice. Participants in Cook's study did not think that the government should ban smoking in public, as it would interfere with 'independence' and 'people's rights. ${ }^{, 130}$ For parents this notion was often extended to their own children. Many parents believed that education about the health risk of smoking was a good idea in schools and did not want their own children to smoke while still at school. However, to a large extent many felt that once their children had left school it was up to them whether they smoked or not. One father said he believed in 'independence' and two others said that their children could smoke 'as much as they liked when they left school. ${ }^{131}$ These attitudes might have been influenced in part by the parents' own smoking habits, many feeling that they were hypocrites to tell their children not to smoke when they did so themselves. Smoking it seems, remained a potent marker of both adulthood and the individual's right to choose what he or she consumed.

1962 marked the first serious return to an anti-smoking discourse, yet by this time smoking was an integral part of social life, of working life, and was seen as both an entitlement and a pleasure. 1962-3 marked the zenith of smoking consumption in New

\footnotetext{
${ }^{127}$ Royal College of Physicians, pp.49-50.

128 'Case 9' in McKinnon, p.19.

${ }^{129}$ Hobson, p.8.

130 'Case 11' and 'Case 12' in Cook, 'Smoking and lung pathology', pp.46, 49.

131 'Case 11' in Cook, 'Smoking and lung pathology', p.46; 'Case 7' and 'Case 11' in McKinnon, pp.17, 21.
} 
Zealand however rates remained consistently high through the period to the mid-1970s. This chapter has charted the shifts and developments in the arguments around smoking through the period 1900-1962, from the small but clearly enunciated anti-smoking campaigners in the pre-first world war years, through to the development of a prosmoking discourse in the 'normative' phase of tobacco consumption from the first world war to the 1950s, and lastly to the development of a strong and conclusive health case against smoking from the 1950s to 1962. The greater part of the period 1920-1950 was dominated as much by a noticeable lack of anti-smoking rhetoric as it was by the presence of a pro-smoking rhetoric. Through this period 'health' understandings were sometimes positive, generally contradictory and largely promulgated by commercial interests. The development of a health discourse in the later period dealt with in this chapter, 1950-1962, was based on research linking the rise in smoking prevalence with the emergence of a strong lung cancer disease trend. The impact of this research was limited in New Zealand through this period. It was not until the conclusive, qualified and indisputable reports of 1962 and 1964 that medical officials were obliged to take on responsibility to oppose smoking. However the nature of public attitudes and resistance to the report as discussed in the final section of this chapter reveals the complex and conflicting ways that smoking was understood at that crucial turning point in 1962. The common and popular place of smoking was so entrenched that changing the way that smoking was understood - as well changing a national habit - would prove to occupy health administrators and lobbyists for many decades to come. 


\section{Conclusion}

The central aim of this thesis has been to chart and explain the upward trend in tobacco consumption in New Zealand over the period 1920-1962. In doing so, this study has looked beyond existing commodity statistics to the broader social and cultural context in which a distinct and prevalent smoking culture evolved. The thesis has focused on particular times and places when smoking became questionable and has examined how this rhetoric changed over the study period. Through the years 1920-1962 smoking became a common and acceptable behaviour and a prominent feature in the daily lives of men and women in New Zealand. Three elements were central to the rise of this smoking culture: the foundation and government support of a successful local tobacco growing and manufacturing industry from the 1920s; the massive promotional influence of the tobacco industry on the expansion of smoking into more spaces and activities and among both men and women; and lastly the notable absence of anti-smoking rhetoric (along either health or moral lines) through most of this period, and the rise of a pro-smoking discourse which elevated the individual's 'right' to smoke.

The development of new manufacturing technologies in the late nineteenth century provided the impetus for the rapid and widespread growth of the tobacco industry around the world. Tobacco became cheaper to manufacture; machines rapidly produced tailor-made cigarettes which lowered prices and increased the availability of cigarettes and tobacco on the consumer market. Investment in the growth and manufacture of tobacco in New Zealand in the 1920s and 1930s was supported by both international tobacco companies and successive New Zealand governments. Both proved to be motivated by the massive potential of tobacco to generate profits - with tobacco remaining a constant and lucrative form of taxation right throughout the twentieth century. Successive governments' investment and support of the tobacco industry culminated during the second world war with the official classification of tobacco production and distribution as an 'essential' industry. In doing so, the wartime government also silenced negotiation around tobacco's place as a luxury or necessary item, however at odds this action was with the government's continued heavy taxation of tobacco. By the time of the second world war both government and parliament recognised the absolute and vital importance of tobacco to, as Sid Holland articulated in 1942, the 'forgotten man' (or woman) in New Zealand - 'that hardworking, self-reliant, 
thrifty soul', for whom tobacco was a 'necessity'. 'The government's role was integrally tied up in supporting the egalitarian rights of all New Zealanders to access and enjoy their share of tobacco.

With the advent of a domestic growth and manufacturing industry, tobacco companies needed to expand their consumer base. Through the interwar years advertising became central to the recruitment of new smokers. Most importantly, advertising was also the crucial - and overwhelmingly successful - driving force behind the expansion of the times, spaces and activities in which it became acceptable and appropriate to smoke. This study has shown that the bulk of tobacco advertising stressed a core message of universality - the notion that all adults could smoke anywhere at anytime. In leisure spaces smoking was seen to complement and enhance the enjoyment of leisure activities. The ritual of offering a cigarette also became an important feature of sociability. Over the period 1920-1962 the connection between smoking and work or occupational identities also strengthened. Advertisers positioned smoking as a reward or entitlement for paid work both 'on the job' and in break times. The second world war saw an intensification of tobacco advertisers' messages smoking became increasingly important as a way of relaxing from the stresses of war. More New Zealanders were working - harder than before - both on the battlefield and on the home front, and therefore greater numbers of men and women felt entitled to a share of the limited tobacco supply in return for their contribution to the war effort. The study has shown that the messages put forward in tobacco advertising associating smoking with leisure and work were also adopted into the language used by men and women.

Opposition to smoking was found in New Zealand in the years immediately preceding and at the end of the study period. Prior to the first world war anti-smoking campaigns were relatively small in both size and impact, and were grounded in objections to smoking being habitual, a waste of money and a pollutant to the body. Opposition to smoking at the other end of the time period was on very different grounds. From mid-century health researchers in Britain and the United States began to investigate a suspected link between tobacco smoking and the rising trend in lung cancer emerging around the world. However, this new health discourse was not widely disseminated or absorbed in medical, government or public spheres until the Royal College of Physicians and the Surgeon General of the United States released reports in

${ }^{1}$ Holland, NZPD, vol. 261, 6 May 1942, p.214. 
the early 1960s establishing a conclusive link between smoking and lung cancer and other diseases. Between these two periods there was a long phase of almost 50 years marked by a distinct lack of opposition or objection to smoking. Encouraged by advertising messages, the language used by New Zealanders through this period elevated the 'right' to smoke across time and space.

Although smoking has been a feature of the lives of New Zealanders right throughout the twentieth century, some generations have been more marked than others by the relatively fast and widespread change in smoking patterns which occurred over the middle of the century. The generation born in the late 1910s and 1920s, who came of age around the time of the second world war were the potential young consumers targeted by the tobacco industry to take up smoking in the late 1930s and 1940 s - the period which saw the sharpest rise in total tobacco consumption. By the time this generation was in its teenage years and early twenties, smoking was ubiquitous in daily life. It was likely that their fathers and male relatives smoked, if not their mothers. Smoking was practised at the sports clubs and sports grounds they attended, at dances and parties, was a popular way to pass the time on public transport, was cheap, plentiful and widely available at tobacconists, in pubs or hotels, in grocery stores, in cafeterias and in department stores. If young New Zealanders from this generation were not smoking themselves, they were never far from someone who was. Smoking was a powerful marker of adulthood, which was also achieved through participation in paid work and through service in the second world war. If a person from this generation did not smoke before the war, it is likely that he or she took it up during the war, increasing consumption in the post-second world war era as tobacco production recovered and quickly caught up with rising demand.

In later years this generation was also the most sensitive to the emergence of the anti-smoking discourse from 1962. For all of their lives smoking had increasingly been the thing to do, normal and uncontroversial, popular and attractive, yet was now seen as a major cause of disease. The government which had, less than two decades earlier, deemed tobacco 'essential', now condemned the habit and began moves to encourage people to cut down or quit smoking. While this generation's lifespan most closely coincides with the rising popularity and prevalence of smoking, those born in the 1930s and 1940s were also targets of widespread and sustained tobacco promotion which continued to propel a historically high tobacco consumption trend through to the mid1970s. From the early 1960s tobacco was no longer uncontroversial and benign, yet the 
social norm which had been established through the first half of the twentieth century proved much harder to unravel. Tobacco consumption gradually declined from the mid1970s and by 1990 had returned to the level of 1920 .

The history of smoking is unique and remarkable in the wider history of commodities and behaviours. In the course of one generation's lifespan, over a 70 year period, a product which was previously unnecessary in the daily lives of most New Zealanders grew exponentially in use and popularity, maintained high rates of consumption and then declined to its previous level. But was New Zealand's experience exceptional within the wider international history of smoking in the twentieth century? The New Zealand case study detailed in this thesis has drawn from and contributes to an existing international historiography of smoking patterns and behaviour. New Zealand's smoking patterns most closely mirror those detailed in the Australian and British case studies, particularly in stressing the importance of the second world war in relation to the uptake and rising consumption of tobacco from the 1940s. However it has not been found, as in the Australian example examined by Tyrrell, that a strong anti-smoking rhetoric persisted right through the twentieth century. New Zealand discourses about smoking were much more characterised by isolated and often unrelated negotiations over the right to smoke in particular spaces.

There was also some local variation in what New Zealanders smoked. As in Australia, Canada and Norway, New Zealanders smoked proportionally more loose tobacco for roll your own and pipe smoking than consumers in the United States and Britain. It was not until 1955 that manufactured cigarettes rose above 50 per cent of total tobacco sales in New Zealand. At the end of the study period loose tobacco still amounted for 38 per cent of total sales. ${ }^{2}$ Another feature suggesting a local pattern of taste unique to New Zealand was the development of a domestic tobacco industry which manufactured and imported international brands as well as fostering many local lines of tobacco. Brands such as 'Tasman', 'Silver Fern', 'Riverhead Gold' and 'Cavendish' remained competitive with American and British imports. Other countries such as Canada and Australia also developed their own industries and tastes for locally grown and produced tobaccos. An increased localisation of taste occurred around the second world war as New Zealand manufacturers were compelled to use a greater proportion of local leaf in their products.

${ }^{2}$ Laugesen, Tobacco statistics, p.12. 
Though there are strong elements of local variation, New Zealanders' tobacco consumption and smoking experiences were not highly divergent from the broad international pattern. In fact, as Major Spraggon so confidently asserted to the Napier Rotary Club in 1953, New Zealanders were among the heaviest smokers in the world. At this point only three other Western countries (Canada, the United States and the Netherlands) had higher per capita adult consumption than New Zealand. High consumption, particularly through the 1950s and 1960s, indicates not only the prevalence of smoking among New Zealanders at this time, but also underlines New Zealand's place as an active and progressive participant in the wider international rise in tobacco consumption. New Zealand was not isolated from the wider trends by distance or small population size, but rather was connected to a much wider smoking culture. In this sense New Zealanders were modern international subjects, exposed to the same advertising, brands, and smoking habits that were present on the streets of Sydney, Montreal, New York or London.

The history of smoking from 1962 to the present is characterised by the regulation and control of smoking by health and government authorities, the dissemination of knowledge about the health risks of smoking, and the absorption of this knowledge by the public. Within this regulatory pattern, the study of the history of smoking is a useful parallel to the divergent history of alcohol as a commodity which was also heavily taxed and regulated in the twentieth century. The period 1920-1962 was marked by a distinct lack of regulation of where and when an adult could smoke. In contrast the sale and consumption of alcohol was restricted in both time and place with six o'clock closing at pubs, introduced during the first world war, remaining in place until 1967. In the post1960s era this pattern reversed with alcohol becoming increasingly deregulated and more freely available, particularly following the passage of the 1989 Sale of Liquor Act. Increasingly stringent spatial regulation became the central means through which government and health officials sought to control and reduce smoking. The most extensive legislative change to control space did not occur, however, until almost 30 years after the RCP's report was published, with the passage of the Smokefree Environments Act in 1990. The provisions of this act were extended through the 1990s, controlling and restricting smoking in all work places, public transport, restaurants, cafes 
and sports clubs. ${ }^{3}$ While both alcohol and tobacco have caused considerable concern at different points over the twentieth century, the strong and conclusive health rationale against smoking and resulting degree of political mobilisation have proven to be the most powerful drivers for regulatory change in recent years.

The developing pattern of regulation saw the gradual control of tobacco advertising and sales, and spaces in which to smoke from 1962 to the present, yet the proliferation of knowledge and belief in the community is considerably more complex. As chapter three has shown, there was great variation in the nature of the public reaction to the release of the RCP's report in 1962. Smoking was overwhelmingly normative and people were resistant to stopping what had become a daily, regular source of pleasure and relaxation. The defence in the 2006 Pou vs. BATNZ court case successfully argued that in 1968 when Janice Pou started smoking, health-smoking risks were 'common knowledge' in New Zealand. However as the divergence of ideas around 1962 indicates, knowledge does not simply translate into what could be conceived as rational behaviour change. The broader trend which saw tobacco consumption remain historically high through the 1970s instead contradicts the idea that New Zealanders were fully aware of and acted on knowledge about the dangers of smoking. In the legal setting the 2006 case excused the tobacco companies from having a 'duty to warn' if it was likely that reasonable New Zealanders in 1968 were aware of the risks associated with their product, yet does little to explain the gap between 'knowledge' and behaviour.

The Pou vs. BATNZ case was the first tobacco litigation case in New Zealand and has had a huge bearing on the potential of future cases to succeed in this country. As Kate Tokeley has argued, the case essentially 'forecloses the possibility of any New Zealand smoker ever successfully claiming damages from the tobacco industry for harm caused by smoking. ${ }^{44}$ For the period leading up to 1960, it would be hard to establish that the tobacco industry knew about the harmful effects of their product and therefore did not have a 'duty to warn'. The first health warnings appeared on cigarette packets from 1974. Therefore the tobacco industry can potentially be liable for the damages caused by their product on those people who started smoking between 1960 and 1974 . By agreeing that the dangers of smoking were 'common knowledge' to a reasonable New Zealander in 1968, the judgement in the Pou vs. BATNZ case significantly narrowed the pool of smokers who have a chance of making a claim against tobacco

\footnotetext{
${ }^{3}$ Smokefree Coalition, 'The history of tobacco control in New Zealand', http://www.sfc.org.nz/infohistory.html, accessed 5 February 2009.

${ }^{4}$ Tokeley, p.136.
} 
companies. ${ }^{5}$ Here it is evident that New Zealand's history in the post-1962 era again diverges from international trends. Tobacco litigation has been a much more prominent feature of the American legal landscape over the past 20 years and continues to be so, where a different legal system (and legal precedence) has seen monumental payouts to class-action suits brought against 'big tobacco'.

This thesis has examined the creation of a social norm over the period 1920-1962. The 1962 and 1964 reports effectively put the dominant historical pattern into reverse, however the strength and pervasive nature of the social norm has proven to take much longer to unravel and remains a major health focus in the early twenty first century. 2012 will mark 50 years since the publication of the RCP's 1962 report. Yet almost 50 years on New Zealand's rate of lung cancer, despite unequivocal knowledge, control, and education remains a major preventable disease. Smoking continues to be a major focus for health policy makers, education policy makers, the public health system as a whole, and remains a part of the lives of just under a quarter of New Zealanders. ${ }^{6}$ As well as the Pou vs. BATNZ case and its associated historical report, the other main focus in literature around smoking has arisen from this policy perspective. This thesis has approached smoking from a social history perspective, examining the history of understandings around a product and a behaviour which was a highly characteristic aspect of twentieth-century life in New Zealand, and as part of a wider international phenomenon. It is an historical study of the dramatically shifting values around a distinctive product which also has the potential to inform current policy concerns. These concerns are primarily aimed at reversing the persistent social norm established through the middle of the twentieth century when smoking was, as Peter McKinnon asserted in his 1962 preventive medicine dissertation, 'commonplace', 'socially acceptable', and free from 'social stigma."

\footnotetext{
5 Tokeley, pp.136-7. Beyond starting smoking in this time frame, Tokeley also identifies other factors in a claimant which would make a stronger case against the tobacco companies than Janice Pou's, such as stronger evidence that they 'would not have started smoking if warned of the dangers', attempting to give up once warnings were placed on the tobacco packets, and establishing causation of lung cancer from tobacco smoking. Yet the likelihood of these factors (and the others detailed in Tokeley's argument) aligning to find a tobacco company liable for damages are still 'minimal.' Tokeley, pp. 142-3.

${ }^{6}$ In 2006 the prevalence of current smokers in New Zealand was 23.5 per cent. See Ministry of Health, New Zealand tobacco use survey, p.20.

${ }^{7}$ McKinnon, pp.3-4.
} 


\section{Bibliography}

\section{Primary Sources}

\section{Unpublished Official}

Advertising, 1936-1957, TB, 7, W2303, 2, 1/8, part 1, Archives New Zealand, Wellington.

Aid to Britain Campaign, 1947, TB, W2303, 5/6, Archives New Zealand, Wellington.

Allied Prisoners of War and Civilians in Enemy Territory, Parcels, Cigarettes and Tobacco For Personnel in Europe, 1941-1945, EA, 1, 662, 88/8/4, part 1, Archives New Zealand, Wellington.

Annual Reports Press Reports, 1941-1954, TB, W2303, 2, 1/7, part 2, Archives New Zealand, Wellington.

Army and Navy Requirements, 1940-1946, TB, W2303, 18, 13/17, Archives New Zealand, Wellington.

Bylaw: Town Hall, No Smoking and Consumption of Liquor Bylaw, 1929-1968, item registration 00001:88:5/90, Wellington City Archives, Wellington.

Canteens - tobacco and cigarettes for troops on active service, 1915, AD, 1, 1021, 32/24, Archives New Zealand, Wellington.

Car Accommodation on Mixed Trains Proportion of Smoking to Non Smoking cars on All Services, 1907-1959, AAEB, W3199, 108, 07/1177, 1, Archives New Zealand, Wellington.

Exhibitions, Films and Displays (c), 1937-1959, TB, W2303, 3, 1/18, Archives New Zealand, Wellington.

Export of Cigarettes and Tobacco on Behalf of the War Office, 1940-1941, TB, W2303, 8, 5/12, Archives New Zealand, Wellington.

Food Hygiene - Smoking in Food Premises, 1946-1985, ABQU, 632, W4452, 906, 143/4/2, Archives New Zealand, Wellington.

Health Education and Publicity - Campaign against cigarette smoking, 1957-1961, H1, 1777, 34/74, Archives New Zealand, Wellington.

Hutchinson, Captain C. P., 'Camp office Diary, 1 July 1942 -7 February 1943', ABIA, W3918, 1, 1, Archives New Zealand, Wellington.

Import Control Policy - Importation of Tobacco and Cigarettes, 1939-1949, C, 1, 40/55, Archives New Zealand, Wellington. 
Miscellaneous - Cigarette smoking among soldiers, 1916, AD, 1, 1141, 46/421, Archives New Zealand, Wellington.

Miscellaneous - Cigarettes on transports - Prohibition of, 1915, AD, 1, 1141, 46/4110, Archives New Zealand, Wellington.

Miscellaneous Press Cuttings, 1936-1941, TB, W2303, 2, 1/9, part 1, Archives New Zealand, Wellington.

Miscellaneous Press Cuttings, 1954-1960, TB, W2303, 2, 1/9, part 3, Archives New Zealand, Wellington.

Mobilisation - ASC [Army Service Corps] 2nd line rations etc., 1941, AD, 1, 1253, 271/22/5, Archives New Zealand, Wellington.

Patriotic Funds - Postal Tobacco Scheme - For Prisoners of War, c.1943, IA, 1, 3072, 172/24/18, Archives New Zealand, Wellington.

Rationing of Cigarettes, 1942-1943, TB, W2303, 17, 13/10, Archives New Zealand, Wellington.

Returns - Consumption of tobacco and cigarettes, 1946-1950, N, 1, 580, 18/36/121, part 6, Archives New Zealand, Wellington.

Smoking in the Workplace, 1904-1988, ABJP, W4098, 33, 04/399, 1, Archives New Zealand, Wellington.

'Smoking on tramcar', H. L. James, 12 October 1909, item reference number 00233:177: 1909/1842, Wellington City Archives, Wellington.

Supplies - Rations - Hospitals (Military), 1916-1919, AD, 1, 1267, 50/241, Archives New Zealand, Wellington.

Supplies - Rations- NZEF camps - Cost per head per day, 1918-1919, AD, 1, 994, 50/359, Archives New Zealand, Wellington.

Supplies - Returns - Rations - Actual number issued, 1918, AD, 1, 995, 50/595, Archives New Zealand, Wellington.

Teachers. General. Smoking in Schools, 1937-1947, E2, 1947/53d, 24/1/130, Archives New Zealand, Wellington.

Tobacco and cigarettes - Manufacture of by Nelson Tobacco Company Limited, Nelson, IC, 1, 17/3/8, Archives New Zealand, Wellington.

Tobacco Research, 1936-1945, TB, W2303, 13, 11/1 part 1, Archives New Zealand, Wellington.

War Series - Tobacco and cigarettes for forces in New Zealand, 1939-1947, C, 1, 41/20/8, Archives New Zealand, Wellington. 
Women and children travelling in smoking carriages, 1907-1962, AAEB, W3199, 112, 07/3088, 1, Archives New Zealand, Wellington.

\section{Unpublished Manuscripts}

Lindis Pass Ladies’ Patriotic Guild Minute Book, 1941-1945, Misc-MS-1196, Hocken Library, Dunedin.

Nicholls, Walter, Poems, 1914-1919, MS-Papers-5727, Alexander Turnbull Library (ATL), Wellington.

Otago and Southland Retail Tobacconists' and Registered Hairdressers' Association Records, Minutes, MS-1028, 1924-1976, Hocken Library, Dunedin.

Perrin family papers, Correspondence, c.1855-1874, MS-Papers-2579-2, ATL, Wellington.

Record book of tobacco issued to ex-servicemen in individual hospitals, 1916-1922, AG-113/182, Otago Provincial Patriotic Council Records, ARC-0514, Hocken Library, Dunedin.

\section{Published}

\section{Newspapers and Periodicals}

ANZA: The Official Organ of the Association of N.Z Advertisers, 1935 - 1937, ATL, Wellington.

Auckland Weekly News, 1920 - 1940.

Craccum, 1935, Special Collections, University of Auckland Library, Auckland.

Dominion, 1930 - 1962.

The Mirror, 1922 -1938 (title varies over period).

New Zealand Herald, 1920 - 1962.

New Zealand Listener, 1940 - 1962.

New Zealand Tablet, 1940 - 1950.

New Zealand Sportsman, 1946 - 1956.

New Zealand Woman's Weekly, 1934 - 1960.

N. Z. Freelance, 1918 - 1960.

N.Z. Sportswoman, 1949.

The New Zealand Draper, Clothier and Boot Retailer, 1926 - 1940. 
The New Zealand Hairdressers' and Retail Tobacconists' Review, 1934 - 1938, ATL, Wellington.

The New Zealand Illustrated Sporting and Dramatic Review, 1920 - 1940.

The New Zealand Railways Magazine, 1934, 1936.

The Press, $1920-1962$.

The Tobacconist and Hairdresser, 1932, ATL, Wellington.

War Cry, 1910 - 1919.

White Ribbon, 1900 - 1945.

Women in Sport, 1948 - 1949.

\section{Books and articles}

'Cigarette smoking: is it wise? - we think not', Consumer, vol. 64, 1970, pp.164-175.

Department of Internal Affairs, New Zealand's patriotic war effort: 1939-1946, Wellington, 1946.

Doll, R., and A. B. Hill, 'Smoking and carcinoma of the lung: preliminary report', British Medical Journal, no. 4682, 1950, pp.739-48.

Gardiner, C. E. and C. N. D. Taylor, Smoking habits of New Zealand doctors: a survey of the smoking habits of medical practitioners in New Zealand, Wellington, 1964.

Gardiner, C. E., C. N. D. Taylor, and L. D. Roberts, Smoking habits of school children: a survey of the smoking babits of New Zealand school children, Wellington, 1961.

Mulgan, John, Man alone, Hamilton 1960 (first published 1939).

New Zealand Official Year Book, Wellington, 1901.

New Zealand Parliamentary Debates, 1940-1945.

Pascoe, John, 'Tobacco in the mountains', Tobacco, 1 November 1937, pp.49-50, ATL, Wellington.

Royal College of Physicians, Smoking and health: a report of the Royal College of Physicians of London on smoking in relation to cancer of the lung and other diseases, London, 1962.

Salmond, G. C., and M. K. Geddes, The health of former servicemen, Wellington, 1977.

Terry, Dr Luther L., Surgeon General of the United States of America, et al., Smoking and bealth, Washington, 1964.

The Public Acts of New Zealand 1908-1931, vol. 8, Wellington, 1932. 


\section{Secondary Sources}

\section{Books, Chapters and Articles}

Ashton, Toni and Susan St John, Insights into excises: a focus on alcohol, tobacco and motor fuels taxation, Wellington, 1985.

Atkinson, Neill, Trainland: how railways made New Zealand, Auckland, 2007.

Baker, J. V. T., War economy, Wellington, 1965, available from

http://nzetc.org/tm/scholarly/tei-WH2Econ.html, accessed 12 September 2008.

Bardsley, Dianne, The land girls: in a man's world, 1939-1946, Dunedin, 2000.

Barrowman, Rachel, Victoria University of Wellington 1899-1999: a history, Wellington, 1999, available from http://nzetc.org/tm/scholarly/tei-BarVict.html, accessed 12 September 2008.

Belich, James, Paradise reforged: a history of the New Zealanders from the 1880s to the year 2000, Auckland, 2001.

Bioletti, Harry, The yanks are coming: the American invasion of New Zealand 1942-1944, Auckland, 1989.

Blair, Ross D., 'McGavin, Donald Johnstone 1876 - 1960', Dictionary of New Zealand Biography, updated 22 June 2007, available from http://www.dnzb.govt.nz, accessed 11 April 2009.

Boyle, P. et al., (eds.), Tobacco: science, policy and public health, Oxford, 2004.

Brandt, Allan M., The cigarette century: the rise, fall, and deadly persistence of the product that defined America, New York, 2007.

Brandt, Allan M., 'The cigarette, risk, and American culture', Daedalus, vol. 119, no. 4, 1990, pp. 155-176.

Brittenden, Wayne, The celluloid circus: the heyday of the New Zealand picture theatre 1925-1970, Auckland, 2008.

Brookes, Barbara, Annabel Cooper and Robin Law, (eds.), Sites of gender: women, men and modernity in Southern Dunedin 1890-1939, Auckland, 2003.

Broughton, John, Puffing up a storm: “kapai te torori!”, Dunedin, 1996.

Broughton, John and Mark Lawrence, Maori women and smoking: a Maori health research project - Nga wahine Maori me te kai paipa: he rangahau hauora, Dunedin, 1993.

Brown, Bruce, 'Nordmeyer, Arnold Henry 1901 - 1989', Dictionary of New Zealand Biography, updated 22 June 2007, available from http://www.dnzb.govt.nz, accessed 11 April 2009. 
Bryder, Linda, (ed.), A bealthy country: essays on the social history of medicine in New Zealand, Wellington, 1991.

Bunkle, Phillida, and Beryl Hughes, (eds.), Women in New Zealand society, Auckland, 1980.

Colquhoun, David, (ed.), As if running on air: the journals of Jack Lovelock, Nelson, 2008.

Cook, Sharon Anne, “Liberation Sticks" or "Coffin Nails"? Representations of the working woman and cigarette smoking in Canada, 1919-1939', Canadian Bulletin of Medical History, vol. 24, no. 2, 2007, pp.367-401.

Daley, Caroline, Leisure and pleasure: reshaping and revealing the New Zealand body 1900-1960, Auckland, 2003.

Dalley, Bronwyn, 'Chance residues: photographs and social history', Tony Ballantyne and Brian Moloughney, (eds.), Disputed histories: imagining New Zealand's pasts, Dunedin, 2006, pp.169-189.

Dalley, Bronwyn, Living in the twentieth century: New Zealand history in photographs 1900-1980, Wellington, 2000.

Dalley, Bronwyn, and Gavin McLean, (eds.), Frontier of dreams: the story of New Zealand, Auckland, 2005.

Davis, Donald F. and Barbara Lorenzkowski, 'A platform for gender tensions: women working and riding on Canadian urban public transit in the 1940s', Canadian Historical Review, vol. 79, no. 3, 1998, pp. 431-465.

Day, Patrick, The radio years: a history of broadcasting in New Zealand, volume one, Auckland, 1994.

Dow, Derek A., Safeguarding the public health: a history of the New Zealand Department of Health, Wellington, 1995.

Dunstan, Keith, Wowsers: being an account of the prudery exbibited by certain outstanding men and women on such matters as smoking, drinking, prostitution and gambling, Melbourne, 1968.

Easton, Brian 'Smoking in New Zealand: a census investigation', Australian Journal of Public Health, vol. 19, no. 2, 1995, pp. 125-9.

Easton, Brian, The economic regulation of tobacco consumption in New Zealand, Central Institute of Technology, Upper Hutt, Wellington, 1998.

Easton, Brian, The social costs of tobacco use and alcohol misuse, Wellington, 1997.

Ebbett, Eve, When the boys were away: New Zealand women in World War II, Wellington, 1984. 
Elliot, Rosemary, 'Everybody did it' - or did they?: the use of oral history in researching women's experiences of smoking in Britain, 1930-1970', Women's History Review, vol. 15, no. 2, 2006, pp.297-322.

Elliot, Rosemary, Women and smoking since 1890, New York and London, 2008.

Else, Anne, (ed.), Women together: a bistory of women's organisations in New Zealand: nga ropu wabine o te motu, Wellington, 1993.

Fox, Richard Wightman, and T. J. Jackson Lears, 'Introduction', Richard Wightman Fox, T. J. Jackson Lears, (eds.), The culture of consumption: critical essays in American history, 1880-1980, New York, 1983, pp. ix-xvii.

Gatley, Julia, (ed.), Long live the modern: New Zealand's new architecture 1904-1984, Auckland, 2008.

Goldsmith, Paul, We won, you lost, eat that! a political history of tax in New Zealand since 1840, Auckland, 2008.

Grant, David, On a roll: a history of gambling and lotteries in New Zealand, Wellington, 1994.

Gustafson, Barry, Kiwi Keith: a biography of Keith Holyoake, Auckland, 2007.

Hay, David, Heart sounds: a life at the forefront of health care, Wellington, 2005.

Hercus, Sir Charles and Sir Gordon Bell, The Otago Medical School under the first three deans, Edinburgh and London, 1964.

Hilliard, Chris, The bookmen's dominion: cultural life in New Zealand 1920-1950, Auckland, 2006.

Hilton, Matthew, Smoking in British popular culture 1800-2000, Manchester and New York, 2000 .

Hughes, Beryl and Shelia Ahern, Redbricks and bluestockings: women at Victoria 1899-1993, Wellington, 1993.

Ilott, Jack, Creating customers: the story of Ilott Advertising New Zealand, 1892-1982, Auckland, 1985.

Isted, Bruce, 'The history of cigarette and trade cards', New Zealand Memories, vol. 18, 1999, pp.206-8.

Keys, Barbara J., Globaliving sport: national rivalry and international community in the 1930s, Cambridge, Massachusetts, 2006.

King, Wayne, 'Smoke clouds over New Zealand', New Zealand Memories, vol. 53, 2005, pp.28-33.

Laugesen, Murray, The big kill continues: the human cost of smoking in New Zealand in the 1990s, Wellington, 1996. 
Laugesen, Murray, Tobacco statistics 1991: trends in tobacco consumption and smoking prevalence in New Zealand, Wellington, 1992.

Laugesen, Murray and Mark Clements, Cigarette smoking mortality among Maori, 1954-2028, Wellington, 1998.

Lears, T. J. Jackson, 'From salvation to self-realization: advertising and the therapeutic roots of the consumer culture, 1880-1930', Richard Wightman Fox, T. J. Jackson Lears, (eds.), The culture of consumption: critical essays in American history, 1880-1980, New York, 1983, pp.3-38.

Lee, P.N., (ed.), Tobacco consumption in various countries, $4^{\text {th }}$ edition, London, 1975.

Logan, Mary, Nordy: Arnold Nordmeyer a political biography, Wellington, 2008.

Lum, K. L., J. R. Polansky, R. K. Jackler and S. A. Glantz, 'Signed, sealed and delivered: "big tobacco" in Hollywood, 1927-1951', Tobacco Control, vol. 17, 2008, pp.313-323.

McAloon, William and Jill Trevelyan, (eds.), Rita Angus: life and vision, Wellington, 2008.

Maclean, Chris, John Pascoe, Nelson, 2003.

Maclean, F. S., Challenge for health: a history of public health in New Zealand, Wellington, 1964.

McClintock, Anne, Imperial leather: race, gender and sexuality in the colonial contest, New York, 1995.

McGibbon, Ian, (ed.), The Oxford companion to New Zealand military history, Auckland, 2000.

McGill, David, The guardians at the gate: the history of the New Zealand Customs Department, Wellington, 1991.

Martin, John E., Holding the balance: a bistory of New Zealand's Department of Labour 1891 1995, Christchurch, 1996.

Mason, W. Wynne, Prisoners of War, Wellington, 1954, available from http://nzetc.org/tm/scholarly/tei-WH2Pris.html, accessed 11 April 2009.

Mein Smith, Philippa, A concise history of New Zealand, Cambridge and Melbourne, 2005.

Ministry of Health, New Zealand tobacco use survey 2006, Wellington, 2007, available from http://www.moh.govt.nz/moh.nsf/indexmh/nz-tobacco-use-survey-2006, accessed 23 February 2009.

Montgomerie, Deborah, 'The limitations of wartime change: women war workers in New Zealand', New Zealand Journal of History, vol. 23, no. 1, 1989, pp.68-86.

Montgomerie, Deborah, The women's war: New Zealand women 1939-45, Auckland, 2001.

Nevett, T. R., Advertising in Britain: a history, London, 1982. 
Nolan, Melanie, 'Introduction', Melanie Nolan, (ed.), Revolution: The 1913 great strike in New Zealand, Christchurch, 2005.

Nye, Edwin R., (ed.), Medical research in Otago, 1922-1997: as portrayed by 75 years of the Proceedings of the University of Otago Medical School, Dunedin, 1998.

O’Donnell, Jean-Marie, "Electric servants', and the science of housework: changing patterns of domestic work, 1935-1956', Barbara Brookes, Charlotte Macdonald and Margaret Tennant, (eds.), Women in History 2, Wellington, 1992, pp.168-183.

Orsman, Elizabeth, and Harry Orsman, (eds.), The New Zealand Dictionary, Auckland, 1994.

O'Shea, Patricia K., The golden harvest: a history of tobacco growing in New Zealand, Christchurch, 1997.

Page, Dorothy, Anatomy of a medical school: a history of medicine at the University of Otago, 1875 2000, Dunedin, 2008.

Pearson, Bill, Coal flat, Auckland, 1963.

Peiss, Kathy, Hope in a jar: the making of America's beauty culture, New York, 1998.

Phillips, Jock, 'Advertising', Te Ara - the Encyclopedia of New Zealand, forthcoming entry, 2009, available from http://www.TeAra.govt.nz.

Phillips, Jock, A man's country?: the image of the Pakeha male: a bistory, revised edition, Auckland, 1996.

Proctor, Robert N., 'The Nazi war on tobacco: ideology, evidence, and possible cancer consequences', Bulletin of the History of Medicine, vol. 71, no. 3, 1997, pp.435-488.

Reid, Paparangi, and Robert Pouwhare, The gift from a distant place: te taonga mai tawhiti, Auckland, 1991.

Renwick, William, (ed.), Creating a national spirit: celebrating New Zealand's centennial, Wellington, 2004.

Rice, Geoffrey W., Black November: the 1918 influenza pandemic in New Zealand, $2^{\text {nd }}$ edition, Christchurch, 2005.

Roberts, Evan, “'Don't sell things, sell effects”: overseas influences in New Zealand department stores, 1909-1956', Business History Review, vol. 77, no. 2, 2003, pp.265-289.

Rudy, Jarrett, The freedom to smoke: tobacco consumption and identity, Montreal, 2005.

Russell, Ronald S., Imperial preference: its developments and effects, London, 1947.

Sinclair, Keith, A bistory of the University of Auckland 1883-1983, Auckland, 1983. 
Sivulka, Juliann, Soap, sex, and cigarettes: a cultural history of American advertising, Belmont, California, 1998.

Sprecher, Danielle, 'Good clothes are good business: gender, consumption and appearance in the office, 1918-1939', Caroline Daley and Deborah Montgomerie, (eds.) The gendered Kiwi, Auckland, 1999, pp.141-162.

Steel, Frances, 'A source of our wealth, yet adverse to our health? Butter and the dietheart link in New Zealand to c.1990', Social History of Medicine, vol. 18, no. 3, 2005, pp.475-493.

Steel, Frances, "New Zealand is butterland': interpreting the historical significance of a daily spread', New Zealand Journal of History, vol. 39, no. 2, 2005, pp.179-194.

Stout, T. Duncan M., New Zealand medical services in Middle East and Italy, Wellington, 1956, available from http://nzetc.org/tm/scholarly/tei-WH2Medi-c3-55.html, accessed 12 April 2009.

Tate, Cassandra, Cigarette wars: the triumph of the 'little white slaver', New York, 1999.

Taylor, Nancy M., The New Zealand people at war: the home front volume II, Wellington, 1986, available from http://nzetc.org/tm/scholarly/tei-WH2-2Hom.html, accessed 13 September 2008.

Thomson, George, and Nicholas Wilson, Resource document: a brief history of tobacco control in New Zealand, Wellington, 1997.

Thomson, George and Nicholas Wilson, 'Rethinking the regulatory framework for tobacco control in New Zealand', New Zealand Medical Journal, vol. 118, no. 1213, 2005, available from http://www.nzma.org.nz/journal/118-1213/1405/content.pdf, accessed 10 April 2009.

Thomson, George, and Nicholas Wilson, 'Tobacco control in New Zealand from 1945 to 1961', New Zealand Medical Journal, vol. 112, no. 1084, 1999, pp.101-3.

Tinkler, Penny, 'Rebellion, modernity, and romance: smoking as a gendered practice in popular young women's magazines, Britain, 1918-1939', Women's Studies International Forum, vol. 24, no. 1, 2001, pp.111-122.

Tinkler, Penny, 'Red tips for hot lips': advertising cigarettes for young women in Britain, 1920-70', Women's History Review, vol. 10, no. 2, 2001, pp.249-272.

Tinkler, Penny, 'Refinement and respectable consumption: the acceptable face of women's smoking in Britain, 1918-1970', Gender and History, vol. 15, no. 2, 2003, pp.342360 .

Tinkler, Penny, Smoke signals: women, smoking and visual culture, Oxford and New York, 2006. 
Tokeley, Kate, 'Case note: Pou v. British American Tobacco (NZ) Ltd - a comprehensive win for the New Zealand tobacco industry', Waikato Law Review, vol. 14, 2006, pp.136-144.

Tyrrell, Ian, 'Before the Surgeon General's report: public discourse in Australia over tobacco addiction to 1964', Australian Journal of Politics and History, vol. 44, no. 2, 1998, pp.177-90.

Tyrrell, Ian, Deadly enemies: tobacco and its opponents in Australia, Sydney, 1999.

Tyrrell, Ian, 'The limits of persuasion: advertising, gender and the culture of Australian smoking', Australian Historical Studies, vol. 114, 2000, pp.27-48.

Vaknin, Judy, Smoke signals: 100 years of tobacco advertising, London, 2007.

Walker, Robin, Under fire: a bistory of tobacco smoking in Australia, Melbourne, 1984.

Yska, Redmer, New Zealand green: the story of marijuana in New Zealand, Auckland, 1990.

\section{Unpublished Theses, Research Essays and Judgement}

Burgess, Charlotte, 'Looking to the heart: young people, romance and courtship in interwar New Zealand', MA thesis in History, University of Auckland, 2007.

Callon, Lynette Gillian, 'Fighting fit? a study of the army's medical examinations 1916-1918', BA (Hons) research essay in History, University of Otago, 1980.

Christoffel, Paul, 'Removing temptation: New Zealand's alcohol restrictions, 1881-2005', PhD thesis in History, Victoria University of Wellington, 2006.

Cook, O. B., 'Smoking and lung pathology', preventive medicine dissertation, Otago Medical School, University of Otago, 1962.

Fosbender, M.R., 'Parental attitudes on smoking and drinking', preventive medicine dissertation, Otago Medical School, University of Otago, 1972.

Gray, D. H., 'Giving up smoking', preventive medicine dissertation, Otago Medical School, University of Otago, 1963.

Hobson, Edison R., 'Cigarette smoking motivation in women', preventive medicine dissertation, Otago Medical School, University of Otago, 1962.

Lang, Justice Graham, Judgement, Pou vs. British American Tobacco (New Zealand) Ltd., Auckland High Court, CIV-2002-404-1729, 3 May 2006.

McKinnon, P. A., 'Survey on smoking', preventive medicine dissertation, Otago Medical School, University of Otago, 1962.

Salamonsen, R. F., 'The smoking habits of young adults between the ages of 16 to 25 years', preventive medicine dissertation, Otago Medical School, University of Otago, 1964. 
Skinner, Mary L. D., 'Cancer of the lung', preventive medicine dissertation, Otago Medical School, University of Otago, 1951.

Sprecher, Danielle, 'The right appearance: representations of fashion, gender, and modernity in inter-war New Zealand, 1918-1939', MA thesis in History, University of Auckland, 1997.

Steel, Frances, 'Source of our wealth yet adverse to our health? A history of New Zealand butter', Postgraduate Diploma in Arts research essay in History, University of Otago, Dunedin, 2003.

Stowe, Deborah, 'John Pascoe's photography of the New Zealand home front during the Second World War: an historical analysis', MA thesis in History, Victoria University of Wellington, 2006.

Thomson, Sarah, 'Evils of the fragrant weed: a history of the 1903 Juvenile Smoking Suppression Act', MA research essay in History, University of Auckland, 1992.

Thomson, Sarah, 'Stubbing out the social cigarette', MA research essay in History, University of Auckland, 1992.

Whiteside, Heidi, 'We shall be respectable': women and representations of respectability in Lyttleton 1851-1893', MA thesis in History, University of Canterbury, 2007.

\section{Oral History Interviews}

Interview with Georgina Kiripuai Te Aomarere, interviewed by Rachael Selby, 2 March 2002, Otaki Oral History Project, OHInt-0673/08, ATL Oral History Centre, Wellington.

Interview with Herbert Thomas Hughes, interviewed by Nicholas Boyack, Jane Tolerton, 4 November 1989, OHInt-0006/38, World War One Oral History Archive, ATL Oral History Centre, Wellington.

\section{Images}

Henderson, Louise, 'Portrait of Betty Curnow', 1954, Christchurch Art Gallery, Christchurch.

'Ngaio in the Spotlight', portrait of Ngaio Marsh, photographer unknown, 194-, ADQ4294, Christchurch City Libraries, Christchurch.

Smith, May, 'Characterisation in colour', 1941, Auckland Art Gallery, Auckland. 


\section{Websites}

Legacy Tobacco Documents Library, available from http://legacy.library.ucsf.edu/, accessed 15 December 2008.

Medical Research Council, 'Stories of Discovery: Smoking', available from http://www.mrc.ac.uk/OurResearch/Impact/Cancer/Smoking/MRC003518, accessed 8 July 2008.

The Smokefree Coalition, 'The history of tobacco control in New Zealand', available from http://www.sfc.org.nz/infohistory.html, accessed 24 March 2008. 